
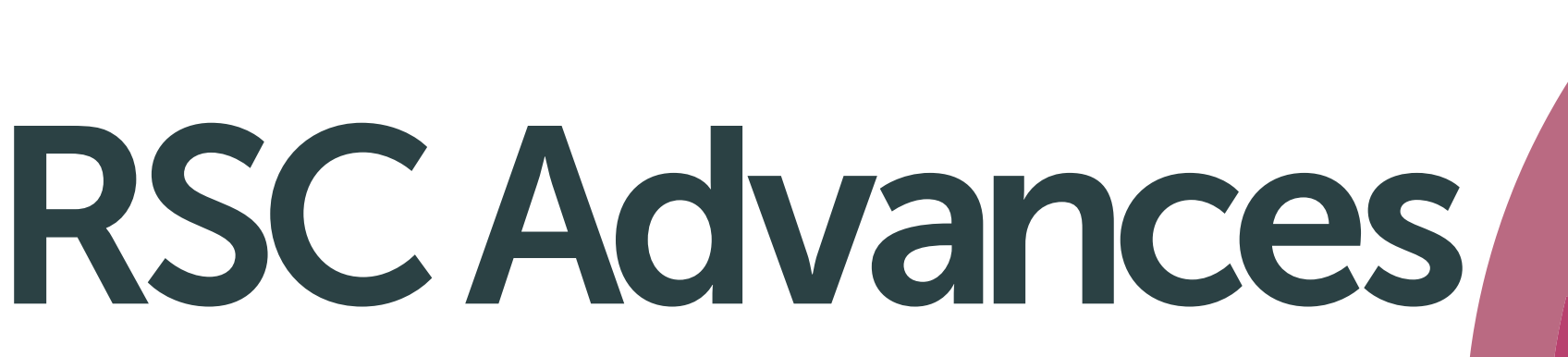

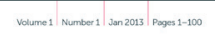

\section{RSC Advances}

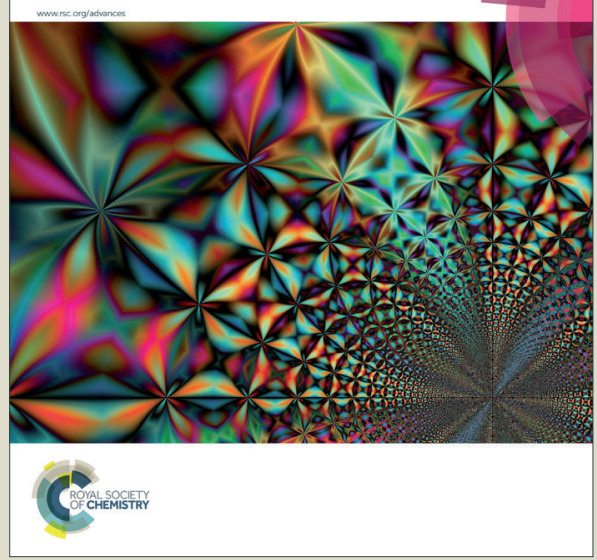

This is an Accepted Manuscript, which has been through the Royal Society of Chemistry peer review process and has been accepted for publication.

Accepted Manuscripts are published online shortly after acceptance, before technical editing, formatting and proof reading. Using this free service, authors can make their results available to the community, in citable form, before we publish the edited article. This Accepted Manuscript will be replaced by the edited, formatted and paginated article as soon as this is available.

You can find more information about Accepted Manuscripts in the Information for Authors.

Please note that technical editing may introduce minor changes to the text and/or graphics, which may alter content. The journal's standard Terms \& Conditions and the Ethical guidelines still apply. In no event shall the Royal Society of Chemistry be held responsible for any errors or omissions in this Accepted Manuscript or any consequences arising from the use of any information it contains. 


\title{
Self-assembled monolayers of thiolates on metals: A review article on sulfur-metal chemistry and surface structures
}

\author{
C. Vericat, M.E. Vela, G. Corthey ${ }^{\&}$, E. Pensa, E. Cortés ${ }^{\dagger}$, M. Fonticelli, F. Ibañez, G.E. Benitez, \\ P.Carro ${ }^{+*}$ and R.C. Salvarezza* \\ 5 Instituto de Investigaciones Fisicoquímicas Teóricas y Aplicadas (INIFTA), Universidad Nacional de La Plata - CONICET, Sucursal 4 \\ Casilla de Correo 16 (1900) La Plata, Argentina \\ ${ }^{+}$Departamento de Química, Area Química Física. Instituto de Materiales y Nanotecnología, Universidad de La Laguna, Tenerife, Spain \\ \& Present address: G.C.: Max Planck Institute for the Structure and Dynamics of Matter, Luruper Chaussee 149, 22761 Hamburg, \\ Germany. \\ 10 'Present address: E.C.: Centro de Investigaciones en Bionanociencias (CIBION) - CONICET, Godoy Cruz 2390, Buenos Aires, \\ Argentina.
}

\section{Received (in $X X X, X X X) X$ th $X X X X X X X X X 20 X X$, Accepted $X$ th $X X X X X X X X X 20 X X$} DOI: $10.1039 / b 000000 x$

\begin{abstract}
15 A review article on fundamental aspects of thiolate selfassembled monolayers (SAMs) on the (111) and (100) surfaces of the $\mathrm{Cu}$ and $\mathrm{Ni}$ groups is presented. In particular this work is focused on two important points that remain poorly understood in most of these metals: the chemistry of the S-metal interface, 20 which strongly depends on the nature of the metallic surface, and the role of the interaction forces that not only guide the selfassembly process but also influence the surface structure of SAMs. In addition to recent experimental and theoretical data on these issues we present new density functional calculations 25 including van der Waals forces for an important number of known thiolate surface structures as a function of the hydrocarbon chain length.
\end{abstract}

\section{Introduction}

Self-assembly is one of the most important concepts of the $21 \mathrm{st}$ 30 century. In fact, self-assembly is the construction of systems without guidance from external sources other than that provided by the environment. ${ }^{1}$ Self-assembled monolayers (SAMs) are examples of intermolecular self-assembly that takes places at gasliquid, gas-solid, and liquid-solid interfaces. ${ }^{2}$ Solid surfaces of 35 metals, semiconductors and oxides with different topographies can be used as scaffolds for the construction of these supramolecular systems through the adsorption of different molecules. ${ }^{3}$ These SAMs are two-dimensional molecular structures, usually with thickness between 1 and $3 \mathrm{~nm}$, which can

40 be precisely tuned by the molecular dimension and arrangement on the surface.

In a typical SAM, molecules are bonded to the solid substrate by a reactive head that provides a strong molecule-substrate link to the system. ${ }^{3,4}$ On the other hand, van der Waals forces between 45 molecules stabilize the supramolecular assembly introducing long-range or short-range ordering, depending both on the molecule and on the substrate. ${ }^{3,4}$ The molecular terminal group provides chemical functionality to the SAM and can be used to tailor the physical chemistry of the solid surface. The interest in 50 surface-confined molecular assemblies arises from their potential to combine and manipulate topological, chemical and functional features that are essential for a wide variety of technological applications such as microanalysis, biotechnology, nanofabrication or corrosion protection, among others.

${ }_{55}$ SAMs of thiol molecules (RSH) on metal surfaces are the fundamental building blocks for creating complex structures by the so-called "bottom-up" approach. These SAMs can be easily prepared by using thiols (either aliphatic or aromatic), alkyldisulfides, dialkylsulfides ${ }^{3,}, 4$, alkylthiosulfates ${ }^{5}$, organic ${ }_{60}$ xanthates $^{6}$, and alkylthiocyanates ${ }^{7}$ on single-crystal, rough or nanoparticle (NP) surfaces of clean metals, ${ }^{8}$ both from gas phase and liquid-phase adsorption. This is an interesting point, as solution-processable organic molecules have advantages over those deposited from gas phase since they involve a low cost,

65 allow mass production, processability at lower temperatures, and can be arranged over large substrate areas. ${ }^{9}$ Thiol SAMs can be studied using a large variety of surface characterization techniques, as discussed in Ref. ${ }^{8}$

Some aspects of the thiolate-metal systems are today well 70 established. $^{3}$ It is well known that thiols adsorb at room temperature forming a strong thiolate-metal bond (RS-Me) following dissociation of the $\mathrm{S}-\mathrm{H}$ bond, which spontaneously occurs on all clean metal surfaces. The $\mathrm{H}$ atom produced by this reaction can be adsorbed or eliminated from the metal surface 75 forming $\mathrm{H}_{2}$, depending on the $\mathrm{H}$ atom-metal surface interaction. The exception is methanethiol (MT), which remains intact after adsorption; therefore, dimethydisulfide $\left(\left[\left(\mathrm{CH}_{3} \mathrm{~S}\right)_{2}\right]\right.$, DMDS) is used to form MT monolayers. Adsorbed thiolates form lyingdown (LD) or standing-up (SU) arrangements depending on the 80 concentration (liquid- phase adsorption) or doses (gas-phase adsorption) used in the self-assembly process. ${ }^{4}$ If the LD configuration is preferred, a transition to denser SU arrangement is usually observed as the thiol concentration/dose or adsorption time increases. This transition is driven by the energy gain 85 resulting from an increased number of thiolates (this is more evident for large molecules) and by van der Waals (vdW) interactions among adjacent adsorbed molecules. The interplay 
between long-range vdW thiol species and molecule-substrate interactions in dense phases determines the tilt angle $(\alpha)$ of the thiol with respect to the substrate normal, as already discussed in the pioneer work of Allara et al. ${ }^{10}$ For large molecules vdW s interactions prevail, and $\alpha$ varies from 0 to $37^{\circ}$ depending on the metal surface. In contrast, for smaller thiols, vdW moleculesubstrate interactions are also important and $\alpha$ values increase (in some cases to values $>50^{\circ}$ ).

10 Table 1. List of some important acronyms used in the text

\begin{tabular}{|c|c|}
\hline $\mathbf{A}$ & Unit cell area \\
\hline AES & Auger Electron Spectroscopy \\
\hline $\mathbf{B E}$ & Binding Energy (XPS) \\
\hline$\overline{B T}$ & Butanethiol \\
\hline$d$ & nearest-neighbor distances \\
\hline DMDS & Dimethydisulfide \\
\hline DOS & Density of states \\
\hline DFT & Density Functional Theory \\
\hline DT & Dodecanethiol \\
\hline$E_{b}$ & Binding energy (DFT) \\
\hline$E_{r}$ & Reconstruction energy (DFT) \\
\hline ET & Ethanethiol \\
\hline GIXRD & Grazing incidence X-ray diffraction \\
\hline HDT & Hexadecanethiol \\
\hline HOMO & $\begin{array}{lll}\begin{array}{l}\text { Highest } \\
\text { Orbital }\end{array} & \text { Occupied } & \text { Molecular } \\
\end{array}$ \\
\hline HT & Hexanethiol \\
\hline LD & Lying-Down \\
\hline IR & Infrared spectroscopy \\
\hline LEED & Low Energy Electron Diffraction \\
\hline LED & Light Emitting Diode \\
\hline LUMO & Lowest Occupied Molecular Orbital \\
\hline MBA & Mercaptobenzoic acid \\
\hline MT & Methanethiol \\
\hline$n$ & Number of $\mathrm{C}$ atoms \\
\hline NC & Nanocluster \\
\hline $\mathbf{N P}$ & Nanoparticle \\
\hline NT & Nonanethiol \\
\hline $\mathbf{N}_{\mathrm{t}}$ & Number of thiolates in the unit cell \\
\hline OT & Octanethiol \\
\hline PDOS & Projected Density of States \\
\hline PET & Phenylethanethiol \\
\hline PT & Propanethiol \\
\hline $\mathbf{q}_{\text {Bader }}$ & Bader charge \\
\hline SAM & Self Assembled Monolayer \\
\hline SERS & $\begin{array}{ll}\text { Surface Enhanced } & \text { Raman } \\
\text { Spectroscopy }\end{array}$ \\
\hline STM & Scanning Tunneling Microscopy \\
\hline SU & Standing-Up \\
\hline TEM & Transmission Electron Microscopy \\
\hline TMA & Thiomalic acid \\
\hline UHV & Ultra High Vacuum \\
\hline vdW & van der Waals \\
\hline XAFS & X-ray Absorption Fine Structure \\
\hline XPS & X- ray Photoelectron Spectroscopy \\
\hline XRD & X- ray Diffraction \\
\hline$\alpha$ & Tilt angle \\
\hline$\gamma$ & Surface free energy \\
\hline$\phi$ & Work function \\
\hline$\mu$ & Surface dipole \\
\hline$\theta$ & Thiolate surface coverage \\
\hline
\end{tabular}

The experimentally measured maximum thiolate surface coverage $(\theta)$ in these dense phases ranges from $1 / 3$ to $1 / 2$ on the (111) and (100) surfaces, respectively, but can reach $\theta \approx 2 / 3$ on NP surfaces ${ }_{15}$ due to curvature effects. ${ }^{11}$ The strong RS-Me bond provides an efficient anchor of the molecules to the metal substrates.
However, other sulfur species are often present in thiolate SAMs such as adsorbed sulfide, disulfides, non-bonded thiols, and oxidized thiol species such as sulfonates. ${ }^{3,4,6-9,12,13}$

20 Thiol chemisorption (as thiolates) on metal surfaces results in a decrease of the corresponding work function $(\phi)$ with respect to the clean metal $(\Delta \phi)$. Charge transfer from the metal to the S-head atom of the thiol molecule generates an interfacial dipole $(\mu)$ that changes with the nature of the metal while is nearly independent 25 for alkanethiolates. The molecular dipoles can be tuned by introducing atoms such as fluorine in the terminal group. Also, the surface chemistry of SAMs can be changed using hydrophobic $\left(-\mathrm{CH}_{3},-\mathrm{CF}_{3}\right)$ or hydrophilic $\left(-\mathrm{COOH},-\mathrm{NH}_{2}\right)$ terminal groups. This allows the control of surface properties 30 related to wettability, friction, lubrication, corrosion behavior, protein adsorption and bacterial adhesion, among others. The terminal groups of the thiol molecules have also been employed to capture and sense different molecules and make organic reactions in two dimensions for building complex and stable 35 three-dimensional molecular structures.

Despite the great amount of information on thiol SAMs on metals some fundamental topics are far from being completely understood, such as the precise atomic level details of the structures at the thiol-metal interface and the variables that

40 control them, which include both the S-head-substrate interaction and van der Waals forces among organic molecules. In particular, for most of the metals studied here, the thiol/metal interface continues to be modeled using thiyl radicals (RS•) adsorbed on metal surfaces without considering substrate reconstructions and 45 the complex surface chemistry reported in the last years. The knowledge of these topics is the starting point to make reliable evaluations on optical properties and electron transport across the organic layer, both important for the design of thiolate-based devices. ${ }^{14-17}$ Moreover, the understanding of the chemistry and

50 structure of thiolates on NP surfaces is also crucial as they are widely used in different technological fields. Thermodynamic considerations have shown that NPs exhibit mainly (111) and (100) faces and thus thiol self-assembly on these metallic planes needs to be considered. ${ }^{18}$ Although recent efforts have been made

55 to evaluate the possible reconstruction of the NP surface and metal-thiolate complex formation ${ }^{11}$ other works still continue to model the thiolate-metal interaction simply as adsorbates on an unreconstructed metal surface. ${ }^{18,19}$

In this work we outline fundamental aspects of thiolate SAMs on 60 the (111) and (100) faces of $\mathrm{Au}, \mathrm{Ag}, \mathrm{Cu}, \mathrm{Pt}, \mathrm{Pd}$ and $\mathrm{Ni}$. We briefly review SAM applications, chemical reactions of thiol molecules, and the structure of the stable dense phases on these surfaces. Two aspects that remain controversial are particularly analyzed: the S-metal chemistry and the role of intermolecular

${ }_{65}$ forces on the surface structure. We have based this contribution mainly on scanning tunneling microscopy (STM), X-ray photoelectron spectroscopy (XPS), and density functional theory (DFT) data which, despite their limitations ${ }^{20}$, still remain as the most powerful tools to study these aspects of self-assembled 70 monolayers on surfaces. ${ }^{21}$

In particular, we present new DFT calculations for a large number of surface structures experimentally observed at saturation coverage on these metals using the periodic planewave basis set code VASP 5.2.12. ${ }^{22,}{ }^{23}$ We have followed the ${ }_{75}$ scheme of nonlocal functional proposed by Dion et al., ${ }^{24,}{ }^{25}$ and the optimized exchange implementation optB88-vdW ${ }^{25}$ in order to introduce the vdW interactions in these calculations. This functional yields indeed a reasonable good agreement between experimental and calculated data for different systems. ${ }^{26,27}$

80 Nowadays there are a large number of papers that use DFT to study alkanethiol adsorption on metals, although most of them ${ }^{28-}$ 
${ }^{30}$ do not include vdW, with the exception of a few papers where the dispersion interactions have been applied with different approaches ${ }^{31,32,33}$. We expect that the good agreement between experimental results and the calculations supports the theoretical 5 benchmark applied in our study. With this calculation approach we analyze the impact of the dispersion forces on the stability of the different surface structures for different alkanethiols molecules with lengths up to as the size of octanethiol.

The information presented here should also be of interest to better 10 understand several aspects of thiol-covered surfaces such as electrochemical behavior, tunneling across SAMs, and the relationship between thiolate-covered surfaces and thiolateprotected metal clusters, topics that are not the focus of the present work.

\section{${ }_{15}$ 2. Thiolate SAMs on Metals}

\subsection{Gold}

Gold is an interesting material due to its chemical stability, surface chemistry, biocompatibility, and unique optical properties that are associated with a convenient range of processing 20 technologies. Oxide-free, clean, flat $\mathrm{Au}$ surfaces can be easily modified by thiols not only in gas phase but also in liquid media under ambient conditions. These features have led to the use of thiolate SAMs on gold in many applications, particularly in biological systems, such as fluorescent biological detection of ${ }_{25}$ pathogens and proteins, and immunoassays. Also, thiol SAMs on planar $\mathrm{Au}$ surfaces have been used as building blocks for the fabrication of sensing, ${ }^{34}$ electronic ${ }^{35,36}$ and optical-light responsive devices. In particular, nanostructured $\mathrm{Au}$ has been used to prepare SERS active surfaces for chemical and 30 biochemical sensing and devices that can be switched by light. Also, polycrystalline gold films coated with thiol-based SAMs form the basis of a wide range of nanomechanical sensor platforms $^{37}$ in which detection of adsorbates relies on the transmission of mechanical forces mediated by chemically 35 derived stress at the SAM-Au interface.

On the other hand, thiolate-protected AuNPs can be regarded as assemblies of gold thiolates (RS-Au) on a metallic core that acts as a templating device. These have also been widely explored in the last decades due to their promising applications in biology, 40 medicine (therapy, diagnostics and imaging), catalysis, photonics, and electronics. ${ }^{38-41}$

\section{Surface structures and chemistry}

STM data have shown that self-assembly of thiols on $\mathrm{Au}(111)$ from gas phase initially involves the formation of disordered gas45 like adsorbates, followed by the formation of LD surface structures with molecular axes parallel to the substrate (Figure 1a). ${ }^{4,42}$ These lattices, known as striped phases, have a thiol surface coverage $\theta<1 / 3$, and can be in general described as $p \times \sqrt{3}$, where $p$ is an integer. ${ }^{43}$ Several ordered LD phases have 50 been described. ${ }^{44,45}$ Two of these can be observed in Fig 1a: the $\beta$ lattice with molecules completely confined to the surface plane in adjacent rows arranged in a head-head/ tail-tail configuration and the $\delta$ phase that would correspond to alkyl chains in adjacent rows with an out-of-plane interdigitated configuration. ${ }^{44}$ These 55 lattices usually coexist with domains of a disordered liquid-like phase $(\varepsilon)$ (Fig 1a). High resolution STM images have revealed that at low coverage the thiolate species adsorbed on the $\mathrm{Au}(111)$ surface are thiol- $\mathrm{Au}$ adatom $\left(\mathrm{Au}_{\mathrm{ad}}\right)$ gold complexes $\left(\mathrm{RS}-\mathrm{Au}_{\mathrm{ad}}{ }^{-}\right.$ $\mathrm{SR}){ }^{46}$ where the $\mathrm{Au}$ adatoms are provided by the lifting of the 60 stable $22 \times \sqrt{3}$ surface reconstruction (the herringbone pattern) induced by thiol adsorption. Indeed, the $22 \times \sqrt{3}$ structure shows significant compressibility, leading to the ejection of $\mathrm{Au}$ atoms ${ }^{47}$ that have a tendency to form linear $\mathrm{S}-\mathrm{Au}_{\mathrm{ad}}-\mathrm{S}$ 'staple' arrangements. ${ }^{48}$ When the dose/concentration or incubation time 65 is increased, a phase transition occurs from the LD structure to dense phases of SU molecules. ${ }^{49}$ This transition is driven by the possibility of increasing the number of thiolate bonds (this is particularly true for alkanethiols with a number of C atoms $n>4$ ) and vdW interactions among the hydrocarbon chains. In self70 assembly from solution the system usually evolves directly to the $\mathrm{SU}$ phases. In these cases, as in Fig 1a, LD phases can be prepared by partial desorption of the dense structures in the liquid phase by thermal or electrochemical controlled desorption., ${ }^{40}$
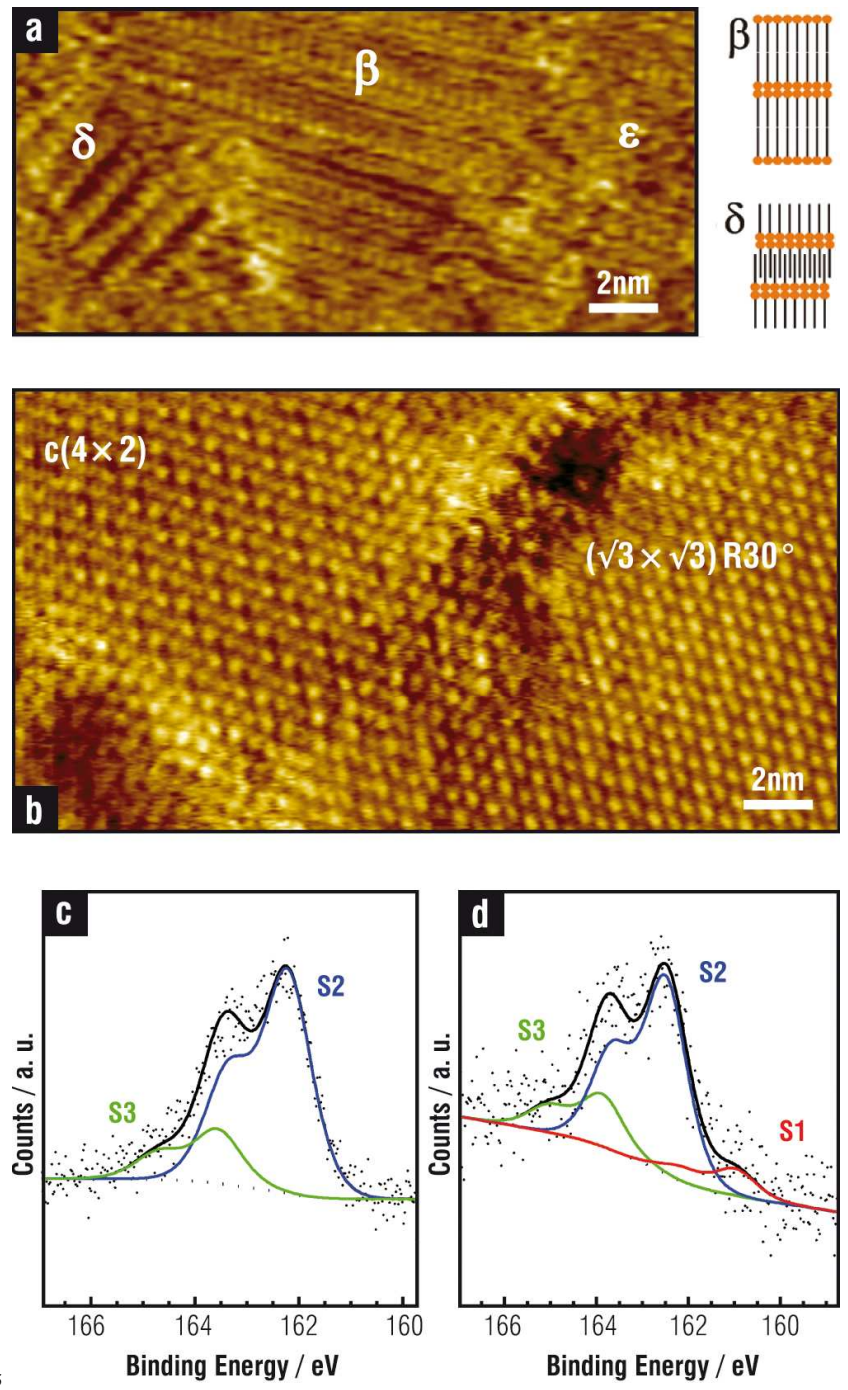

Figure 1. a) Coexisting HT LD phases $(\beta, \delta, \varepsilon)$ on $A u(111)$. A scheme of the ordered LD phases is also shown. b) Domains of the HT "zigzag" c $(4 \times 2)$ and $(\sqrt{ } 3 \times \sqrt{ } 3) R 30^{\circ}$ lattices. c) XPS $S 2 p$ of a DT SAM on $A u(111)$. S2 and $S 3$ correspond to thiolates and ${ }_{80}$ free non-bonded thiols, respectively. d) XPS $S 2 p$ of a DTprotected AuNP. S2, S3, and S1 correspond to thiolates, free thiol, and atomic $S$, respectively. The $S 1$ component has also been assigned to thiolates on other adsorption sites and to adsorbed disulfides, as discussed in the text.

${ }_{85}$ On the other hand, SU phases on the $\mathrm{Au}(111)$ surface exhibit thiol-thiol nearest-neighbor distances $\boldsymbol{d}=0.499 \mathrm{~nm}, \theta=1 / 3$ (Figure 1b), and bear strong covalent thiolate bonds, characterized by the XPS $S 2 p$ peak at $B E \approx 162 \mathrm{eV}$ (S2 
component in Figure 1c). 1, 3, 42, 51, 52 Small amounts of free (nonbonded) thiols trapped in the SAM can also be detected (S3 component at $\mathrm{BE} \approx 163 \mathrm{eV}$ in Figure $1 \mathrm{c}$ ).

Van der Waals forces are also important in SAM stability, adding ${ }_{5} \approx 0.1 \mathrm{eV}$ per $\mathrm{C}$ atom and aligning the alkyl chains parallel to each other in a nearly all-trans configuration. Since the optimal distance between alkane chains is around $0.43 \mathrm{~nm}$ rather than $\boldsymbol{d}=$ $0.5 \mathrm{~nm}$, the tilt angle results in $\alpha \approx 26-37^{\circ} 10,53,54$ to optimize the vdW forces. Exceptions are small thiol molecules that can exhibit ${ }_{10} \alpha \approx 50-60^{\circ} 55$ due to molecule-substrate interactions. The chain order is usually analyzed by infrared spectroscopy (IR) by considering the $\mathrm{CH}_{2}$ stretching vibrations of the alkyl chain, which are sensitive to packing density and to the presence of gauche defects. ${ }^{10}$ In particular, the antisymmetric $\mathrm{CH}_{2}$ stretching 15 vibration $\left(\mathrm{d}^{-}\right)$at $\approx 2918 \mathrm{~cm}^{-1}$ and $\approx 2926 \mathrm{~cm}^{-1}$ indicate high quality and heavily disordered SAMs, respectively.

Different surface structures have been observed depending on the hydrocarbon chain length. ${ }^{56}$ Thus, MT $(n=1)$, ethanethiol (ET, $n$ $=2$ ), and propanethiol (PT $n=3$ ), for which $\mathrm{vdW}$ forces are 20 relatively weak, organize in $(3 \times 4)$ lattices formed by the RS$\mathrm{Au}_{\mathrm{ad}}-\mathrm{SR}$ complexes in a trans-configuration (Figure $\left.2 \mathrm{a}, \mathrm{a}^{\prime}\right){ }^{57} \mathrm{On}$ the other hand, for $n>3$ alkanethiols organize in $\mathrm{c}(4 \times 2)$ lattices, better described as $(3 \times 2 \sqrt{ } 3)^{57}$ (Figure 1b), where RS-Au $\mathrm{ad}_{\mathrm{ad}} \mathrm{SR}$ complexes are in a cis-configuration (Figure 2b, $\mathrm{b}^{\prime}$ ), and with an 25 orthorhombic packing structure. ${ }^{58}$ The surface coverage by RS$\mathrm{Au}_{\mathrm{ad}}$-SR species $(\theta=0.33)$ requires $\theta_{a d} \approx 0.165$ which could be mainly provided by step edges or by the uptake of $\mathrm{Au}$ surface atoms at terraces, depending on the location of thiolate adsorption. This process leads to single vacancies that later 30 coalesce to form vacancy islands at terraces or diffuse to yield serrated-like steps. However, as the hydrocarbon chain length is further increased, a $(\sqrt{3} \times \sqrt{3}) \mathrm{R} 30^{\circ}$ surface structure (Figure $\left.1 \mathrm{~b}\right)$ is observed with a packing structure that has been also described as monoclinic. ${ }^{58}$ Also, STM and grazing incidence X-ray diffraction $35($ GIRXD) data indicate that the $(\sqrt{3} \times \sqrt{3}) \mathrm{R} 30 \% /(4 \times 2)$ surface coverage ratio increases with $n$. $^{53,59}$
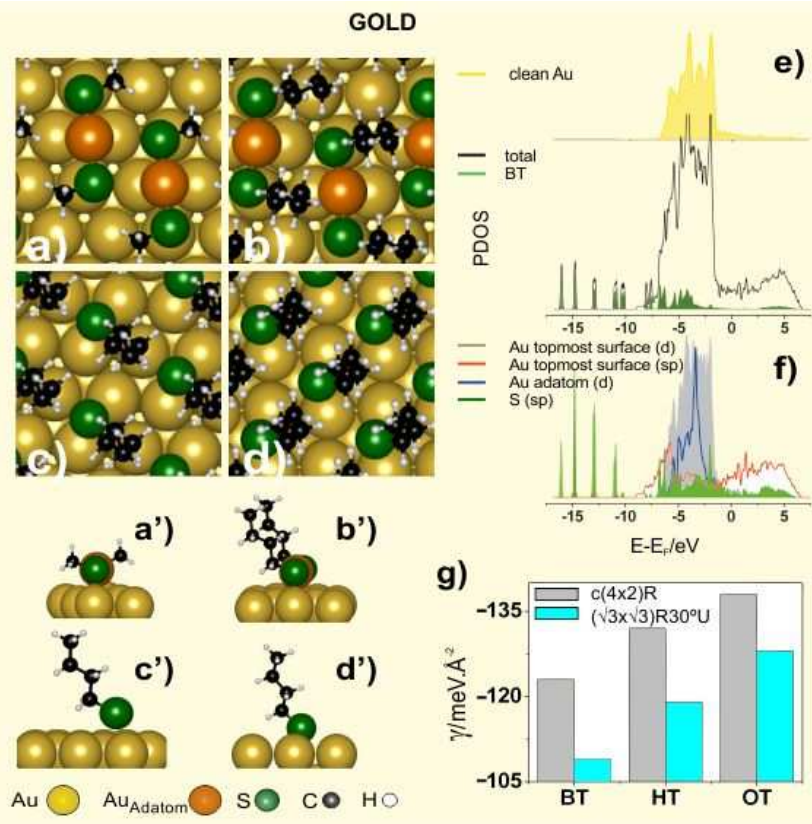

Figure 2. Top view schemes of the surface structures optimized

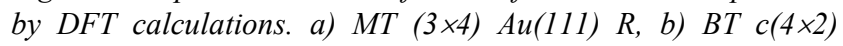

$A u(111) R$ c) $(\sqrt{ } 3 \times \sqrt{ } 3) R 30^{\circ} A u(111) U$ d) $c(2 \times 2) A u(100) U . a^{\prime}$ $\left.d^{\prime}\right)$ Lateral view of the lattices shown in $(a-d)$. e) DOS of clean ${ }_{45} A u(111, B T c(4 \times 2) A u(111) R$ and PDOS of adsorbed BT f) PDOS of topmost surface $A u d$ and $s p$ states, $A u_{a d} d$ states and $S s p$ states corresponding to $B T c(4 \times 2) A u(111) R$. The Fermi level is aligned at the origin of the energy scale. $g) \gamma$ values corresponding to $c(4 \times 2)$ with the staple motifs $(R)$ and for the ${ }_{50}(\sqrt{3} \times \sqrt{3}) R 30^{\circ}$ on $A u(111)(U)$ for $B T$, hexanethiol (HT) and octanethiol (OT).

Table 2

Geometric and energetic parameters for the different Au surface structure models discussed in the text and figures

55

\begin{tabular}{|c|c|c|c|c|c|c|}
\hline \multirow{2}{*}{$\begin{array}{c}\text { Surface } \\
\text { structure }\end{array}$} & \multirow{2}{*}{$E_{r} / \mathbf{N}$} & \multirow{2}{*}{$E_{b} / \mathbf{e V}$} & \multirow{2}{*}{$\gamma / \mathrm{eV} . \AA^{-2}$} & \multicolumn{2}{|c|}{$\mathbf{q}_{\text {Bader }} / \mathbf{e}$} & \multirow{2}{*}{$\alpha^{\circ}{ }^{\circ}$} \\
\hline & & & & M & $\mathbf{S}$ & \\
\hline $\begin{array}{c}(111) \mathbf{R} \\
(3 \times 4)-\mathrm{MT} \\
\text { Figure } 2 a\end{array}$ & +0.51 & -2.92 & -0.120 & $\begin{array}{c}+0.14^{*} \\
0.00\end{array}$ & -0.16 & 67.3 \\
\hline $\begin{array}{c}\quad(111) \mathbf{R} \\
\mathrm{c}(4 \times 2)-\mathrm{BT} \\
\text { Figure } 2 b\end{array}$ & +0.52 & -3.28 & -0.123 & $\begin{array}{c}+0.14^{*} \\
0.00\end{array}$ & -0.18 & 34.4 \\
\hline $\begin{array}{c}(111) \mathbf{R} \\
\mathrm{c}(4 \times 2)-\mathrm{HT}\end{array}$ & +0.52 & -3.49 & -0.132 & $\begin{array}{c}+0.15^{*} \\
0.00\end{array}$ & -0.18 & 32.2 \\
\hline $\begin{array}{c}(111) \mathbf{R} \\
\mathrm{c}(4 \times 2)-\mathrm{OT}\end{array}$ & +0.58 & -3.68 & -0.138 & $\begin{array}{c}+0.15^{*} \\
0.00\end{array}$ & -0.18 & 32.8 \\
\hline $\begin{array}{c}(111) \mathbf{U} \\
(\sqrt{3} \times \sqrt{3}) \mathrm{R} 30^{\circ}- \\
\text { MT }\end{array}$ & 0 & -2.19 & -0.098 & +0.05 & -0.23 & 56.4 \\
\hline $\begin{array}{c}(111) \mathbf{U} \\
(\sqrt{3} \times \sqrt{3}) \mathrm{R} 30^{\circ} \\
\text { BT } \\
\text { Figure } 2 \mathrm{c}\end{array}$ & 0 & -2.44 & -0.109 & +0.03 & -0.20 & 29.1 \\
\hline $\begin{array}{c}(111) \mathbf{U} \\
(\sqrt{ } 3 \times \sqrt{ } 3) R 30^{\circ} \\
\text { HT }\end{array}$ & 0 & -2.67 & -0.119 & +0.03 & -0.19 & 26.4 \\
\hline $\begin{array}{c}(111) \mathbf{U} \\
(\sqrt{3} \times \sqrt{3}) \mathrm{R} 30^{\circ} \\
\text { OT }\end{array}$ & 0 & -2.88 & -0.128 & +0.03 & -0.19 & 24.5 \\
\hline $\begin{array}{c}(100) \mathbf{U} \\
\mathrm{c}(2 \times 2)-\mathrm{BT} \\
\text { Figure } 2 \mathrm{~d}\end{array}$ & 0 & -2.84 & -0.164 & +0.06 & -0.17 & 23.8 \\
\hline
\end{tabular}

While the presence of RS- $\mathrm{Au}_{\mathrm{ad}}-\mathrm{SR}$ moieties has been confirmed for $(3 \times 4)$ and $c(4 \times 2)$, the nature of the thiolate species forming the $(\sqrt{3} \times \sqrt{3}) \mathrm{R} 30^{\circ}$ lattice remains controversial. ${ }^{4}$ In fact, $\mathrm{RS}-\mathrm{Au}_{\mathrm{ad}}$ ${ }_{60}$ complexes are compatible with the $(\sqrt{3} \times \sqrt{3}) \mathrm{R} 30^{\circ}$ lattice, but this exhibits lower stability in terms of the surface free energy $\gamma=$ $\left(\mathrm{N}_{\mathrm{t}} / \mathrm{A}\right.$ ) $\left[E_{b}+E_{\mathrm{r}} / \mathrm{N}_{\mathrm{t}}\right]$ (where $\mathrm{N}_{\mathrm{t}}$ is the number of thiol molecules in the unit cell, $\mathrm{A}$ is the unit cell area, $E_{b}$ and $E_{\mathrm{r}}$ are the binding and the surface reconstruction energies, respectively) than a ${ }_{65}(\sqrt{3} \times \sqrt{3}) \mathrm{R} 30^{\circ}$ lattice formed by simple $\mathrm{RS} \bullet$ adsorbates on the unreconstructed $(\mathrm{U}) \mathrm{Au}(111)$ surface (Figure $\left.2 \mathrm{c}, \mathrm{c}^{\prime}\right)^{4}$. In order to solve this problem it has been proposed that the $(\sqrt{3} \times \sqrt{3}) \mathrm{R} 30^{\circ}$ thiol lattice observed by STM is due to the terminal methyl group arrangement ${ }^{3}$ while the thiolate-Au species are organized in a $70 c(4 \times 2)$ lattice. ${ }^{57}$ Also, it has been suggested that STM imaging under non optimal conditions is responsible for the observation of the $(\sqrt{3} \times \sqrt{3}) \mathrm{R} 30^{\circ}$ pattern for terphenylthiolate SAMs on $\mathrm{Au}(111) .{ }^{60}$ However, these explanations cannot account for the coexistence of $(\sqrt{3} \times \sqrt{3}) \mathrm{R} 30^{\circ}$ and $c(4 \times 2)$ lattice domains for the 75 same thiol, and in the same STM image, taken under the same tunnelling conditions, as shown in Figure $1 b$.

We note that the difference in surface stability between the $c(4 \times 2)$ with staple motifs (R surface) and the $(\sqrt{3} \times \sqrt{3}) \mathrm{R} 30^{\circ}$ with 
RS• adsorbates (U surface) decreases as $n$ is increased (Figure $2 \mathrm{~g}$ ). One could thus speculate that long alkanethiols, usually prepared from the liquid phase, and for which LD phases are seldom formed, adsorb on $\mathrm{Au}(111)$ as RS• species adopting the ${ }_{5}(\sqrt{ } 3 \times \sqrt{ } 3) \mathrm{R} 30^{\circ} \mathrm{U}$ lattice structure. This arrangement would allow a better optimization of $\mathrm{vdW}$ interactions for longer hydrocarbon chains than in the $c(4 \times 2)$ staple lattice. In fact, we observe that accommodation of the longer alkyl chains into the $c(4 \times 2)$ staple lattice shifts the $\mathrm{Au}$ surface atoms to slightly more unfavourable 10 positions, a fact that is reflected in a small increase in $E_{r}$. Evidence about changes in the hydrocarbon chain configuration with $n$ has been given by broad-bandwidth sum frequency generation spectroscopy indicating that $\alpha$ decreases from $34^{\circ}$ (short chains) to $30^{\circ}$ (long chains). ${ }^{61}$ This is not surprising, as 15 crystalline monolayers of long hydrocarbon chains exhibit $0^{\circ}<\alpha$ $<25^{\circ} .{ }^{62}$ Presumably, as vdW interactions decrease, Au-S interactions prevail and the molecules become more tilted.

Therefore, results in Figure $2 \mathrm{~g}$ could explain the increase in the $(\sqrt{ } 3 \times \sqrt{3}) \mathrm{R} 30 \%(4 \times 2)$ ratio with $n .{ }^{53,}{ }^{59}$ However, simple RS• 20 adsorption on the $\mathrm{U} \mathrm{Au}(111)$ substrate cannot explain vacancy island coverage $\theta_{v a c} \approx 0.12-0.14$ observed for SAMs of longer thiols such as dodecanethiol (DT) for which $(\sqrt{3} \times \sqrt{3}) \mathrm{R} 30^{\circ}$ largely dominates. Also, this $\theta_{v a c}$ value is close to that originated by the $\mathrm{RS}-\mathrm{Au}_{\mathrm{ad}}-\mathrm{SR}$ moieties. ${ }^{4}$ Vacancies have been previously assigned 25 to thiol etching ${ }^{63}$ or ejection of Au surface atoms resulting from shrinkage of the substrate surface during self-assembly. ${ }^{64}$ As for AuNPs, it has been found that there is a relative contraction of facets and expansion of the curved surface regions in contact with SAM-forming thiolate ligands. ${ }^{65}$ There are other interesting 30 experimental observations that deserve attention. Thiols with functional terminal groups distinct from alkyl, such as thiomalic acid (TMA) ${ }^{66}$, and small aromatic thiols such as mercaptobenzoic acid (MBA), ${ }^{67}$ and 6-mercaptopurine ${ }^{68}$ form diluted and ordered SAMs with surface coverage $0.2<\theta<0.25$, thus smaller than $\theta=$ ${ }_{35} 0.33$ observed for alkanethiolates or biphenyl thiols. ${ }^{42}$ Interestingly, for small aromatic thiols, vacancy islands, which are evidence for surface reconstruction and $\mathrm{RS}-\mathrm{Au}_{\mathrm{ad}}-\mathrm{SR}$ formation at atomically smooth terraces, are absent.

Models containing RS- $\mathrm{Au}_{\mathrm{ad}}$-SR moieties have a larger stability

40 than those involving RS• adsorbates on the $\mathrm{U} A u(111)$ surface, as shown by comparing the $\gamma$ values in Table 2 . The staple stability arises from surface $\mathrm{Au}$ sites that contain single Au-S coordination, anchoring the staple units to the substrate, and some $\mathrm{Au}-\mathrm{Au}$ coordination. Also, staple sites contain double Au-S 45 coordination as well as long-range "aurophilic" $\mathrm{Au}-\mathrm{Au}$ coordination between the staple and the Au substrate ${ }^{69}$

It is well known that the relativistic effects in Au are important to understand the interactions with the adsorbates. This effect induces a contraction of $s$ and $p$ shells and a slight expansion of $d$

50 shell so that the $6 s-5 d$ separation decreases. This feature can be observed in Fig. $2 \mathrm{f}$ where the $d$ and $s p$ states of $\mathrm{Au}$ adatom hybridize effectively with $s p$ states of $\mathrm{S}$ atom. Also the analysis of the PDOS of $\mathrm{Au}$ (Figure 2e-f) gives interesting information about the staple bonding to the $\mathrm{Au}(111)$ surface. In fact, the $d$ ${ }_{55}$ PDOS of the $\mathrm{Au}_{\mathrm{ad}}$ in the "staple" is narrow compared to the topmost $\mathrm{Au}$ surface atoms (Figure 2f) indicating its molecular behavior (or nonmetallic bonding nature). In comparison, the topmost $\mathrm{Au}$ surface atoms show significantly wider $d$-PDOS, very similar to the $d$-PDOS of the clean Au surface atoms (Figure ${ }_{60} 2 \mathrm{e}$ ) and consistent with their metallic behavior. Figure $2 \mathrm{f}$ also shows that $\mathrm{S}-\mathrm{Au}$ bonding involves $\mathrm{S} s p$ and $\mathrm{Au} 6 s$ and $5 d$ states. Evidence of the bonding in Fig $2 \mathrm{f}$ is the broadening of the electronic states of the adsorbed BT, especially in the region -1.2/ $-7.5 \mathrm{eV}$. Nevertheless, gold has the most extended $d$ states, the
${ }_{65}$ largest $V_{a d}^{2}$ (square of the adsorbate-metal $d$ coupling matrix element) and therefore the largest Pauli repulsion. ${ }^{70}$ Because of that, BT has a lower $E_{b}$ on gold than on silver and copper.

The S-Au bond is important to understand the electronic properties. Scanning tunneling spectroscopy data of 70 octanethiolate $(\mathrm{OT})$ SAMs with $c(4 \times 2)$ and $(\sqrt{3} \times \sqrt{3}) \mathrm{R} 30^{\circ}$ domains have shown that electronic states originated in the covalent bond between the S-head and the $\mathrm{Au}(111)$ substrate $(\approx-$ $2,+2 \mathrm{eV})$ contribute to the electrical conduction in the tunneling junction at low bias voltage. On the other hand, at high bias 75 voltage a conductive state arising from the alkyl chains $(-3 /-4.5$ $\mathrm{eV}$ ) and an image potential state at $\approx 4.4 \mathrm{eV}$ has been observed. ${ }^{71}$ The same behavior has been measured for the LD OT phase, although the position of the image potential state shifts to higher energies as the adsorbate density decreases.

80 Thiolate adsorption on metals leads to an interfacial dipole $(\Delta \mu)$ which involves two additive contributions, one from the S-Au bond $\left(\mu_{\mathrm{CHEM}}\right)$ and the other from the intrinsic dipole of the molecular layer $\left(\mu_{\mathrm{SAM}}\right)$. The $\mathrm{S}-\mathrm{Au}$ bond is nearly apolar and its contribution to the surface dipole is relatively small. ${ }^{72}$ In fact, ${ }_{85}$ Bader analysis show that the RS- $\mathrm{Au}_{\mathrm{ad}}-\mathrm{RS}$ species in vacuum bear $+0.17 \mathrm{e}$ and $-0.13 \mathrm{e}$ on the $\mathrm{Au}_{\mathrm{ad}}$ and on each $\mathrm{S}$ atom, respectively, while $+0.14 /+0.15 \mathrm{e}$ and $-0.16 /-0.18 \mathrm{e}$ are found for $\mathrm{Au}_{\mathrm{ad}}$ and $\mathrm{S}$ atoms of the staple on the Au surface (Table 2). This means that the charge reordering in the $\mathrm{S}-\mathrm{Au}$ bond at the $\mathrm{Au}$ surface does 90 not produce significant changes in $\Delta \mu\left(\mu_{\mathrm{CHEM}} \approx 0\right)$, which remains close to that estimated for the isolated thiolate species in vacuum (i.e. $\Delta \mu \approx \mu_{\mathrm{SAM}}$ ) ${ }^{4}$ Bond formation influences the $\phi$ and the alignment of the electronic levels in the SAM with respect to the metal Fermi energy. ${ }^{73}$ It has been shown that substitutions at 95 the terminal groups of the molecules are electrostatically decoupled from the S-Au bond interface in densely packed SAMs. Therefore, $\Delta \phi$ and the level alignment can be tuned by the chemistry terminal group. Thus alkylthiolates produce a decrease in $\operatorname{Au}(111) \phi$, whereas fluorinated alkylthiolates make it 100 increase. $^{74}$

In contrast to the wide research on thiol self-assembly on the $\mathrm{Au}(111)$ surface, much less attention has been given to such process on the $\mathrm{Au}(100)$ surface. It has been reported that alkanethiols with small $n$ form a $c(2 \times 2)$ overlayer with $\boldsymbol{d}=0.416$ $105 \mathrm{~nm}, \theta=0.5$ and $\alpha \approx 30^{\circ 75}$ (Figure $2 \mathrm{~d}, \mathrm{~d}^{\prime}$ ). On the other hand, STM images taken in electrolyte solutions for ET show a slightly different quadratic arrangement with $\boldsymbol{d}=0.44 \mathrm{~nm}$ and $\theta=0.43$. $^{76}$ These images also reveal $\mathrm{Au}$ islands with a surface coverage close to that expected from the lifting of the hexagonal 110 reconstruction of the $\mathrm{Au}(100)$ surface to form the $\mathrm{Au}(1 \times 1)$ surface, i.e. the (100) surface remains unreconstructed. This simple scenario is valid for small alkanethiol molecules, as longer chain homologues exhibit more complex diffraction patterns. ${ }^{75}$

Thermal stability of thiolate SAMs on $\mathrm{Au}(111)$ is restricted to $T \approx$ ${ }_{115} 400 \mathrm{~K} .{ }^{77,78}$ Increasing the temperature above this value results in thiol desorption, mainly as disulfides. The remaining thiolates adopt a lying-down configuration and the $\mathrm{Au}_{\mathrm{ad}}$ form islands or are incorporated at step edges. The LD phase is desorbed at $T \approx 500$ $\mathrm{K}$, mainly as thiolates. Final desorption of an appreciable amount 120 of gold-containing molecules is observed at $T \approx 700 \mathrm{~K}$, thus supporting the presence of $\mathrm{RS}-\mathrm{Au}_{\mathrm{ad}}$ complexes. Only small amounts of $\mathrm{S}$ are observed after complete desorption, indicating that $\mathrm{S}-\mathrm{C}$ bond breaking is difficult on the $\mathrm{Au}(111)$ surface even at high temperatures. ${ }^{79}$ This is reasonable because the $d$ band of $\mathrm{Au}$ 125 is far from the Fermi level (Figure 2e) and its catalytic activity is relatively poor. Sometimes, however thiol SAMs on $\mathrm{Au}(111)$ exhibit a small S $2 p$ component at $\mathrm{BE}$ of $\approx 161 \mathrm{eV}$ (S1) in addition to the main thiolate feature at $\approx 162 \mathrm{eV}$ (S2 component). 
This component has been attributed either to some atomic $\mathrm{S}$ produced by cleavage of the thiolate C-S bonds ${ }^{80}$ or to the presence of thiolates with a different binding chemistry and/or geometry as compared to the "conventional" thiolate bond (S2 5 component). The former assignment arises from the fact that for annealed SAMs $(T>400 \mathrm{~K})$ it was observed that the thiolaterelated doublet shifted to $\approx 161 \mathrm{eV}$ upon some cleavage of the $\mathrm{C}$ $\mathrm{S}$ bond in the SAM constituents, and also because S1 appears for $\mathrm{S}$ and sulfide adsorption on $\mathrm{Au}(111) .{ }^{81}$ The latter assignment is 10 based on kinetic studies of SAM formation: S1 was observed at early stages of molecular assembly, i.e. for a short immersion time, and disappear later. Plausible reasons can be a hybridization change, adsorption site differences, adsorption at defect sites (such as step edges), or different molecular orientations (striped 15 phases). ${ }^{82,83}$ This $\mathrm{S} 1$ component is enhanced in some aromatic thiols and is also more evident in AuNPs (S1 S 2p component in Figure 1d). In this case this can be accounted by the increased reactivity of the curved NP surfaces ${ }^{66}$ or by the presence of different thiolate species on the facets or by $\mathrm{S}$ ${ }_{20}$ contamination/formation during NP synthesis. ${ }^{64}$ Also, the $161 \mathrm{eV}$ doublet has been attributed to disulfide associated with the AuNP surface $^{84}$ Indeed, this topic is open to more experimental and theoretical work.

Finally, it is interesting to note that thermodynamically stable 25 thiolate-protected $\mathrm{Au}$ nanoclusters (AuNCs) with the formula $\mathrm{Au}_{\mathrm{m}}(\mathrm{SR})_{\mathrm{n}}$, with $\mathrm{m}=24,25,38,102,130,144,225^{85}$ are protected by two types of "staple" motifs (RS-Au $\mathrm{ad}-\mathrm{SR}$ and RS-Au $\mathrm{ad}_{\mathrm{ad}}$-RS$\left.\mathrm{Au}_{\mathrm{ad}}-\mathrm{SR}\right)^{86}$, i.e. they are protected by the same species found for the $(3 \times 4)$ and $\mathrm{c}(4 \times 2)$ lattices on $\mathrm{Au}(111)$ surfaces. Also, the (111) 30 faces of AuNPs $(>2 \mathrm{~nm}$ ) exhibit $\boldsymbol{d} \approx 0.5 \mathrm{~nm}$ and $\approx 1 \mathrm{~nm}$ similar to those observed in the $c(4 \times 2)$ structures shown in Figure $2 .{ }^{87}$ Therefore, in general we expect that (111) faces of AuNPs should reconstruct to be protected by the staples, while the (100) faces should remain unreconstructed protected by RS• adsorbates.

\section{2. 2. Silver}

Silver has many useful optical, physical, and chemical properties. In particular, it has the highest electrical and thermal conductivities of all metals. This is interesting since lowresistance printed conductors are crucial for the development of 40 ultralow cost electronic systems. ${ }^{88}$ Thiolate-protected AgNPs can be printed and subsequently annealed to form plastic-compatible low-resistance conductor patterns. Silver electrodes modified with SAMs of thiolates have been used to modify and improve metal/organic contacts in organic electronic devices such as ${ }_{45}$ LEDs and photovoltaic cells. ${ }^{89}$ Also, AgNPs offer a broad range of applications in molecular diagnostics and photonic devices, which take advantage of the novel optical properties of these nanomaterials. Single layers of silver nanowires have been used to construct arrays for molecule-specific sensing in conjunction 50 with Raman spectroscopy. Thermochromic films made of thiolate-capped AgNPs embedded into polymers have been used as active materials for optical sensing. ${ }^{90}$ Thiolate-protected $\mathrm{Ag}$ nanoclusters are also attractive for biomedical applications, especially for subcellular imaging, because of their ultra-small ${ }_{55}$ hydrodynamic diameters $(<3 \mathrm{~nm})$, facile post-functionalization and good stability. ${ }^{91}$ They also possess superior antimicrobial properties against multidrug-resistant bacteria via generation of a high concentration of intracellular reactive oxygen species. Also AgNPs have been proposed and used as biocides in burns, 60 diabetic skin ulcers ${ }^{92}$ and Human Immunodeficiency Virus infection. $^{93}$

AgNP-based catalysts have been studied as suitable materials for oxygen electroreduction, although their electrocatalytic activity is relatively low with respect to PtNPs. ${ }^{94}$ However, it has been 65 reported that thiolate-protected AgNPs supported on carbon can markedly enhance or inhibit the electrocatalytic activity for $\mathrm{O}_{2}$ reduction, depending on the thiolate ligand. ${ }^{95}$ This opens the possibility of manipulating the electrocatalytic activity by modification of the NP electronic energy via the organic ligand.

\section{${ }_{70}$ Surface structures and chemistry}

Thiols adsorb at saturation coverage on $\operatorname{Ag}(111)$ forming a distorted hexagonal $(\sqrt{7} \times \sqrt{7}) \mathrm{R} 19.1^{\circ}$ lattice of SU molecules with $\theta \approx 0.43$ and $\alpha \approx 0-19^{\circ}$ (Figure $3 \mathrm{a}, \mathrm{b}$ ). ${ }^{10,96}$ Similar lattices have been described for other sulfur organic compounds, such as 75 thiourea and ethylthiourea, which also adsorb as thiolates on the $\operatorname{Ag}(111)$ surface (Figure $3 \mathrm{c}, \mathrm{d}){ }^{97}$
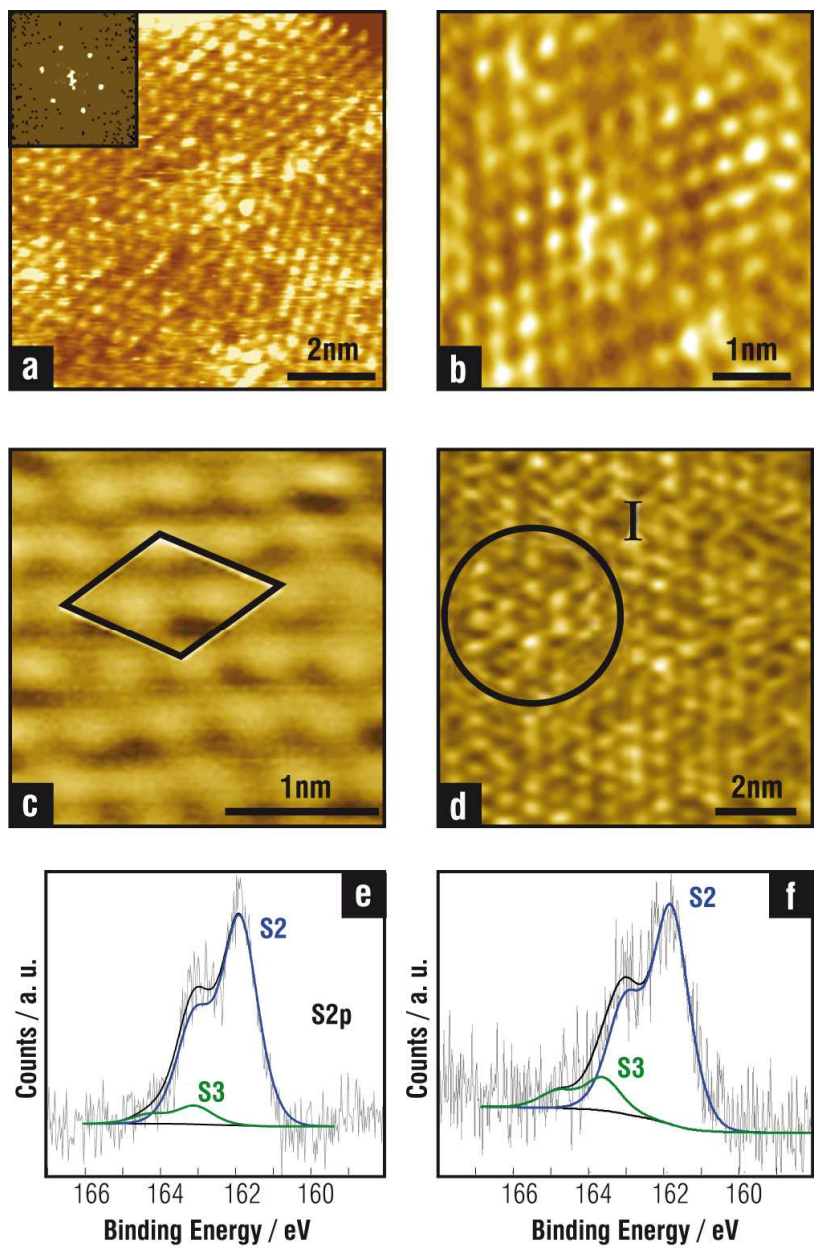

Figure 3. STM images of SAMs on Ag(111). a) PT, inset: Fast Fourier Transform of the $(\sqrt{ } 7 \times \sqrt{ } 7) R 19.1^{\circ}$ lattice. Adapted with 80 permission from J. Phys. Chem. B 2004, 108, 1898-1905. Copyright (2004) American Chemical Society. b) DT. The $(\sqrt{ } 7 \times \sqrt{ } 7) R 19.1^{\circ}$ lattice observed in a) and b) is marked in white lines. b) Adapted with permission from J. Phys. Chem. B 2002, 106, 12267-12273. Copyright (2002) American Chemical Society. 85 c) Thiourea. Adapted with permission from J. Phys.Chem. B 2002, 106, 9831-9838. Copyright (2002) American Chemical. d) Ethylthiourea. The same $2 D$ lattice observed in a-c is shown in the domain inside the circle named I. d) Adapted with permission from Langmuir 2003, 19, 5336-5343. Copyright (2003) American ${ }_{90}$ Chemical Society e) HT f) Hexadecanethiol (HDT) XPS spectra 
of the $S 2 p$ region. e) Adapted with permission from Langmuir 2003, 19, 5336-5343. Copyright (2003) American Chemical Society.

A more stable structure involving a greater density (5/7) of 5 topmost $\mathrm{Ag}$ atoms has recently been proposed, in which the number of $\mathrm{Ag}$ atom vacancies at the surface $\left(\theta_{v a c}=2 / 7\right)$ is markedly reduced with respect to the previous model. ${ }^{98}$ The optimized structure of this reconstructed lattice (R) is shown in Figure $4 a, a^{\prime}$, while the energetic and geometric data are listed in 10 Table 3. The surface structure consists of $\mathrm{Ag}_{3}(\mathrm{MT})_{3}$ units surrounded by hexagons of $\mathrm{Ag}$ atoms. Alkanethiols longer than MT exhibit similar patterns, although $\boldsymbol{d}$ increases to $\approx 0.47 \mathrm{~nm}$ in order to optimize hydrocarbon chain interactions (Figure $\left.4 \mathrm{~b}, \mathrm{~b}^{\prime}\right) .{ }^{99,100}$ X-ray diffraction of layered silver thiolates (RS-Ag, $n$ $15=6-17)$ has shown a monoclinic unit cell with a lattice constant $0.455 \mathrm{~nm}$ and $\alpha \approx 12^{\circ}$, both figures in close agreement with that found for alkanethiolates on the $\operatorname{Ag}(111)$ surface. ${ }^{101}$ The smaller $\alpha$ value $\left(\alpha \approx 0-19^{\circ}\right)$ of the hydrocarbon chains on $\operatorname{Ag}(111)$ allows allocating the molecules in a denser packing $(\theta \approx 0.43)$ compared 20 to the case of $\operatorname{Au}(111)\left(\alpha \approx 25-34^{\circ}, \theta \approx 1 / 3\right) .{ }^{10}$ Also, alkanethiolate SAMs on $\operatorname{Ag}(111)$ form well-ordered and crystalline structures with the hydrocarbon chains in fully extended all-trans configuration.

Concerning the S-Ag metal bond, XPS data of thiolate SAMs on ${ }_{25} \mathrm{Ag}(111)$ show the thiolate component at $\mathrm{BE} \approx 162 \mathrm{eV}(\mathrm{S} 2)^{102}$, which is usually accompanied by a smaller signal at $\mathrm{BE} \approx 163.5$ $\mathrm{eV}$ (S3) (Figure $3 \mathrm{e}, \mathrm{f}$ ) corresponding to non-bonded thiols or disulfides. ${ }^{101}$ In contrast to $\mathrm{Au}(111)$, LD phases on $\operatorname{Ag}(111)$ have rarely been observed. Some evidence for the presence of $\mathrm{LD}$ or a 30 highly tilted alkanethiolate phase preceding the formation of dense SU structures has only been obtained for short alkanethiols adsorbed from the gas phase at low doses. ${ }^{103}$

Experimental data from different techniques for the dense $(\sqrt{7} \times \sqrt{7}) \mathrm{R} 19.1^{\circ}$ thiol lattice suggest that $\operatorname{Ag}(111)$ surface is 35 markedly reconstructed. ${ }^{99}$ Indeed, it has been proposed that MT reconstructs this surface forming a near-hexagonal surface layer with a Ag density that is only 3/7 that of the underlying substrate layers. The MT radicals are adsorbed into threefold coordinated hollow sites with $\boldsymbol{d}=0.44 \mathrm{~nm} .{ }^{104}$ The local S-Ag coordination 40 and structure proposed in this model is very similar to that in $f$ cubic $\mathrm{Ag}_{2} \mathrm{~S}$. However, it has been shown that this lattice exhibits the same stability as the $(\sqrt{ } 7 \times \sqrt{ } 7) \mathrm{R} 19.1^{\circ}$ MT structure on the $U$ $\operatorname{Ag}(111)$ due to the high energy cost to create a large number of Ag atom vacancies $\left(\theta_{v a c}=4 / 7\right.$ coverage $) .{ }^{105}$

${ }_{45}$ The smaller number of vacancies required in this model improves its stability, which becomes more stable than the same arrangement on the $\mathrm{U} \operatorname{Ag}(111)$ surface (Figure 4c,c'), as shown by comparing their $\gamma$ values (Table 3 ). However, as observed for $\mathrm{Au}(111)$, the difference in $\gamma$ between the $(\sqrt{ } 7 \times \sqrt{7}) \mathrm{R} 19.1^{\circ}$ thiol ${ }_{50}$ lattice on the $\mathrm{R}$ and $\mathrm{U}$ surfaces tends to vanish as $n$ is increased (Figure 4g). Also in this case the organization of the long OT alkyl chains requires the reconstruction of the $\operatorname{Ag}(111)$ surface atoms in slightly more unfavorable positions than MT and BT, as shown by comparing the $E_{r}$ values in Table 3 .

${ }_{55}$ On the other hand, MBA SAMs on $\operatorname{Ag}(111)$ show diluted lattices with $\theta=0.25-0.30$ instead of the $\theta=0.43$ found for alkanethiols on the $\operatorname{Ag}(111)$ surface, ${ }^{106}$ a result that agrees with that reported for the same molecule on the $\mathrm{Au}(111)$ surface. ${ }^{67}$ As in the case of $\mathrm{Au}(111)$ these two observations require further experimental and 60 theoretical work in order to understand the role of hydrocarbon chains and the effect of small thiol molecules adsorption on surface reconstruction.

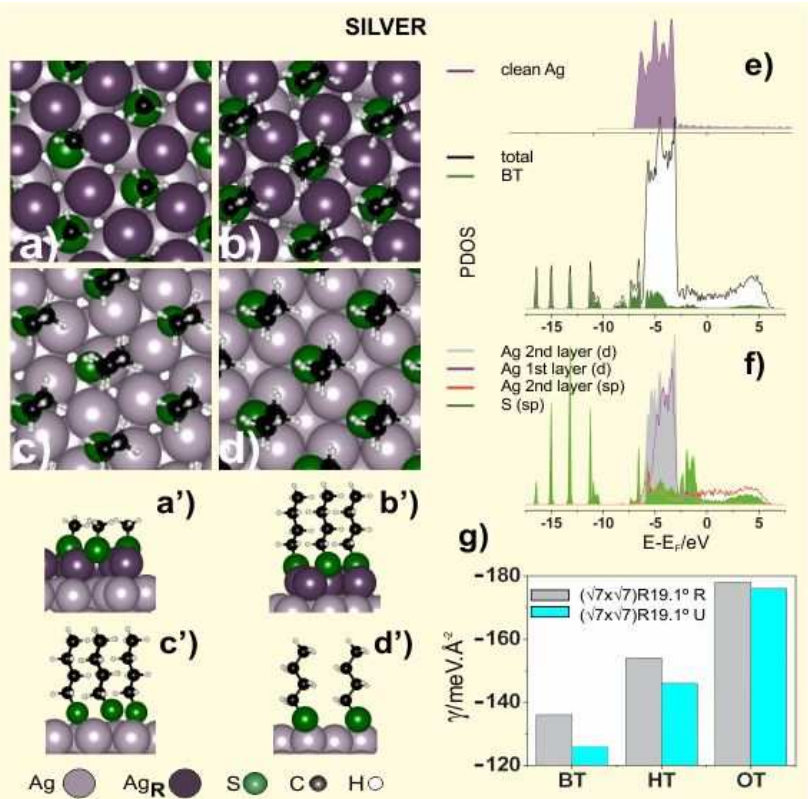

Figure 4. Top view schemes of the surface structures optimized ${ }_{65}$ by DFT calculations. a) $M T(\sqrt{ } 7 \times \sqrt{ }) R 19.1^{\circ} \mathrm{Ag} R 5 / 7$ b) $B T$ $(\sqrt{ } 7 \times \sqrt{7}) R 19.1^{\circ} \mathrm{Ag} \mathrm{R5/7}$ c) $B T(\sqrt{7} \times \sqrt{ } 7) R 19.1^{\circ} \mathrm{Ag}(111) \mathrm{U}$ d) $B T$ c(2×2) $\left.\mathrm{Ag}(100) U . a^{\prime}-d^{\prime}\right)$ lateral view of the lattices shown in (ad). e) DOS of clean $\mathrm{Ag}(111), B T(\sqrt{7} \times \sqrt{7}) \mathrm{R} 19.1^{\circ} \mathrm{Ag}(111) \mathrm{R} 5 / 7$ and PDOS of adsorbed BT f) PDOS Ag of $2^{\text {nd }}$ layer $d$ and $s p$ 70 states, Ag atoms of $1^{\text {st }}$ layer $d$ states and $S$ sp states in the BT Ag $(\sqrt{7} \times \sqrt{7}) R 19.1^{\circ} \mathrm{Ag}(111) \mathrm{R} 5 / 7$. The Fermi level is aligned at the origin of the energy scale $g) \gamma$ for BT, HT and OT on $(\sqrt{7} \times \sqrt{ } 7) R 19.1^{\circ} \mathrm{Ag}(111) \mathrm{R} 5 / 7$ and $\mathrm{Ag}(111) \mathrm{U}$.

Table 3

75 Geometric and energetic parameters for the different Ag surface structure models discussed in the text and figures

\begin{tabular}{|c|c|c|c|c|c|c|}
\hline \multirow{2}{*}{$\begin{array}{c}\text { Surface } \\
\text { structure }\end{array}$} & \multirow{2}{*}{$E_{r} / \mathbf{N}$} & \multirow{2}{*}{$E_{b} / \mathrm{eV}$} & \multirow{2}{*}{$\gamma / \mathbf{e V} \cdot \AA^{-2}$} & \multicolumn{2}{|c|}{$\mathbf{q}_{\text {Bader }} / \mathbf{e}$} & \multirow{2}{*}{$\alpha /^{\circ}$} \\
\hline & & & & $\mathbf{M}$ & $\mathbf{S}$ & \\
\hline $\begin{array}{c}(111) \mathbf{R} \\
(\sqrt{7} \times \sqrt{7}) \mathrm{R} 19.1^{\circ} \\
\text { MT } \\
\text { Figure } 4 a\end{array}$ & +0.51 & -2.86 & -0.136 & +0.22 & -0.35 & 8.9 \\
\hline $\begin{array}{c}(111) R \\
(\sqrt{7} \times \sqrt{7}) R 19.1^{\circ} \\
B T \\
\text { Figure } 4 b\end{array}$ & +0.51 & -3.18 & -0.154 & +0.22 & -0.37 & 4.2 \\
\hline $\begin{array}{c}(111) \mathbf{R} \\
(\sqrt{ } 7 \times \sqrt{ } 7) \mathrm{R} 19.1^{\circ} \\
\text { OT }\end{array}$ & +0.56 & -3.63 & -0.178 & +0.20 & -0.37 & 4.7 \\
\hline $\begin{array}{c}(111) \mathbf{U} \\
(\sqrt{ } 7 \times \sqrt{7}) \mathrm{R} 19.1^{\circ} \\
\text { MT }\end{array}$ & 0.0 & -2.18 & -0.126 & +0.10 & -0.36 & 42.9 \\
\hline $\begin{array}{c}(111) \mathbf{U} \\
(\sqrt{7} \times \sqrt{7}) \mathrm{R} 19.1^{\circ} \\
\mathrm{BT} \\
\text { Figure } 4 c\end{array}$ & 0.0 & -2.53 & -0.146 & +0.13 & -0.38 & 6.1 \\
\hline $\begin{array}{c}(111) \mathbf{U} \\
(\sqrt{ } 7 \times \sqrt{7}) \mathrm{R} 19.1^{\circ} \\
\text { OT }\end{array}$ & 0.0 & -3.01 & -0.174 & +0.13 & -0.38 & 8.4 \\
\hline $\begin{array}{c}(100) \mathbf{U} \\
\mathrm{c}(2 \times 2)-\mathrm{BT} \\
\text { Figure } 4 d\end{array}$ & 0 & -2.75 & -0.160 & +0.16 & -0.39 & 8.3 \\
\hline
\end{tabular}

The PDOS of the stable BT $(\sqrt{ } 7 \times \sqrt{7}) \mathrm{R} 19.1^{\circ} \mathrm{Ag}$ R5/7 surface (Figure $4 \mathrm{e}, \mathrm{f}$ ) shows that the $4 d$-band of the reconstructed $\mathrm{Ag}$ layer becomes slightly narrower with respect to the second layer 
as a consequence of the lower number of $\mathrm{Ag}$ atoms in the topmost layer. Nevertheless, on both sides of the $d$ band two peaks appear that can be attributed to bonding and antibonding states of the adsorbate with the $s p$ and $d$ states of the metal. The electronic 5 states of the adsorbed BT between -3.5 and $-8.0 \mathrm{eV}$ (Fig 4e) are substantially broadened showing a strong coupling with the electronic states of the metal, in particular with the lower part of the $d$-band. The strong localized states below $-10 \mathrm{eV}$ are less affected by the presence of the metal as occurred in the Au (Fig 10 2e-f)

Much less information can be found for thiol adsorption on the $\operatorname{Ag}(100)$ face, where thiolates seem to be adsorbed in fourfold hollow sites through their S head and $\boldsymbol{d}=0.414 \mathrm{~nm},{ }^{107}$ with no evidence of surface reconstruction (Figure $4 d, d^{\prime}$ ).

15 In contrast to $\mathrm{S}-\mathrm{Au}$, the $\mathrm{S}-\mathrm{Ag}$ bond has a stronger polar character resulting from the charge transfer from the Ag surface to the Shead, as shown in the Bader charge analysis (Table 3). ${ }^{108}$ In fact, in this case the charge in the S head atom of the BT adsorbate in vacuum is only $-0.06 \mathrm{e}$, while in the adsorbed BT it increases to 200.37 e. This means that the surface dipole $\Delta \mu$ increases as a consequence of the increase in $\mu_{\text {CHEM }}$. XPS data for HT and DT on the $\mathrm{Ag}(111)$ surface show the presence of thiolate bonds (BE $\approx 161.9 \mathrm{eV}$ ), and of small amounts of free non-bonded thiols (BE $\approx 163.2 \mathrm{eV})$, without evidence of adsorbed sulfide $(\approx 161.4 \mathrm{eV})$ ${ }_{25}$ (Figure 3e,f ). In fact, it has been reported that thiols remain intact on $\operatorname{Ag}(111)$ from the gas phase adsorption at room temperature. ${ }^{103}$ However, exposure to UV radiation, ${ }^{109} \mathrm{X}$-rays or thermal desorption at high temperature ${ }^{103}$ can cause $\mathrm{C}-\mathrm{S}$ bond scission and the formation of S-rich Ag surfaces. The onset of 30 thiol desorption from the Ag surface starts at $425 \mathrm{~K}$ and finishes at $475 \mathrm{~K}$ and mainly involves alkyl disulfides as products. The amount of $\mathrm{S}$ detected at the end of the desorption process is very small, in agreement with recent results on $\mathrm{Au}(111)$. The desorption energy is $1.43-1.30 \mathrm{eV}$, which is slightly larger than 35 the value reported for chemisorbed alkanethiols on $\mathrm{Au}(111)$. Note that, as in the case of $\mathrm{Au}$, the $d$-band of $\mathrm{Ag}$ is well below the Fermi level (Figure 4e).

The situation for $\mathrm{Ag}$ nanoclusters and nanoparticles is more complex. The structure of AgNPs $2 \mathrm{~nm}$ in size prepared by

40 reduction of $\mathrm{Ag}\left(\mathrm{SCH}_{2} \mathrm{CH}_{2} \mathrm{Ph}\right)$ precursors has been described as a core-shell structure model with a 92-atom Ag core and an encapsulating protective shell containing $\mathrm{Ag}$ atoms and 60 thiolates arranged in a network of six-membered rings closely resembling the geometry found in alkanethiolate SAMs on ${ }_{45}$ reconstructed $\operatorname{Ag}(111)$ (Figure 4a,b). ${ }^{110}$ Thus, a correlation between thiol organization on the $\operatorname{Ag}(111)$ and AgNP surfaces is also proposed, with thiolates adsorbed on a vacancy-rich (low density) Ag metal surface. However other recent experimental results for DT-protected AgNPs seem to be consistent with a 50 core-shell structure consisting of a metallic Ag core surrounded by a $\mathrm{Ag}_{2} \mathrm{~S}$-like phase. ${ }^{111}$ A similar core-shell structure has been found for thiolate-protected AgNPs prepared from allylmercaptane adsorption. ${ }^{112}$ Thus, in these cases thiolates seem to be grafted to a sulfide-covered AgNP surface, a model that ${ }_{55}$ closely resembles that described for thiolate-protected PdNPs. ${ }^{113}$ This would imply the ability of AgNP defective surfaces to break the C-S bond, a fact that is not evident on the $\operatorname{Ag}(111)$ surfaces. However, XPS data for DT-protected AgNPs synthesized by the two-phase Brust-Schiffrin method ${ }^{11}$ showed only a small amount 60 of sulfide, which is not consistent with thiolates grafted on $\mathrm{Ag} @ \mathrm{Ag}_{2} \mathrm{~S}$ core@shell model. Also, thermogravimetric analysis data for thiolate-protected AgNPs prepared by the one phase Brust-Schiffrin method showed no excess of $\mathrm{S}$ in relation to that intact thiolate species. ${ }^{114}$ A similar conclusion has been reported ${ }_{65}$ for MBA-protected AgNPs, $5 \mathrm{~nm}$ in size, prepared by the ligand exchange method after a-careful electron diffraction and XPS analysis. ${ }^{106}$ However, DFT calculations have shown that thiolateprotected AgNPs and thiolate-protected Ag@ $\mathrm{Ag}_{2} \mathrm{~S}$ core@shell NPs have similar stability. ${ }^{11}$ Also, on prolonged exposure to the 70 adsorbate solution, the Ag surface becomes extensively sulfidized. ${ }^{10}$ Therefore, the final product should depend on details of the self-assembly procedure or on the presence of sulfide impurities.

On the other hand, DFT calculations for $\mathrm{Ag}_{m}\left(\mathrm{SCH}_{3}\right)_{n}$ 75 nanoclusters have predicted that $\mathrm{RS}-\mathrm{Ag}_{\mathrm{ad}} \mathrm{-RS}$ complexes (RS = thiolate) could be the stable species on the $\mathrm{Ag}$ surface ${ }^{115}$ as it has been observed on AuNCs. ${ }^{86}$ This has been experimentally confirmed for $\mathrm{Ag}_{44}(\mathrm{MBA})_{30}$ nanoclusters that are protected by six $\mathrm{Ag}_{2}(\mathrm{MBA})_{5}$ units in which $\mathrm{Ag}$ cations bind to three thiolate 80 ligands in a planar $\operatorname{Ag}(\mathrm{MBA})_{3}$ configuration. ${ }^{116}$ The presence of these species was also confirmed for fluorinated arylthiols on the same clusters. ${ }^{117}$ Therefore, AgNCs exhibit surface structure and chemistry that cannot be easily correlated with experimental data for thiol arrangement on the planar Ag and NPs surfaces.

\section{2.3. Copper}

Copper-based electrical contacts are widely used due to the high electric conductivity and low cost of this metal. However, the efficiency and durability of the devices are affected by several factors, including metal oxidation and corrosion. SAMs of 90 alkanethiols are employed to passivate $\mathrm{Cu}$ surfaces in an attempt to preserve surface cleanliness. ${ }^{118}$ Indeed, thiol SAMs formed on $\mathrm{Cu}$ surfaces have been found to retard surface oxidation and the degree of protection can be enhanced by using alkanethiols with longer carbon chain length. ${ }^{119}$ Indeed, it was reported that a SAM 95 of 1-hexanethiol formed on $\mathrm{Cu}$ protected the surface against contamination during storage in ambient conditions. After 3 days of storage, the SAM was desorbed by an in situ annealing step in inert nitrogen ambient to provide a clean $\mathrm{Cu}$ surface. ${ }^{120}$ SAMs on $\mathrm{Cu}$ prepared either from the gas phase or from the liquid phase 100 have also been used in atomic layer deposition processes. ${ }^{121}$ For instance, in the damascene process the thiol SAMs should form only on the copper surface but not on the insulators. The feasibility of exploiting SAMs in microelectronic applications was demonstrated by the enhancement of $\mathrm{Cu}$ wire bonding onto 05 thiol-passivated $\mathrm{Cu}$ bond pads. ${ }^{122}$

There has been an increased interest in the preparation of stable thiolate-protected CuNPs because of their promising electronic and optical properties, and also because they can be new tools in organic synthesis and catalysis. Unfortunately, short-chain 110 alkanethiols or arylthiols are often inadequate for protecting the $\mathrm{Cu}$ metallic core against oxidation in ambient conditions because gaps form easily on the nanoparticle surface and thus longer thiolates should be used for technological applications.

Copper nanoparticles have been studied as candidates for direct115 spray printing inks to form conductor lines. ${ }^{123}$ Also thiolateprotected $\mathrm{Cu}$ nanoclusters evolve into thiolate-capped $\mathrm{Cu}_{2} \mathrm{~S}$ nanodiscs under controlled temperature treatment. ${ }^{124}$ The nanodiscs can be later self-assembled into $\mathrm{Cu}_{2} \mathrm{~S}$ nanochains and nanoribbons with interesting applications in the fabrication of 120 photovoltaic, plasmonic and charge storage devices. ${ }^{125}$

\section{Surface structures and chemistry}

The growth processes and structure of thiol self-assembled monolayers on $\mathrm{Cu}$ single-crystal surfaces have been investigated by using XAFS and STM. At low coverage, thiolates on $\mathrm{Cu}(111)$ 125 have a disordered structure with a LD configuration. ${ }^{126,127}$ At a surface coverage of $0.7 \mathrm{ML}$, thiolates stand up and form dense surface structure accompanying significant reconstruction of the 
substrate. Two-photon photoemission measurements of thiophenol and p-fluorothiophenol on $\mathrm{Cu}(111)$ also confirmed the LD to SU transition, although in this case the phase transition took place at $0.4-0.5 \mathrm{ML} .^{128}$

${ }_{5}$ On the other hand, STM and LEED data ${ }^{129}$ for MT adsorption from DMDS revealed a pseudo-(100) surface reconstruction where the outermost $\mathrm{Cu}$ atomic layer adopts a structure similar to $\mathrm{Cu}(100)$ surface ( $\mathrm{R}$ surface). Here the thiolate species are in fourfold coordinated hollow sites of a near-square $c(2 \times 2)$ mesh $(\theta$ $10=0.33)$ with dimensions $0.406 \mathrm{~nm} \times 0.418 \mathrm{~nm}$ and a tilt angle $\approx 11^{\circ}$ (Figure $5 \mathrm{a}, \mathrm{a}^{\prime}$ ). The outermost $\mathrm{Cu}$ layer has only $2 / 3$ of the atomic density of a close-packed $\mathrm{Cu}(111)$ layer, i.e. a diluted $\mathrm{Cu}$ atom surface is formed upon thiol adsorption, as observed for thiols on $\mathrm{Ag}(111)$. Upon relaxation, the (100) layer distorts in 15 such a way that the $\mathrm{Cu}$ atoms in the overlayer occupy hollow positions $^{30}$ with $\mathrm{Cu}-\mathrm{Cu}$ atom distances $15 \%$ larger than those found in the $\mathrm{Cu}(100)$ phase. This behavior would imply that adsorption at the (100) hollow site of the R surface is favored over adsorption on the $\mathrm{U} \mathrm{Cu}(111)$ surface. It was also shown that 20 the pseudo-(100) reconstruction of the $\mathrm{Cu}(111)$ surface also takes place for longer alkanethiolates such as OT. ${ }^{129}$ However, in this case the STM images reveal a honeycomb OT phase (H domains in Figure $6 a)$, a $(5 \times 5)$ lattice with $\theta=0.32$ consistent with an unreconstructed $\mathrm{Cu}(111)$ surface, coexisting with the pseudo-

25 (100) reconstructed phase ( $\mathrm{P}$ domains in Figure 6a) at room temperature. In contrast, for MT the honeycomb phase is entirely transformed into the pseudo-(100) phase under the same conditions. ${ }^{130}$ This is not surprising, as our DFT calculations show that the pseudo-(100) MT lattice is more stable than the 30 honeycomb $(5 \times 5)$ MT lattice (Table 4$)$.

On the other hand, DFT calculations also indicate that the $\gamma$ value for BT on the pseudo-(100) (Figure 5b,b') approaches the same value as on the honeycomb $(5 \times 5)$ lattice (Figure $\left.5 \mathrm{c}-\mathrm{c}^{\prime}\right)$, as shown in Figure $5 \mathrm{~g}$. This result suggests that increasing the thiol chain

35 length, which favors vdW interactions among molecules, makes substrate reconstruction to the pseudo-(100) structure more difficult (Table 4). This trend could explain the coexistence of $U$ and R substrate domains in the same STM image of longer alkanethiols, such as OT (Figure 6a). Also, DFT calculations for

${ }_{40}$ MT show that the pseudo-(100) lattice has the same stability as a hypothetical $(\sqrt{3} \times \sqrt{3}) \mathrm{R} 30^{\circ}$ of the same thiol, while for BT the pseudo-(100) and the honeycomb lattices become more unstable than the corresponding $(\sqrt{3} \times \sqrt{3})$ R $30^{\circ}$ surface structure (see $\gamma$ values in Table 4). The reason why the latter has not been 45 reported yet is an open question that deserves special attention. Also, self-assembly of 1,3,5-tris(4-mercaptophenyl)benzene on $\mathrm{Cu}(111)$ at room temperature leads to a commensurate $(3 \sqrt{3} \times 3 \sqrt{3}) \mathrm{R} 30^{\circ}$ lattice with the RS• adsorbates in a planar configuration, hus-without evidence of pseudo-(100) substrate

50 reconstruction. More important, this SAM is transformed into a network of $\mathrm{RS}-\mathrm{Cu}_{\mathrm{ad}}$ species only upon heating to $433 \mathrm{~K} .{ }^{131}$ At these temperatures mass exchange between step-edges and terraces is the dominant process with an important increase in metal adatom concentration, thus allowing the formation of the ${ }_{55} \mathrm{RS}-\mathrm{Cu}_{\mathrm{ad}}$ moieties. In contrast, this process has not been observed on $\operatorname{Ag}(111)$ where the heating process led to disulfide bond formation between the adsorbed molecules. The absence of metal coordination networks on $\operatorname{Ag}(111)$ is best explained by a different affinity of $\mathrm{Cu}_{\mathrm{ad}}$ and $\mathrm{Ag}_{\mathrm{ad}}$ to form metal-coordination bonds with ${ }_{60} \mathrm{RS} \bullet$ species. ${ }^{131}$

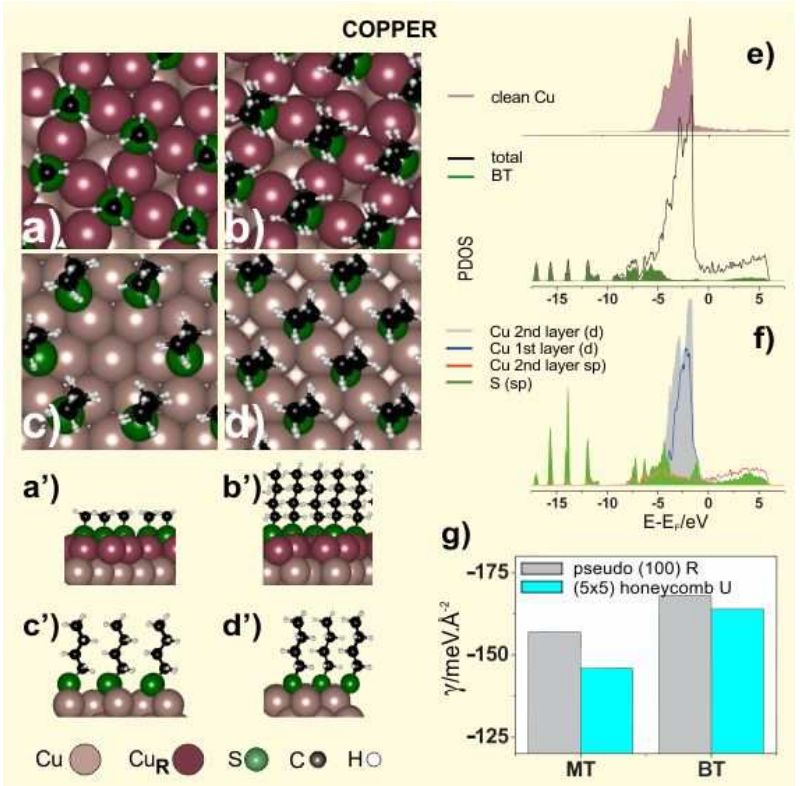

Figure 5. Top view schemes of the surface structures optimized by DFT calculations. a) MT on the pseudo-(100) Cu(111)R b) BT ${ }_{65}$ on the pseudo-(100) $C u(111) R \quad$ c) $B T$ on the honeycomb $(5 \times 5)$ lattice $\mathrm{Cu}(111) U$ d) $\left.B T c(2 \times 2) C u(100) . a^{\prime}-d^{\prime}\right)$ Lateral view of the lattices shown in $(a-d)$ e) DOS of clean Cu(111), BT on pseudo-(100) Cu(111)R and adsorbed BT. f) PDOS of Cu $2^{\text {nd }}$ layerd and sp states, $C u 1^{\text {st }}$ layer d states, and $S$ sp states in the ${ }_{70} \mathrm{BT}$ on the pseudo-(100) Cu(111)R. The Fermi level is aligned at the origin of the energy scale. $g$ ) $\gamma$ values corresponding to pseudo-(100) $\mathrm{Cu}(111) \mathrm{R}$ and for the honeycomb lattice $\mathrm{Cu}(111) \mathrm{U}$ for $M T$ and $B T$

Table 4

75 Geometric and energetic parameters for the different $\mathrm{Cu}$ surface structure models discussed in the text and figures

\begin{tabular}{|c|c|c|c|c|c|c|}
\hline \multirow{2}{*}{$\begin{array}{c}\text { Surface } \\
\text { structure }\end{array}$} & \multirow{2}{*}{$E_{r} / \mathbf{N}$} & \multirow{2}{*}{$E_{b} / \mathrm{eV}$} & \multirow{2}{*}{$\gamma / \mathbf{e V} \cdot \AA^{-2}$} & \multicolumn{2}{|c|}{$\mathbf{q}_{\text {Bader }} / \mathrm{e}$} & \multirow{2}{*}{$\alpha /^{\circ}$} \\
\hline & & & & $\mathbf{M}$ & $\mathbf{S}$ & \\
\hline $\begin{array}{c}(111) \mathbf{R} \\
\text { pseudo(100) MT } \\
\text { Figure } 5 a\end{array}$ & +0.76 & -3.46 & -0.157 & +0.23 & -0.42 & 4.0 \\
\hline $\begin{array}{c}(111) \mathbf{R} \\
\text { pseudo(100) BT } \\
\text { Figure } 5 b\end{array}$ & +0.78 & -3.67 & -0.168 & +0.22 & -0.44 & 7.2 \\
\hline $\begin{array}{c}(111) \mathbf{U} \\
(5 \times 5)-\mathrm{MT}\end{array}$ & 0.0 & -2.62 & -0.146 & +0.12 & -0.42 & 39.1 \\
\hline $\begin{array}{l}(111) \mathbf{U} \\
(5 \times 5) \text {-BT } \\
\text { Figure } 5 c\end{array}$ & 0.0 & -2.94 & -0.164 & +0.11 & -0.43 & 7.5 \\
\hline $\begin{array}{c}(111) \mathbf{U} \\
(\sqrt{3} \times \sqrt{3}) \mathrm{R} 30^{\circ} \\
\mathrm{MT}\end{array}$ & 0.0 & -2.69 & -0.156 & +0.12 & -0.43 & 40.5 \\
\hline $\begin{array}{c}(111) \mathbf{U} \\
(\sqrt{3} \times \sqrt{3}) \mathrm{R} 30^{\circ} \\
\mathrm{BT}\end{array}$ & 0.0 & -3.06 & -0.178 & +0.12 & -0.44 & 10.0 \\
\hline $\begin{array}{c}(111) \mathbf{U} \\
(\sqrt{3} \times \sqrt{3}) \mathrm{R} 30^{\circ} \\
\text { OT }\end{array}$ & 0.0 & -3.55 & -0.207 & +0.12 & -0.44 & 7.1 \\
\hline $\begin{array}{c}(100) \mathbf{U} \\
\mathrm{c}(2 \times 2)-\mathrm{BT} \\
\theta=1 / 4\end{array}$ & 0.0 & -3.20 & -0.121 & +0.10 & -0.46 & 5.9 \\
\hline $\begin{array}{c}(100) \mathbf{U} \\
\mathrm{c}(2 \times 2)-\mathrm{BT} \\
\theta=1 / 2 \\
\text { Figure } 5 d\end{array}$ & 0.0 & -2.63 & -0.199 & +0.21 & -0.45 & 5.6 \\
\hline
\end{tabular}


The analysis of the PDOS for the BT on pseudo-(100) $\mathrm{Cu}(111) \mathrm{R}$ is shown in Figure 5e. This metal has the center of the $d$ band higher in energy than $\mathrm{Au}$ (Figure 2e) and Ag (Figure 4e), although it remains below the Fermi level. Also, $d$ states are less 5 extended than gold's. We note that the $3 d$ band of the reconstructed surface becomes slightly narrower with respect to the clean $\mathrm{Cu}(111)$ surface (Figure $5 \mathrm{f}$ ) as a consequence of the lower number of $\mathrm{Cu}$ atoms at the pseudo-(100) surface (Figure 5a).

10 $\mathrm{BT}$ adsorption does not cause a reduction in the $d$-band near the Fermi level and the hybridization with the $\mathrm{S} s p$ induces an increase in PDOS at the lower energy part of the $\mathrm{Cu} d$-band. It is evident that, in contrast to the $c(4 \times 2)$ thiol lattice on the reconstructed $\mathrm{Au}(111)$, the $3 d$ band makes no major contribution 15 to the $\mathrm{S}-\mathrm{Cu}$ bond, which involves $\mathrm{S} s p$ and $\mathrm{Cu} 4 s$ states that show a noticeable broadening (Figure 5f). The Bader analysis indicates that the charge transfer from the $\mathrm{Cu}$ surface to the $\mathrm{S}$ atom of adsorbed BT is significant as it bears -0.44 e while the $S$ atom of the BT molecule in vacuum exhibits only $-0.06 \mathrm{e}$. Therefore, there 20 is an important contribution of $\mu_{\mathrm{CHEM}}$ component to the surface dipole $\Delta \mu$ at the SAM-Cu interface.

Regarding thiols on $\mathrm{Cu}(100)$ surfaces, contradictory results have been reported. Initially, no evidence of substrate reconstruction was observed by STM and XAFS for thiol self-assembly on this ${ }_{25}$ surface. ${ }^{127}$ However, it has been proposed that $\left[\left(\mathrm{CH}_{3} \mathrm{~S}\right)_{2}\right]$ adsorbs in a symmetric fourfold chemisorption site as MT on the $\mathrm{Cu}(100)$ surface, but it builds up regular twofold reconstructed superstructures, $p(2 \times 2)$ at low coverage and $c(2 \times 6)$ and $c(2 \times 2)$ at higher coverage. ${ }^{132}$ Figure $5 \mathrm{~d}, \mathrm{~d}^{\prime}$ shows the optimized $c(2 \times 2) \mathrm{BT}$ 30 lattice and the corresponding geometric and energetic parameters. However, the short intermolecular distance on this dense lattice $(\theta=0.5, \boldsymbol{d}=0.36 \mathrm{~nm})$ results in repulsion, leading to substrate rampling or missing rows. ${ }^{133}$ In contrast, a $(2 \times 2)$ lattice with $\theta=$ 0.25 and $\boldsymbol{d}=0.5 \mathrm{~nm}$ has been experimentally observed for 35 different thiols on the $\mathrm{Cu}(100)$ surface (table in Figure 5).

STM studies of MT imaged in situ on the $\mathrm{Cu}(100)$ in electrolyte solution suggest that the $c(2 \times 6)$ lattice could be formed by RS$\mathrm{Cu}_{\mathrm{ad}}$ dimers. ${ }^{134}$ It is possible that enhanced mobility of the $\mathrm{Cu}_{\mathrm{ad}}$ in electrolyte solution favors the formation of these species. It 40 should be noted that careful XPS and AES analysis of polycrystalline $\mathrm{Cu}$ surfaces indicate the presence of thiolate (BE $\approx 162 \mathrm{eV}$ ) and oxidized $\mathrm{Cu}(\mathrm{I})$ species, respectively (Figure 6bc). ${ }^{135}$ Thus, the presence of $\mathrm{RS}-\mathrm{Cu}_{\mathrm{ad}}$ species on the $\mathrm{Cu}(111)$ and $\mathrm{Cu}(100)$ surface cannot be discarded. ${ }^{136}$ Layered alkanethiolates 45 have $\alpha=13^{\circ}$ which is the same tilt measured for alkanethiolates on the $\mathrm{Cu}(111)$ surface. ${ }^{10,137}$

In order to shed more light on the thiol/ $\mathrm{Cu}$ chemistry we will discuss the reactions that take place as a function of $\mathrm{T}$. Alkanethiolate SAMs on $\mathrm{Cu}$ are stable in air up to $T \approx 400 \mathrm{~K}$, as 50 shown in Figure $6 \mathrm{~d}$ for OT SAMs. ${ }^{136,135}$ In fact, at $T>400 \mathrm{~K} \mathrm{C}-\mathrm{S}$ bond cleavage becomes evident in the XPS S $2 p$ spectra with the progressive transformation of thiolates $(\mathrm{BE} \approx 162 \mathrm{eV})$ into $\mathrm{Cu}_{2} \mathrm{~S}$ (BE $\approx 161 \mathrm{eV})$. Also, ET SAMs formed from diethyl disulfide adsorption on $\mathrm{Cu}$ decompose to form either ethylene or ethane 55 and adsorbed $\mathrm{S}$ at $T \approx 380 / 400 \mathrm{~K} .{ }^{138}$ However, traces of $\mathrm{S}$ during MT adsorption on $\mathrm{Cu}(111)$ were observed even at room $T$ by standing-wave experiments. ${ }^{139}$

Copper nanoclusters and CuNPs also exhibit changes in chemistry with temperature. Phenylethanethiolate-(PET) ${ }_{60}$ protected copper clusters $\mathrm{Cu}_{38}(\mathrm{PET})_{25}$ decompose in about $2 \mathrm{~h}$ at room temperature, forming a mixture of copper thiolates and cuprous sulfide as characterized by XRD. ${ }^{140}$ Also copper nanoclusters $\approx 0.5 \mathrm{~nm}$ in size encapsulated with thiolate monolayer $\mathrm{Cu}_{n}(\mathrm{SR})_{m}{ }^{124}$ under controlled temperatures $(393<\mathrm{T}<$
${ }_{65} 423 \mathrm{~K}$ ) evolve into thiolate-capped $\mathrm{Cu}_{2} \mathrm{~S}$ nanodiscs via thermally activated coalescence and copper-catalyzed interfacial C-S cleavage reactivities.
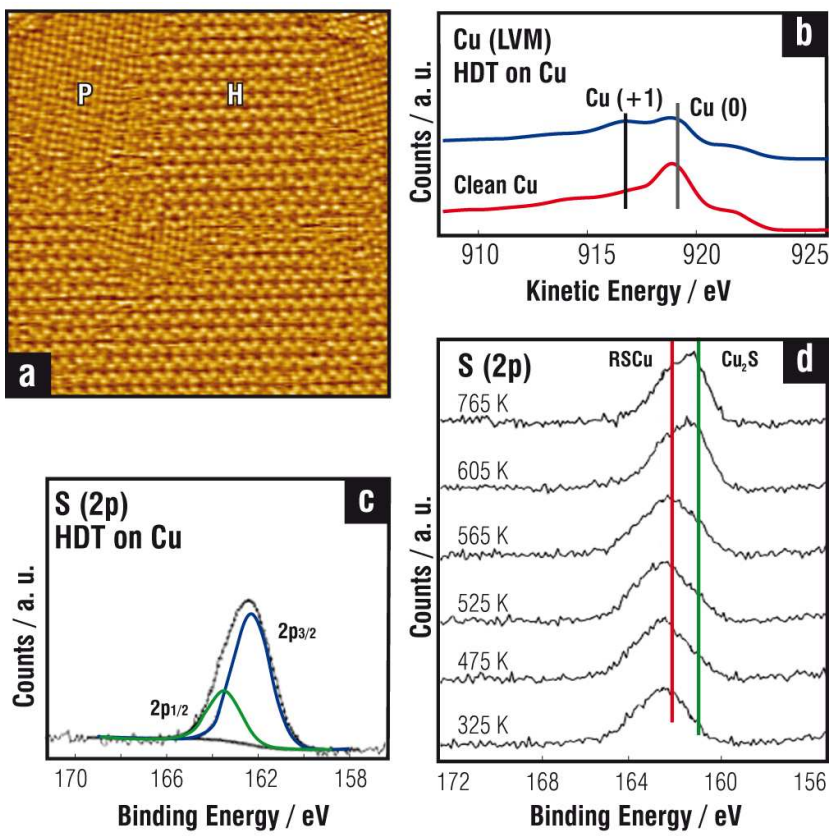

${ }_{70}$ Figure 6. $\left.a-b\right)$ STM image of OT on Cu(111). Domains of the herringbone (H) on the $U \mathrm{Cu}(111)$ and the pseudo-100 (P) on the $R C u(111)$ surface are indicated. Reprinted with permission from Langmuir 2000, 16, 6693-6700. Copyright (2000) American Chemical Society. b) XPS S $2 p$ signal and AES Cu(LMM) signal 75 of HDT SAMs on polycrystalline Cu. Reproduced from Bull Korean Chem.Soc. 2001, 22, 748 with permission of the Korean Chemical Society d) XPS $S 2 p$ spectra of a OT SAM on polycrystalline $\mathrm{Cu}$ at different temperatures. Reproduced from Bull Korean Chem.Soc. 2003, 24, 610 with permission of the ${ }_{80}$ Korean Chemical Society

These results show the complex relation between adsorbed thiolates, copper thiolates and copper sulfides on $\mathrm{Cu}$ surfaces. In general one could conclude that extensive sulfidization from adsorbed RS• or RS-Cu species requires thermal treatment or 85 exposure to ambient conditions. On the other hand, one can speculate that the presence of $\mathrm{RS}-\mathrm{Cu}_{\mathrm{ad}}$ species on the $\mathrm{Cu}$ surfaces depends on the $\mathrm{Cu}$ atom surface mobility at the adsorbed/thiolate $\mathrm{Cu}$ system.

\subsection{Platinum}

${ }_{90}$ Platinum is an interesting metal for the fabrication of thiolateprotected electronic devices. In fact, it is considered to be a good thiolate contact material and to be compatible with the fabrication of silicon microelectronics, in contrast to gold, because of its high surface and bulk diffusivities and the ability to form electronic 95 defects. ${ }^{141}$ It has been reported that the contact resistance is reduced by nearly 2 orders of magnitude by interfacing SAMs with $\mathrm{Pt}$ in relation to $\mathrm{Au}$ electrodes. ${ }^{142}$ It has been shown that strong binding creates lower contact resistance leading to higher conductance value for thiol molecules bound to Pt surfaces. ${ }^{143,144}$

100 The preparation of PtNPs has been motivated by their catalytic properties. ${ }^{145}$ In fact, PtNPs play an important role in a wide variety of catalytic processes and for fuel cells applications. ${ }^{146,147}$ Also, PtNPs deposited on carbon nanotubes show excellent dehydrogenation properties. ${ }^{148}$ On the other hand, they have been 105 also used to hydrogenate allyl alcohol to propanol reducing the $\mathrm{C}$ - 
C double bond. ${ }^{149}$ Mercaptoammonium-protected PtNPs have also been used as catalysts in the hydrogenation of maleic acid to succinic acid. ${ }^{149}$ Furthermore, thiomalic acid-protected PtNPs improve the performance of hydrogen storage alloy materials 5 after electrochemical removal of the thiol molecules ${ }^{150}$ while mercaptoundecanoic-protected PtNPs have been used to prepare Pt@oxide core-shell catalysts. ${ }^{151}$

\section{Surface structures and chemistry}

The adsorption of alkanethiols on Pt surfaces from the gas and 10 vapor phase has been studied by different techniques. ${ }^{152-156}$ At room temperature, the adsorption of $\mathrm{MT}$ on $\mathrm{Pt}(111)$ produces a partially disordered overlayer that gives rise to a diffuse $(\sqrt{3} \times \sqrt{3})$ R30 $0^{\circ}$ LEED pattern and threefold symmetry in the scattering profiles, and $\alpha=45^{\circ} .{ }^{153}$ In situ STM imaging in electrolyte 15 solutions of alkanethiolate SAMs on $\mathrm{Pt}(111)$ (HT, nonanethiol (NT)) and aromatic thiols (benzenethiol, and 4hydroxibenzenethiol) has shown that the thiol molecules organize into $(2 \times 2)(\theta \approx 1 / 4)$ and $(\sqrt{3} \times \sqrt{3}) \mathrm{R} 30^{\circ}(\theta \approx 1 / 3)$ (Figure $7 \mathrm{a}-\mathrm{b}$ ) lattices at low and high concentrations, respectively. ${ }^{157}$ These 20 lattices are well ordered only within a narrow potential range applied to the metal/electrolyte interface. The optimized surface model for the $(\sqrt{ } 3 \times \sqrt{ } 3) \mathrm{R} 30^{\circ}$ BT lattice on the $\mathrm{Pt}(111)$ is shown in Figure $8 \mathrm{a}, \mathrm{a}^{\prime}$. As in the case of the $\mathrm{Cu}$ group metals, thiols adsorb to the Pt surface as thiolates, a fact consistent with the major 25 component of the XPS S $2 p$ spectra at $\mathrm{BE} \approx 162 \mathrm{eV}$, (Figure 7cd). ${ }^{155,158}$ Also, these SAMs usually have small amounts of nonbonded thiol derived species, such as alkyl disulfides and dialkyl sulfides, which are characterized by the small component at $\mathrm{BE}$ $\approx 163.4 \mathrm{eV}$. $^{155,159}$

30 IR spectroscopy data of HT and DT SAMs on Pt (Figure 7e-f) reveal intact hydrocarbon chains in standing-up configuration with $\alpha=6-16^{\circ}$. These data also provide important information about the alkyl chains order in the SAMs (i.e. gauche defects) by looking at changes in the asymmetric ( $\left.\mathrm{d}^{-}\right) \mathrm{CH}_{2}$ stretching 35 vibrations at $\approx 2920 \mathrm{~cm}^{-1}$. Thus, the analysis of the IR spectra of different alkanethiols on $\mathrm{Pt}$ shows a significant increase in the chain order as $n$ increases, which is reflected in the shift of the $\mathrm{d}^{-}$ stretching vibration towards smaller frequencies (Figure $7 \mathrm{e}-\mathrm{f}$ ). ${ }^{150}$ Therefore, DT SAMs on Pt are well-ordered with a quality 40 comparable to those found on Au. However, SAMs of shorter alkanethiols are more defective, less blocking, and have lower thiolate coverage than their Au counterparts. In fact, at a nearly constant total S coverage ( $\theta=0.32-0.34)$ the XPS S $2 p$ spectra for BT and HT show that thiolates only reach $\theta \approx 1 / 4$, a figure 45 lower than $\theta \approx 1 / 3$ expected for a perfect $(\sqrt{ } 3 \times \sqrt{3}) \mathrm{R} 30^{\circ}$ lattice (Figure 8a, $\mathrm{a}^{\prime}$ ).

The chain-length dependent quality of these SAMs has been explained based on DFT and thermodynamic calculations. It has been proposed that the poor quality observed for SAMs of short50 chain thiolates could result from $\mathrm{C}-\mathrm{S}$ bond scission of the thioalkyl radical in a LD configuration, leading to a mixed $\mathrm{S}$ and thiolate adlayer. ${ }^{156}$ This is reasonable, as thermal desorption of MT SAMs from $\operatorname{Pt}(111)$ at $T \approx 300 \mathrm{~K}$ results in $\mathrm{H}$ and small amounts of $\mathrm{CH}_{4}$ suggesting that $\mathrm{C}$-S bond scission at nearly room

55 temperature is possible. ${ }^{160}$ The $\mathrm{C}-\mathrm{S}$ bond breakage at $T \approx 320 \mathrm{~K}$ primarily involves reaction between $\mathrm{MT}$ and coadsorbed hydrogen and leaves atomic $\mathrm{S}$ at the surface.
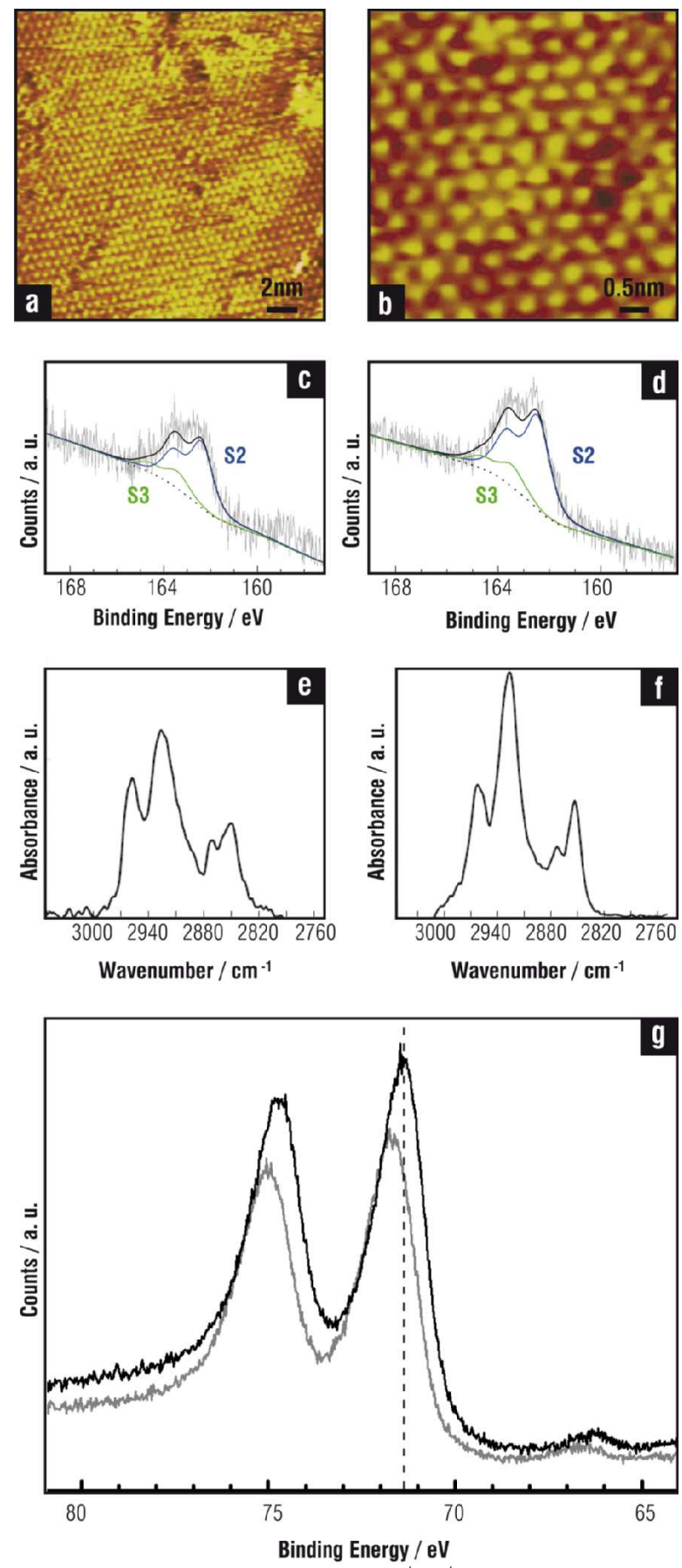

${ }_{60}$ Figure 7. $\left.a-b\right) S T M$ images of the $(\sqrt{3} \times \sqrt{ } 3) R 30^{\circ}$ thiol lattices on Pt(111). a) HT, b) NT. Reprinted with permission from Langmuir, Vol. 20, 2004, 10036. Copyright (2004) American Chemical Society. c-d) XPS $S 2 p$ c) HT SAM d) DT SAM. Adapted with permission from The Journal of Physical Chemistry C, 2011, 115, 65 17788-17798. Copyright (2011) American Chemical Society, e-f) ATR-SEIRA spectra, recorded in ambient atmosphere of (e) HT and (f)DT adsorbed on Pt, g) XPS Pt $4 f$ region of the DT-capped PtNPs before (gray) and after reductive stripping of the thiol adlayer at $-1.8 \mathrm{~V}$ (black). Adapted with permission from The 70 Journal of Physical Chemistry C, 2013, 117, 7589-7597. Copyright (2013) American Chemical Society.

We have explored the stability of a hypothetical mixed $\mathrm{S}+\mathrm{BT}$ $(\sqrt{3} \times 2 \sqrt{ } 3) \mathrm{R} 30^{\circ}$ adlayer, a lattice containing $\theta_{\text {sulfide }} \approx 0.16$ and $\theta_{\text {thiol }}$ $\approx 0.16$ (total S coverage $\theta_{S} \approx 1 / 3$ ), with BT in LD (Figure 8b, $\mathrm{b}^{\prime}$ ) 
and SU configurations. We found that the mixed layer with BT in LD configuration results more stable, i.e. it exhibits a smaller $\gamma$ value, than the same lattice with $\mathrm{BT}$ in SU configuration (Table 5). Also the $\mathrm{S}+\mathrm{BT}(\sqrt{3} \times 2 \sqrt{3}) \mathrm{R} 30^{\circ}$ adlayer in $\mathrm{LD}$ results more 5 stable than the plain BT $(\sqrt{3} \times 2 \sqrt{3}) \mathrm{R} 30^{\circ}$ adlayer in LD (Figure $8 \mathrm{c}$ ) and in the plain BT $(\sqrt{3} \times \sqrt{3}) \mathrm{R} 30^{\circ}$ lattice (Table 5). Note that we have selected BT in LD as BT adsorbs on Pt in a configuration in which the alkyl chain interact with the metal surface favouring adsorbate decomposition. ${ }^{161}$ In the LD configuration (Figure 8c) 10 the PDOS corresponding to $s p$ states of the $\mathrm{C} 1$ atom shows a peak at $\approx-3 \mathrm{~V}$ which overlaps with $d_{z}^{2}$ state of the Pt atom lying just below the $\mathrm{C} 1$ atom (Figure 8e). This means that the interaction between the Pt surface and the $\mathrm{C} 1$ atom, which can lead to $\mathrm{C}-\mathrm{S}$ bond scission, is possible for the alkanethiol molecules in LD 15 configuration. Therefore, SAMs of short thiols could contain some amount of atomic S, thus explaining their chain disorder and less barrier properties. Interestingly, the peak at $-3 \mathrm{eV}$ corresponding to $s p$ states of the $\mathrm{C} 1$ is absent for $\mathrm{BT}$ in the same lattice but in SU configuration (not shown). Therefore, C-S bond 20 cleavage for SAMs of longer alkanethiolate prepared from solutions, for which the LD phases rapidly reorganize in the SU phases driven by the vdW interactions, should be more difficult, thus explaining their good barrier properties. ${ }^{156}$ Unfortunately, atomic $\mathrm{S}$ on $\mathrm{Pt}$ overlaps the $\mathrm{S} 2 p$ signal of thiolates $(\mathrm{BE} \approx 162$ $25 \mathrm{eV})^{13}$, making our hypothesis extremely difficult to verify.

The PDOS corresponding to the clean $\mathrm{Pt}$ and $\mathrm{S}+\mathrm{BT}$ $(\sqrt{ } 3 \times 2 \sqrt{3}) \mathrm{R} 30^{\circ}$ lattice are shown in Figure $8 \mathrm{f}-\mathrm{g}$, respectively. Due to the openness of $d$-shell in Pt (Figure 8f), there are more $5 d$ electrons involved in bonding with $\mathrm{S} s p$ orbital than in the case of 30 $5 d$ electrons of $\mathrm{Au}$, hence there is a more remarkable hybridization, especially in the region from -3.0 to $-7.5 \mathrm{eV}$ (Figure $8 \mathrm{e}$ ). The $\mathrm{S} s p-5 d$ mixings appears just below the Fermi level of the substrate, where the PDOS decreases drastically. The hybridization of the $d$ states with $\mathrm{S} s p$ orbitals leads to empty 35 states within the HOMO-LUMO gap (visible at $0.5 \mathrm{eV}$ in Figure 8e) which are involved in the molecular conductance at low bias voltages. ${ }^{162}$ It should be noted that Pt exhibits the lowest contact resistance for tunnel junctions consisting of alkanethiolate monolayers sandwiched between $\mathrm{Ag}, \mathrm{Au}, \mathrm{Pd}$ and $\mathrm{Pt} .{ }^{142}$

${ }_{40}$ Concerning the chemistry of the S-Pt interface, an energy shift of $1 \mathrm{eV}$ in the Pt $4 f$ level to higher energies was observed in XPS for DT-protected PtNPs. ${ }^{163}$ The contribution at higher energy was attributed to the surface Pt atoms linked to the S-head atom of DT. This shift was also observed for DT-protected PtNPs and ${ }_{45}$ disappeared after electrochemical cleaning (Figure $7 \mathrm{~h}$ ). ${ }^{150}$ On the other hand, it was reported that PtNPs protected by TMA and prepared by the Kimura synthesis exhibit significant amounts of $\operatorname{Pt}(\mathrm{I})$, suggesting the presence of a $\operatorname{Pt}(0)$ core surrounded by $\operatorname{Pt}(\mathrm{I})$ thiolates on the surface. ${ }^{164}$

50

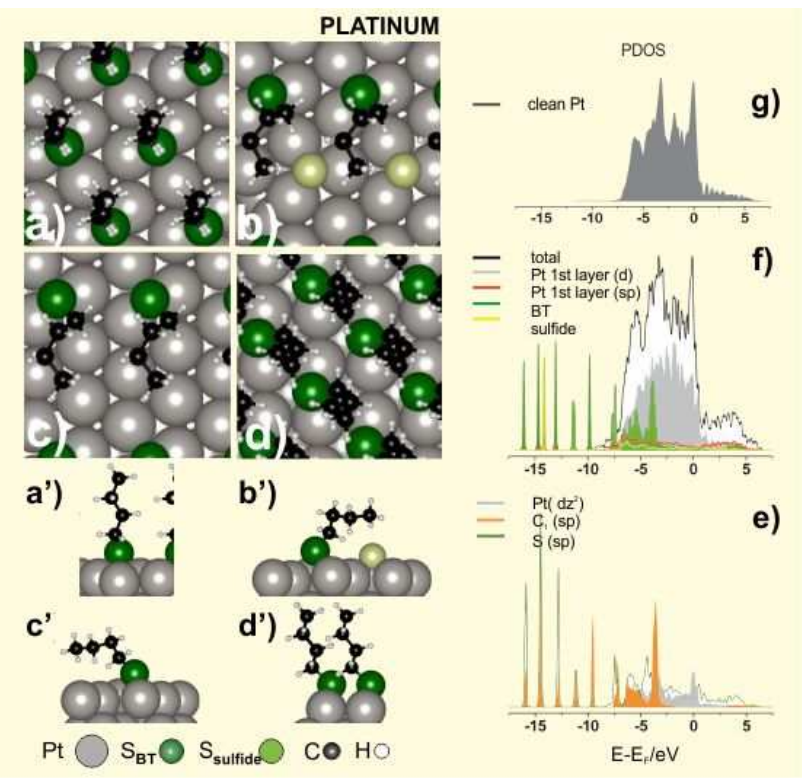

Figure 8. Top view schemes of the surface structures optimized ${ }_{55}$ by DFT calculations. a) $B T(\sqrt{3} \times \sqrt{ } 3) R 30^{\circ} P t(111)$, b) $S+B T L D$ $\left.\left.(\sqrt{ } 3 \times 2 \sqrt{ } 3) R 30^{\circ} \operatorname{Pt}(111), c\right) \quad B T L D(\sqrt{ } 3 \times 2 \sqrt{ } 3) R 30^{\circ} \operatorname{Pt}(111), d\right) B T$ $\left.c(2 \times 2) P t(100) . a^{\prime}-d^{\prime}\right)$ lateral view of the lattices shown in $(a-d)$. e) PDOS for Pt $d z^{2}, C 1 s p$ and $S s p$ in the LD configuration, $f$ ) DOS corresponding to $S+B T L D(\sqrt{ } 3 \times 2 \sqrt{ } 3) R 30^{\circ}$ Pt(111), PDOS ${ }_{60}$ Pt $1^{\text {st }}$ layer $d$ and sp states, adsorbed BT, g) PDOS of the clean Pt(111). The Fermi level is aligned at the origin of the energy scale

Table 5

Geometric and energetic parameters for the different Pt surface 65

\begin{tabular}{|c|c|c|c|c|c|c|}
\hline \multirow{2}{*}{$\begin{array}{c}\text { Surface } \\
\text { structure }\end{array}$} & \multicolumn{2}{|c|}{$E_{b} / \mathrm{eV}$} & \multirow{2}{*}{$\gamma / \mathrm{eV} . \AA^{-2}$} & \multicolumn{2}{|c|}{$\mathbf{q}_{\text {Bader }} / \mathbf{e}$} & \multirow{2}{*}{$\alpha /^{\circ}$} \\
\hline & $\mathbf{S}$ & $B T$ & & M & $\mathbf{S}$ & \\
\hline $\begin{array}{c}(111) \mathbf{U} \\
(\sqrt{3} \times \sqrt{ } 3) \mathrm{R} 30^{\circ} \mathrm{BT} \\
\text { Figure } 8 a\end{array}$ & 0.0 & -3.35 & -0.164 & +0.02 & -0.11 & 9.0 \\
\hline $\begin{array}{c}(111) \mathbf{U} \\
(\sqrt{3} \times 2 \sqrt{3}) \mathrm{R} 30^{\circ} \\
\left(\mathrm{S}+\mathrm{BT}_{\mathbf{L D}}\right) \\
\text { Figure } 8 b\end{array}$ & -5.14 & -3.20 & -0.203 & +0.05 & $\begin{array}{c}-0.23 * \\
-0.09\end{array}$ & $46.6\left(C_{1}\right)$ \\
\hline $\begin{array}{c}(111) \mathbf{U} \\
(\sqrt{3} \times 2 \sqrt{ } 3) \mathrm{R} 30^{\circ} \\
\left(\mathrm{S}+\mathrm{BT} T_{\mathbf{s u}}\right)\end{array}$ & -5.14 & -2.82 & -0.188 & +0.05 & $\begin{array}{c}-0.22 * \\
-0.07\end{array}$ & 16.5 \\
\hline $\begin{array}{c}(111) \mathbf{U} \\
(\sqrt{3} \times 2 \sqrt{3}) \mathrm{R} 30^{\circ} \\
\text { BT }_{\mathbf{L D}} \\
\text { Figure } 8 c\end{array}$ & 0.0 & -3.62 & -0.088 & +0.04 & -0.07 & $52.3\left(\mathrm{C}_{1}\right)$ \\
\hline $\begin{array}{c}(100) \mathbf{U} \\
\mathrm{c}(2 \times 2)-\mathrm{BT} \\
\text { Figure } 8 d\end{array}$ & 0.0 & -3.76 & -0.238 & +0.05 & -0.10 & 24.7 \\
\hline
\end{tabular}


In conclusion, there is no experimental evidence of Pt surface reconstruction upon thiol adsorption, and thus simple adsorbate models could be valid to describe this system. On the other hand, to our knowledge there are no experimental data for thiol 5 adsorption on the (100) surface that we have explored in Figure $8 \mathrm{~d}$. It is evident that more experimental work is needed to characterize thiol adsorption on Pt surfaces.

\subsection{Palladium}

Palladium is a platinum-group metal very well known for its 10 important properties as a catalyst for hydrogenation reactions ${ }^{165}$ and $\mathrm{C}-\mathrm{C}$ bond formation.${ }^{166}$ Also, it has many applications in fields like hydrogen storage ${ }^{167}$ and sensing. ${ }^{168}$

In general, the use of sulfur-based ligands to protect PdNPs usually restricts their use as potential catalysts due to the 15 poisoning effect of sulfur. ${ }^{169}$ However, this effect is not universal because in some cases thiols protect $\mathrm{Pd}$ catalysts against deactivation, as it has been observed during the oxidation of formic acid. ${ }^{170}$ Moreover, alkanethiol SAMs improve the selectivity of Pd-supported catalysts, as reported for the synthesis 20 of 1-epoxibutane from 1-epoxi 3-butene. ${ }^{171}$ DT-protected PdNPs act as active catalysts for the formation of carbon nanotubes ${ }^{172}$ and they have been used as a recyclable catalyst in the SuzukiMiyaura $\mathrm{C}-\mathrm{C}$ coupling reaction of halogenoarenes and phenylboronic acid. ${ }^{173}$

25 Also, alkanethiolate-protected PdNPs have been studied due to their magnetic properties ${ }^{174}$ and their use as hydrogen sensors due to the ability of Pd to absorb large amounts of hydrogen. ${ }^{175}$ Since the capping agent hinders the hydrogen adsorption, it is necessary to clean the NP surface with ozone or thermal treatments prior to 30 their use. ${ }^{176}$ Therefore, the understanding of the thiol-Pd surface chemistry and structure is crucial to improve its potential applications. Contrarily to $\mathrm{Au}$, the thiol-Pd interface has not been extensively studied and thus many aspects regarding the chemical nature and structure of this system remain to be understood.

\section{${ }_{35}$ Surface structures and chemistry}

Thiols adsorb on $\operatorname{Pd}(111)$ forming dense phases of molecules in standing-up configuration with $\alpha \approx 14-18^{\circ} .{ }^{177}$ The analysis of the XPS S $2 p$ signal (Figure 9a) shows significant amounts of total S $\left(\theta_{S} \approx 0.8\right)^{177}$ that largely exceed those found for thiolate SAMs 40 on $\mathrm{Au}, \mathrm{Cu}, \mathrm{Ag}$ and $\mathrm{Pt}$. This quantity is incompatible with simple thiolates on metals due to steric reasons. Therefore, it has been proposed that thiols adsorb on $\operatorname{Pd}(111)$ at saturation coverage forming a complex interface that consists of thiolates $(\mathrm{S} 2, \mathrm{BE} \approx$ $162.9 \mathrm{eV})$ onto a diluted palladium sulfide $\left(\mathrm{PdS}_{\mathrm{x}}\right)$ layer $(\mathrm{S} 1, \mathrm{BE} \approx$ $45162.1 \mathrm{eV}$ ) with $\theta_{\text {sulfide }} \approx 0.4$ and $\theta_{\text {thiolate }} \approx 0.30$ (total S coverage $\theta_{S}$ $\approx 0.7) .{ }^{178}$ Another component, at approximately $164 \mathrm{eV}(\mathrm{S} 3)$, has been assigned to different oxidized sulfur species.

The complex adlayer has been modeled as $(\sqrt{ } 7 \times \sqrt{ } 7) \mathrm{R} 19.1^{\circ}$ sulfide + thiol $\left(\theta_{\text {sulfide }}=3 / 7+\theta=2 / 7\right)$ lattice, as shown in Figure 10a-a' ${ }_{50}$ for BT. This model exhibits a larger stability than those involving simple RS• adsorbates on unreconstructed $\operatorname{Pd}(111)$ surfaces (Figure 10b,b') ${ }^{179,180}$ as concluded from the analysis of the $\gamma$ values in Table 6. Also, DFT calculations reveal that thiol adsorption on the $\mathrm{PdS}_{\mathrm{x}}$ surface is able to extract Pd atoms from 55 the first layers forming $\mathrm{RS}-\mathrm{Pd}_{\mathrm{ad}}-\mathrm{SR}$ moieties (Figure 10a, $\mathrm{a}^{\prime}$ ) similar to those found on thiolate-covered $\mathrm{Au}(111) .{ }^{181}$ This is reasonable, as aliphatic and aromatic Pd complexes forming $\left[\mathrm{Pd}(\mathrm{SR})_{2}\right]_{n}$ polymers have been prepared. ${ }^{182}$

60
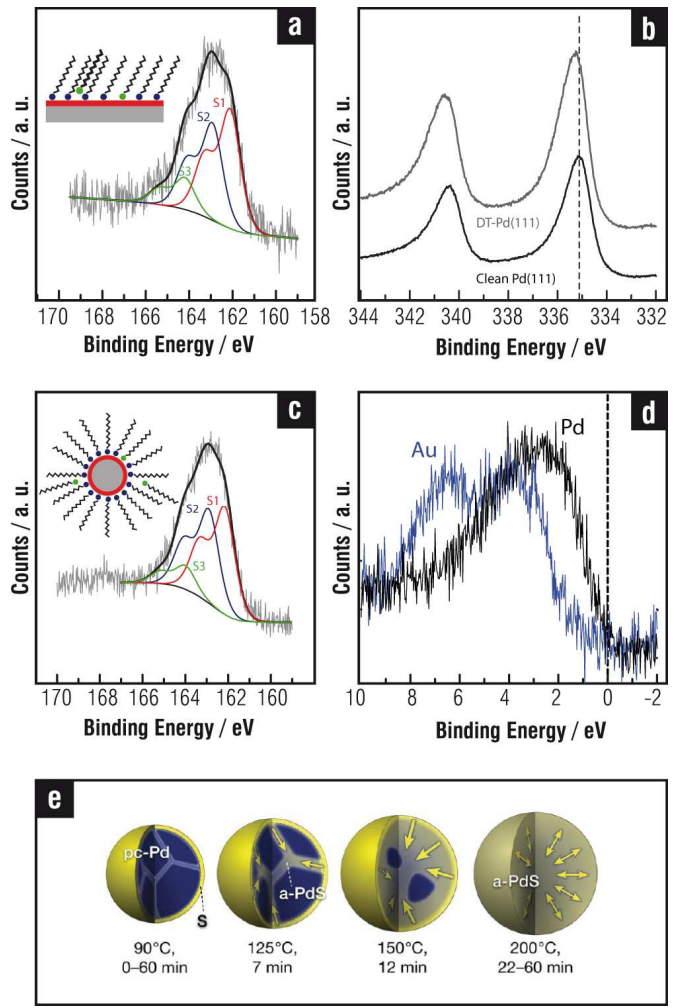

Figure 9. a) XPS S 2p of a DT SAM on Pd(111). S1 corresponds to sulfide, $S 2$ to thiolate and $S 3$ to different oxidized thiol species. ${ }_{65}$ b) XPS Pd $3 d$ of a clean Pd(111) surface and a DT SAM on $P d(111)$. The dashed line indicates the BE for bulk Pd. (a-b) Adapted with permission from J. Phys. Chem. C, 2009, 113, 6735-6742. Copyright (2009) American Chemical Society. c) XPS S $2 p$ of DT protected PdNPs. The components are assigned 70 in the same way than in a). d) XPS of the valence band region for $D T$ protected $A u$ and $P d$ NPs. (c-d) Adapted with permission from J. Phys. Chem. C, 2012, 116, 9830-9837. Copyright (2012) American Chemical Society. e) Sulfidization of PdNPs at different temperatures. Reprinted with permission from Nano Lett., 2013, 75 13, 4893-4901. Copyright (2013) American Chemical Society.

The presence of sulfide reflects the ability of $\mathrm{Pd}$ to promote a dissociative chemisorption process due to its $d$-band populated near the Fermi level (Figures 9d and 10e) leading to the cleavage 80 of the C-S bond of adsorbed thiolates. This is produced by the electron transfer from the $d$-band of the metal to an antibonding orbital of the S-C bond. Adsorbed S and BT exhibit significant broadening of the molecular orbitals, as shown in Figures 10e-f. It is clear from these diagrams that adsorbed $\mathrm{S}$ passivates the $\mathrm{Pd}$ 85 surface (Figure $10 \mathrm{~g}$ ) by shifting the $d$-band to lower energies (higher binding energies) and, therefore, allowing the adsorption of intact alkanethiolates species on top of the diluted sulfide layer. Also the behavior of the $\mathrm{Pd}_{\mathrm{ad}}$ bonded to the $\mathrm{BT}$ species, represented by its localized $d$ states at $-2.5 \mathrm{eV}$, resembles that of 90 the $\mathrm{Au}_{\mathrm{ad}}$ in the staple moieties.

We also performed a Bader analysis to obtain quantitative information about the charge transfer induced by BT adsorption. Results show that Pd atoms in the complex thiolate-sulfide adlayer have a strong positive charge (table in Figure 10). This ${ }_{95}$ prediction has been experimentally confirmed by XPS analysis since a marked positive binding energy shift of the $\mathrm{Pd} 3 d$ signal in thiol-covered surfaces (Figure 9b), much larger than that found 
for the same thiols on Au, was observed. This result was assigned to the contribution of $\mathrm{Pd}$ atoms bonded to sulfides in the adlayer. There are contradictory results concerning the surface chemistry and structure of PdNPs. In many cases possible reactions between 5 adsorbed thiols and reactive PdNP surfaces have been ignored, ${ }^{171}$, 183-185, while in others massive sulfidization of thiol-capped PdNPs has been reported. ${ }^{186,187}$ Recent results have shown that thiolates are also adsorbed on a diluted sulfide adlayer on the PdNP surfaces, ${ }^{113,188}$ as in the case of planar Pd(111) surfaces. ${ }^{178,}$ $10{ }^{181}$ In fact, the total amount of $\mathrm{S}$ in PdNPs is about twice that found in AuNPs of a similar size, in agreement with that observed when thiols on $\mathrm{Pd}(111)$ and $\mathrm{Au}(111)$ surfaces are compared, thus revealing the presence of sulfides. Also for PdNPs three components are necessary to fit the $\mathrm{S} 2 p$ signal in XPS 15 measurements (Figure 9c), showing that the chemical nature of the NPs surface is very similar to the one described for SAMs on planar Pd surfaces. An interesting phenomenon is that the sulfide adlayer induces marked changes in the small PdNPs $(\sim 3 \mathrm{~nm})$ structure as they become amorphous, in contrast to thiolate${ }_{20}$ protected AuNPs that are crystalline. ${ }^{113}$ It has also been recently shown that larger amine-protected PdNPs $(\sim 6 \mathrm{~nm})$ gradually transform into amorphous $\mathrm{PdS}_{\mathrm{x}}$ with the addition of an excess amount of OT. ${ }^{189}$ Below $T=363 \mathrm{~K}$ sulfidization is restricted to the PdNP surface, while for higher temperature sulfide diffusion 25 takes place to the NP core (Figure 9e). However, it is still not clear how deep into metal cores of different sizes sulfide needs to diffuse to produce NPs which appear amorphous when observed with a transmission electron microscope (TEM).

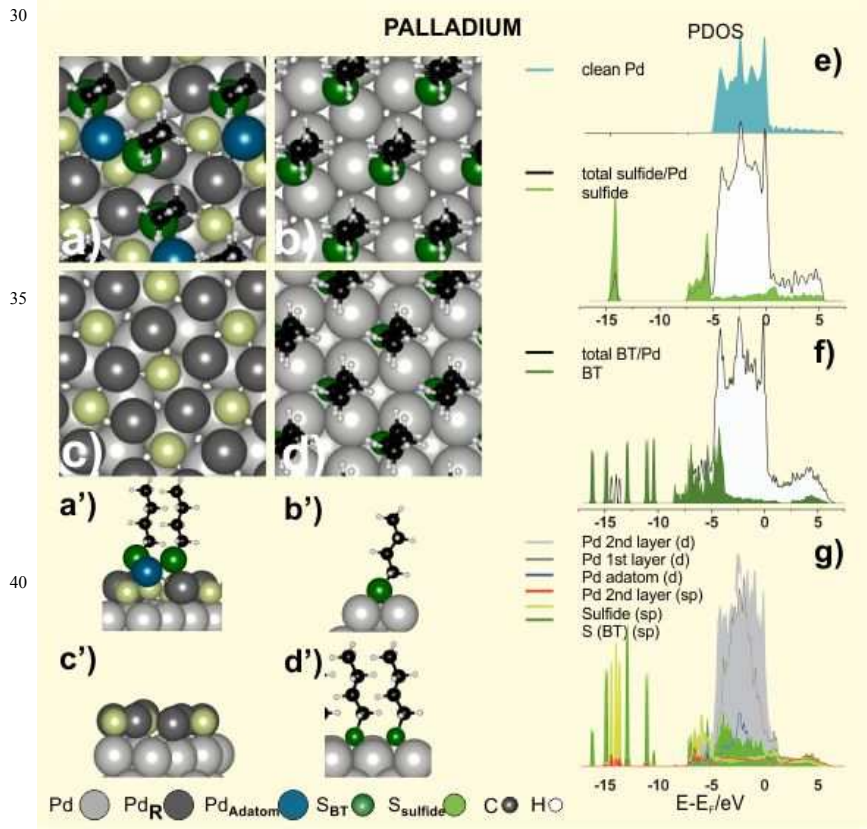

${ }_{45}$ Figure 10. Top view schemes of the surface structures optimized by DFT calculations. a) $S+B T(\sqrt{ } 7 \times \sqrt{ } 7) R 19.1^{\circ} P d(111) R$ b) $B T$ $(\sqrt{ } 3 \times \sqrt{ } 3) R 30^{\circ} P d(111) U$ c) $S(\sqrt{ } 7 \times \sqrt{ } 7) R 19.1^{\circ} P d(111) R$ d) $B T$ $\left.c(2 \times 2) P d(100) . a^{\prime}-d^{\prime}\right)$ Lateral view of the lattices shown in $(a-d)$. e) DOS of the clean Pd(111), $S(\sqrt{7} \times \sqrt{ } 7) R 19.1$ and PDOS of 50 adsorbed sulfide f) DOS of $S+B T(\sqrt{ } 7 \times \sqrt{ } 7) R 19.1^{\circ}$ and PDOS of adsorbed $B T g) P d \quad 2^{\text {nd }}$ layer $d$ and sp states, $P d 1^{\text {st }}$ layer $d$ states, $P d$ adatom d states, sulfide ( $s p$ ) and $S$ from BT ( $s p)$. The Fermi level is aligned at the origin of the energy scale.
Table 6

Geometric and energetic parameters for the different Pd surface structure models discussed in the text and figures

\begin{tabular}{|c|c|c|c|c|c|c|}
\hline \multirow{2}{*}{$\begin{array}{l}\text { Surface } \\
\text { structure }\end{array}$} & \multicolumn{2}{|c|}{$E_{b} / \mathbf{e V}$} & \multirow{2}{*}{$\gamma / \mathrm{eV} . \AA^{-2}$} & \multicolumn{2}{|c|}{$\mathbf{q}_{\text {Bader }} / \mathbf{e}$} & \multirow{2}{*}{$\alpha^{\circ}$} \\
\hline & $\mathbf{S}$ & $B T$ & & M & S & \\
\hline $\begin{array}{c}(111) \mathbf{R} \\
(\sqrt{7} \times \sqrt{7}) \mathrm{R} 19.1^{\circ} \\
(\mathrm{S}+\mathrm{BT}) \\
\text { Figure 10a }\end{array}$ & -6.17 & -3.17 & -0.400 & +0.26 & $\begin{array}{l}-0.37^{*} \\
-0.23\end{array}$ & 5.9 \\
\hline $\begin{array}{c}(111) \boldsymbol{U} \\
(\sqrt{3} \times \sqrt{3}) R 30^{\circ} \\
B T \\
\text { Figure } 10 b\end{array}$ & 0.0 & -3.32 & -0.166 & +0.04 & -0.24 & 7.8 \\
\hline 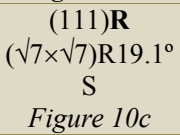 & -6.12 & -3.62 & -0.297 & +0.21 & $-0.42 *$ & - \\
\hline $\begin{array}{c}(100) \mathbf{U} \\
\mathrm{c}(2 \times 2)-\mathrm{BT} \\
\text { Figure 10d }\end{array}$ & 0.0 & -3.37 & -0.219 & +0.12 & -0.21 & 7.9 \\
\hline
\end{tabular}

60

In our best knowledge there are not studies concerning thiol adsorption on the $\operatorname{Pd}(100)$ surface. We have presented a simple $c(2 \times 2)$ surface model for this system in Figure 10d; however, also in this case, one may expect $\mathrm{S}-\mathrm{C}$ bond scission and sulfidization 65 since the (100) face has similar catalytic properties to the $\operatorname{Pd}(111)$ face. ${ }^{190}$ Sulfidization of PdNPs with sizes larger than $3 \mathrm{~nm}$ supports this assumption as they have $\approx 30 \%$ of (100) faces. However, is evident that, as in the case of Pt, we need more experimental and theoretical works on thiol adsorption on ${ }_{70} \operatorname{Pd}(100)$.

In conclusion, both in planar and PdNP surfaces sulfide is formed due to the S-C bond scission during alkanethiol self-assembly or cluster growth, respectively. As a result of that, thiol SAMs on Pd are formed by a mixed thiolate + sulfide layer.

\section{2.6. Nickel}

Metals such as nickel, cobalt and iron are of interest because of their magnetic properties ${ }^{191,192}$ and self-assembled alkanethiol films on these metals are used for patterning, surface functionalization, protection against oxidation, as well as in 80 molecular electronics and spintronics. ${ }^{193}$ Also, magnetic fluids made of NiNPs provide excellent properties to be used as sealants, shock absorption materials, in medical equipment and optical displays. Another application area of NiNPs is the separation and purification of cells and biomolecules in 85 bioprocesses. ${ }^{194}$ NiNPs should be efficient catalysts for chemical reactions such as hydrogenation and treatment of exhaust gas to reduce harmful chemicals. The synthesis of NiNPs is challenging because of their propensity to oxidation in ambient conditions. In principle, the use of thiolates is an attractive alternative to protect 90 these particles. However, thiol adsorption could modify the electronic and geometric properties of NiNPs, hindering their catalytic properties. In fact, not only can adsorbed thiols diminish its catalytic activity in $\mathrm{H}$ sensors ${ }^{27,52}$ but also long alkyl chains may prevent metal-hydrogen interaction. ${ }^{32}$ Finally, the synthesis 95 of thiolate-protected NiNPs is complex, with formation of unexpected intermediates or products. Therefore, any application of thiol-based devices needs a careful characterization of the thiolate-Ni interface.

\section{Surface structures and chemistry}

100 Thiols adsorb on $\mathrm{Ni}(111)$ from the gas phase to form dense SAMs. In the case of MT the adsorption process leads to 
substrate reconstruction. ${ }^{195}$ Thus, the Ni(111) substrate forms a low density outermost square Ni layer (pseudo-(100)) with the organic molecules at hollow sites, as observed for this short alkanethiols on the $\mathrm{Cu}(111)$ surface (see Figure 5a). On the other 5 hand, dense SAMs comprised of long alkanethiols can also be self-assembled on polycrystalline $\mathrm{Ni}$ and $\mathrm{Ni}(111)$ surfaces from solution, although in this case the outer $\mathrm{NiO}$ layer must be previously chemically or electrochemically reduced to $\mathrm{Ni}(0)$. In most cases the surface structure has been considered as simple 10 RS• adsorbates yielding a $(\sqrt{3} \times \sqrt{3}) \mathrm{R} 30^{\circ} \mathrm{Ni}(111)$ surface as shown in Figure 11a,a'. ${ }^{15}$ However, a detailed XPS analysis of thiol SAMs on Ni gives a more complex scenario resembling that of the thiol SAMs on Pd. In fact, DT SAMs on polycrystalline Ni exhibit S $2 p$ signals with three components at BEs $161.9 \mathrm{eV}$ (S1), $15162.5 \mathrm{eV}$ (S2), and $163.5 \mathrm{eV}$ (S3) (Figure 12a) that could be assigned to atomic $\mathrm{S}$, adsorbed thiolates and free thiols, respectively. Similar to $\mathrm{Pd}$, the total $\mathrm{S} 2 p / \mathrm{Ni} 2 p$ ratio indicates a large excess of total $\mathrm{S}$ when compared to that expected for a dense phase of these species on $\mathrm{Au}$ or Ag. Also in this case the $\mathrm{Ni}$ ${ }_{20} 2 p$ signal shows evidence of oxidized Ni species (Figure 12b). The presence of thiolates is supported by comparing the $\mathrm{S} 2 p$ and Ni $2 p$ spectra (Figure 12a-b) with those recorded for synthesized Ni(II)-thiolate (Figure 12c-d). Also, FT-IR spectra have confirmed the presence of intact hydrocarbon chains in thiol ${ }_{25}$ SAMs on the Ni surface. ${ }^{196}$ On the basis of this evidence, one could consider a surface structure composed of thiolates formed on top of nickel sulfide $\left(\mathrm{NiS}_{\mathrm{x}}\right)$. C-S bond scission has already been reported for adsorbed thiolates and determined that the extent of scission depends on the initial substrate condition and 30 alkanethiol coverage. ${ }^{195,197-199}$

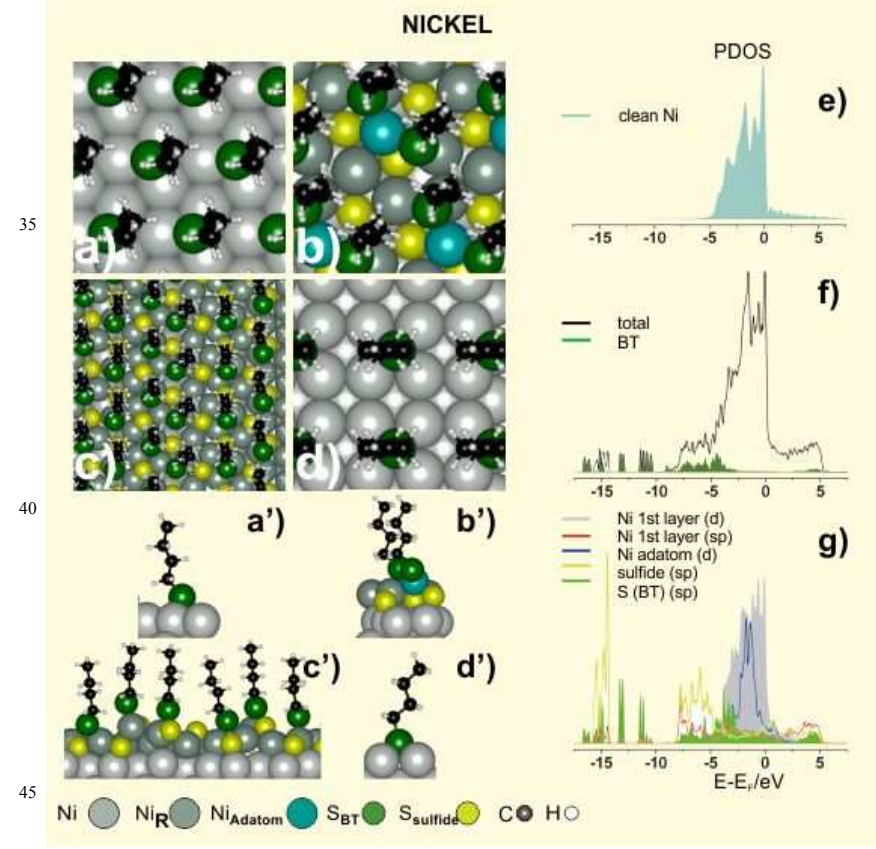

Figure 11. Top view schemes of the surface structures optimized by DFT calculations. a) $B T(\sqrt{3} \times \sqrt{ } 3) R 30^{\circ} \mathrm{Ni}(111) U$ b) $S+B T$ $(\sqrt{ } 7 \times \sqrt{ } 7) R 19.1^{\circ} \mathrm{Ni}(111) R \quad$ c) $B T(5 \sqrt{3} \times 2) \mathrm{Ni}(111) R$ d) $B T(2 \times 2)$ $\left.{ }_{50} \mathrm{Ni}(100) U . a^{\prime}-d^{\prime}\right)$ Lateral view of the lattices shown in $(a-d)$. e) DOS of the clean Ni(111) f) DOS $S+B T(\sqrt{ } 7 \times \sqrt{ } 7) R 19.1^{\circ}$ and PDOS of adsorbed BT g) PDOS of Ni $1^{\text {st }}$ layer $d$ and sp states, $\mathrm{Ni}$ adatom d states, sulfide ( $s p$ ) and $S$ from BT ( $s p)$. The Fermi level is aligned at the origin of the energy scale

55
Table 7

Geometric and energetic parameters for the different Ni surface structure models discussed in the text and figures

\begin{tabular}{|c|c|c|c|c|c|c|}
\hline \multirow{2}{*}{$\begin{array}{c}\text { Surface } \\
\text { structure }\end{array}$} & \multicolumn{2}{|c|}{$E_{b} / \mathbf{e V}$} & \multirow{2}{*}{$\gamma / \mathrm{eV} \cdot \AA^{-2}$} & \multicolumn{2}{|c|}{$\mathbf{q}_{\text {Bader }} / \mathbf{e}$} & \multirow{2}{*}{$\alpha /^{\circ}$} \\
\hline & S & $B T$ & & M & $\mathbf{S}$ & \\
\hline $\begin{array}{c}(111) \mathbf{U} \\
(\sqrt{3} \times \sqrt{3}) \mathrm{R} 30^{\circ} \\
\mathrm{BT} \\
\text { Figure } 11 \mathrm{a}\end{array}$ & 0 & -3.67 & -0.229 & +0.08 & -0.42 & 10.1 \\
\hline $\begin{array}{c}(111) \mathbf{R} \\
(\sqrt{ } 7 \times \sqrt{ } 7) \mathrm{R} 19.1^{\circ} \\
(\mathrm{S}+\mathrm{BT}) \\
\text { Figure } 11 b\end{array}$ & -4.84 & -3.44 & -0.572 & +0.41 & $\begin{array}{l}-0.70 * \\
-0.35\end{array}$ & 12.7 \\
\hline $\begin{array}{c}(111) \mathbf{R} \\
(5 \sqrt{3} \times 2)-(\mathrm{S}+\mathrm{BT}) \\
\text { Figure } 11 c\end{array}$ & -5.68 & 2.22 & -0.550 & +0.33 & $\begin{array}{c}-0.58^{*} \\
-0.24\end{array}$ & 20.3 \\
\hline $\begin{array}{c}(100) \mathbf{U} \\
(2 \times 2)-\mathrm{BT} \\
\text { Figure 11d }\end{array}$ & 0.0 & -4.47 & -0.181 & +0.13 & -0.54 & 16.3 \\
\hline
\end{tabular}

${ }_{60}$ The onset of S-C bond scission for low MT exposures was reported to occur well below room temperature; ${ }^{197-199}$ however, in the presence of pre-adsorbed $\mathrm{S}$ the reaction takes place above room temperature. ${ }^{197,198,200}$ Also, benzenethiolate adsorbed on $\mathrm{Ni}(111)$ starts to form benzene at $290 \mathrm{~K}^{200}$ a reaction where the ${ }_{65}$ adsorbed $\mathrm{H}$ from the S-H bond scission plays a key role. These facts strongly support that, after the initial C-S bond scission, the adsorbed $\mathrm{S}$ passivates the reactive Ni surface in a similar fashion to that reported for the Pd substrate. We have explored the stability of thiol $+\mathrm{S}$ adlayers on $\mathrm{Ni}$ by testing the same 70 $(\sqrt{7} \times \sqrt{7}) \mathrm{R} 19.1^{\circ} \mathrm{S}+$ thiol $\left(\theta_{\text {sulfide }}=3 / 7+\theta=2 / 7\right)$ lattice used for $\operatorname{Pd}(111)$ (Figure 11b, $\mathrm{b}^{\prime}$ ). and a pseudo-(100) S-Ni surface in a $(5 \sqrt{3} \times 2)$ unit cell $\left(\theta_{\text {sulfide }} \approx 0.4\right.$ and $\left.\theta \approx 0.30\right)$ (Figure $\left.11 \mathrm{c}, \mathrm{c}^{\prime}\right)$.

Results showed that these reconstructed surfaces exhibit a stronger adsorption energy and greater stability than those shown 75 by the plain RS- $(\sqrt{3} \times \sqrt{3}) \mathrm{R} 30^{\circ}$ (Figure $11 \mathrm{a}, \mathrm{a}^{\prime}$ ). Note that the $(\sqrt{7} \times \sqrt{7}) \mathrm{R} 19.1^{\circ} \mathrm{S}+$ thiol model also generates $\mathrm{RS}-\mathrm{Ni}_{\mathrm{ad}}-\mathrm{SR}$ species as in the case of Pd.

An analysis of the PDOS for $\mathrm{S}+\mathrm{BT}(\sqrt{7} \times \sqrt{7}) \mathrm{R} 19.1^{\circ} \mathrm{Ni}(111)$ clearly shows that both $\mathrm{S}$ and BT strongly bind to the Ni surface,

80 since not only the adsorbates but also the clean metal modify their electronic structure upon adsorption (Figure 11e-g). Ni surface promotes the dissociative chemisorption process due to its $d$-band being populated near the Fermi level (Figure 11e), which leads to the cleavage of the C-S bond of adsorbed thiolates in a 85 similar way to $\mathrm{Pd}$ surface. These diagrams confirm that adsorbed $\mathrm{S}$ passivates the Ni surface (Figure $11 \mathrm{~g}$ ) by shifting the $d$-band to lower energies, and therefore, allowing the adsorption of intact alkanethiolates species (Figure 11g). Similar to Au and Pd the $d$ state of the $\mathrm{Ni}_{\mathrm{ad}}$ in the nickel thiolate is narrow compared to the 90 topmost Ni surface atoms indicating its molecular behavior.

The adsorption of MT on the (100) plane of Ni was also investigated at $100 \mathrm{~K} .{ }^{199}$ Results are qualitatively similar to those obtained for atomic $\mathrm{S}$ on this surface, which is known to adsorb in the fourfold hollow site on $\mathrm{Ni}(100)$. Attempts to optimize BT 95 on the $(100)$ surface in $c(2 \times 2)$ with $\theta=0.50$ failed, likely due to the small RS• interdistance (less than $0.35 \mathrm{~nm}$ ) leading to repulsion between hydrocarbon chains. In contrast, BT is stabilized in a $(2 \times 2)$ lattice with $\theta=0.25$ with $\boldsymbol{d}=0.497 \mathrm{~nm}$ (Figure $11 \mathrm{~d}, \mathrm{~d}^{\prime}$ ). This lattice has been observed at saturation 100 coverage of cyclohexanethiol on $\mathrm{Ni}(100) .{ }^{201}$ However, C-S bond scission of this molecule was observed at $240 \mathrm{~K}$ whereas DFT calculations were performed at $0 \mathrm{~K}$. Therefore, one may also expect thiolates adsorbed on a S-covered $\mathrm{Ni}(100)$ surface, as evidenced for the $\mathrm{Ni}(111)$ surface. 

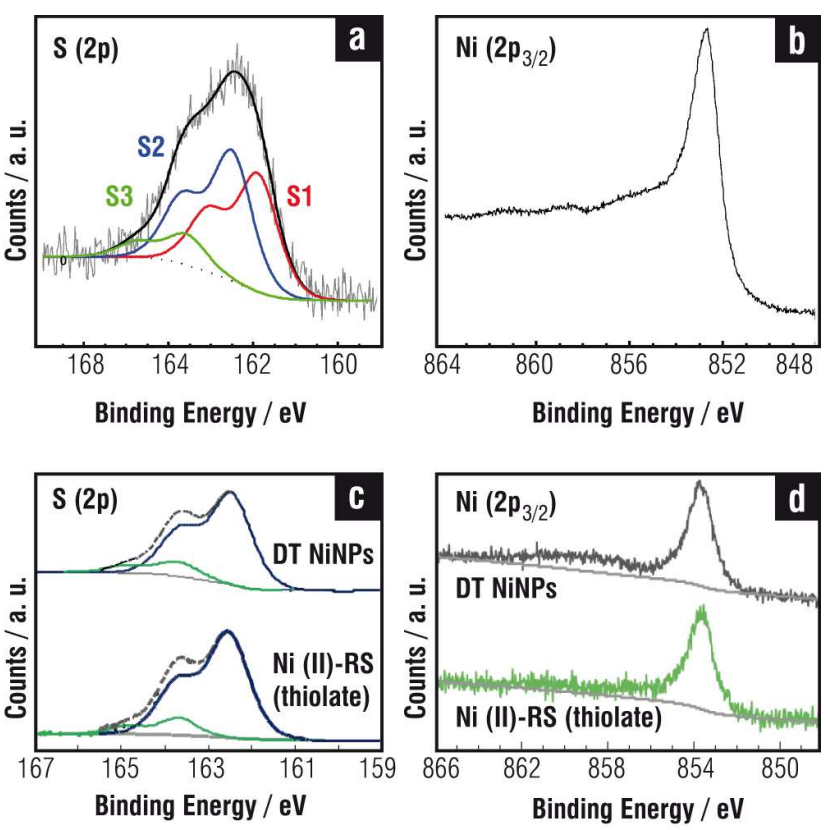

Figure 12. a) XPS S $2 p$ of DT SAM on polycrystalline Ni. S1 is assigned to sulfide, $S 2$ to thiolate and $S 3$ to unbonded thiol species. b) XPS Ni $2 p$ of DT SAM on Ni. c) XPS $S 2 p$ of DT protected NiNPs and DT-Ni(II). d) XPS of Ni $2 p$ of DT protected ${ }_{5} \mathrm{NiNPs}$ and DT-Ni(II). (c-d) Adapted with permission from Langmuir, 2013, 29, 4670-4678. Copyright (2012) American Chemical Society

The synthesis of thiolate-protected NiNPs has been scarcely explored and their chemistry is not fully characterized. ${ }^{202,} 203$ ${ }_{10}$ Recently a detailed analysis of DT-protected NiNPs $(\sim 4 \mathrm{~nm}$ in diameter according to TEM) prepared by the one-phase BrustSchiffrin method ${ }^{204}$ reveals, as in the case of thiolate SAMs on planar $\mathrm{Ni}$, a large excess of $\mathrm{S}$ that include $\mathrm{Ni}(\mathrm{II})$-thiolate, and free thiols as shown in Figure 12c. ${ }^{205}$ Also, the Ni $2 p$ peak shows 15 evidence of $\mathrm{Ni}(\mathrm{II})$-thiolate (Figure 12d). IR data indicate that the DT-protected NiNPs exhibit more disordered alkyl chains than those found for DT-protected AuNPs of the same size. Interestingly, the component assigned to sulfide in the planar surfaces $(\mathrm{BE} \approx 169.9 \mathrm{eV}$ in Figure $12 \mathrm{a}$ ) is not observed in the $20 \mathrm{NiNPs}$ and, accordingly, they are crystalline. One should remember that the mechanism of SAM formation on these NPs should differ from that of SAM formation on flat Ni surfaces since in the former case thiol molecules associate first with $\mathrm{Ni}$ (II) species in solution, and then with NPs surface. Thus, it is ${ }_{25}$ reasonable to think that the $\mathrm{Ni}(\mathrm{II})$-thiolate largely predominates on the NiNP surfaces. A similar situation was observed for TMAcapped AuNPs prepared by the same synthesis where Au(I)-TMA is the main specie on the AuNP surface. ${ }^{206}$

\section{General Discussion}

30 The preceding analysis of thiol adsorption on different metals shows the complexity of the surface structure and chemistry and how it changes with the nature of the metallic surface. We will discuss these topics starting with the interactions of thiols with the clean metal surfaces, then the surface chemistry of the 35 thermodynamically stable dense structures, and finally, the chemical species involved in SAM degradation and desorption.

\subsection{Surface stability and reconstruction}

We start the discussion by considering the RS• radicals forming a hypothetical $(\sqrt{3} \times \sqrt{3}) \mathrm{R} 30^{\circ}$ lattice on the unreconstructed (111) 40 metal surface. Following the approach in $\operatorname{Ref}^{70}$ we consider that the binding energy $E_{b}$ has two components-one from the coupling to the metal $s$ states and the other due to the extra coupling to the $d$ states. Since the contribution from the coupling to the metal $s$ states is approximately the same for each of the 45 metals considered here, the main trends in the $E_{b}$ should be given by the coupling to the $d$ electrons. The analysis of DFT data for the $(\sqrt{3} \times \sqrt{3}) \mathrm{R} 30^{\circ}$ lattices on the $U$ surfaces indicates that, as we move from the $\mathrm{Cu}$ group to the $\mathrm{Ni}$ group, the $\mathrm{RS} \bullet$ radical has a larger $E_{b}$, and therefore the surface structures have larger stability 50 in terms of $\gamma$ values (see the corresponding Tables). In addition, further down the same group interactions become weaker; i.e. the $5 d$ metals are less reactive, and the surface structure has lesser stability than in the case of the $4 d$ and $3 d$ metals. The first effect can be explained by considering that the Ni group metals have $d$ 55 bands with higher energy, and more empty antibonding adsorbate-metal $d$ states than the $\mathrm{Cu}$ group, as shown in the PDOS for the clean metals in the corresponding Figures. In fact, for $\mathrm{Cu}, \mathrm{Ag}$, and $\mathrm{Au}$ the antibonding states are completely filled because the $d$ bands are well below the Fermi level. As we move ${ }_{60}$ to the Ni group, $d$ bands shift up and the antibonding states become depopulated, resulting in stronger RS-Me bonds. ${ }^{70}$

Concerning the second effect, $\mathrm{Cu}, \mathrm{Ag}$ and $\mathrm{Au}$ have a filled $d$ band and, accordingly, a small contribution to the bonding from the emptying of antibonding $\mathrm{S} p$-metal $d$ states. However, there is 65 still a contribution from the interaction between the metal $d$ electrons and the $\mathrm{S} p$ states. The Pauli principle states that $\mathrm{S} p$ states have to become orthogonal to the metal $d$ states when they come into contact. This raises the kinetic energy by an amount proportional to $V_{a d}^{2}$; i.e. the stronger the overlap, the larger the 70 repulsion. In this context the variation in adsorption strength from $\mathrm{Cu}$ to $\mathrm{Au}$ is mainly determined by the Pauli repulsion as $\mathrm{Au}$ has the most extended $d$ states, the largest $V^{2}{ }_{a d}$, and therefore the largest repulsion. This makes RS• adsorbates less stable on $\mathrm{Au}$ and $\mathrm{Ag}$ than on $\mathrm{Cu}$. Using the same arguments RS• adsorbates 75 are expected to be less stable on Pt and Pd than on Ni surfaces. ${ }^{70}$ There is also other interesting analysis resulting from the electron transfer from the substrate to the S-head atom of thiols. The Bader analysis for the RS• adsorbates forming $(\sqrt{ } 3 \times \sqrt{3}) \mathrm{R} 30^{\circ}$ lattices on the (111) U surfaces shows that the negative charge on ${ }_{80} \mathrm{~S}$ atom of the $\mathrm{RS} \bullet$ radical increases from $\mathrm{Au}(-0.23 \mathrm{e})$ to $\mathrm{Cu}(-$ $0.44 \mathrm{e})$ and from $\mathrm{Pt}(-0.11 \mathrm{e})$ to $\mathrm{Ni}(-0.44 \mathrm{e})$. Accordingly, the accumulated positive charges on the metal follow the same trend, leading to the presence of surface dipoles. The thiolate interdistance $\boldsymbol{d}$ decreases as the lattice parameter of the metal ${ }_{85}$ decreases from $\mathrm{Au}$ to $\mathrm{Cu}$ and from $\mathrm{Pt}$ to Ni. Thus, repulsion between the positive adjacent charges of dipoles could produce weakening of the Me-Me bonds, favoring reconstruction. ${ }^{207}$

Therefore, for the (111) surfaces of the coinage metals surface reconstruction proceeds in order to improve the RS-Me bond 90 strength and to lower the repulsion. This is done by ejecting metal surface atoms to form thiolate-metal complexes (Au) or by creating vacancy-rich metal surfaces $(\mathrm{Ag}, \mathrm{Cu})$, a process which in turn depends on the cohesion energy. On the other hand, Pt exhibits the lowest surface dipole and the highest cohesive 95 energy, and thus reconstruction should be difficult for this surface, i.e. the surface can be described in terms of RS• adsorbates on $(\sqrt{3} \times \sqrt{3}) \mathrm{R} 30^{\circ}$. In fact, in contrast to the Au case, the Pt-Pt binding energy is much greater than the Pt-S binding energy, making it unlikely that a $\mathrm{Pt}$ atom would hop off the 100 surface to form a dimer-like configuration such as RS-Pt $t_{\mathrm{ad}}-\mathrm{RS}$. ${ }^{15}$ In the case of Pd and $\mathrm{Ni}$ surfaces the situation is complicated by 
the S-C bond scission of the thiol molecules that results from the initial contact between the clean metal surfaces and adsorbed molecules, leading to S-rich surfaces as discussed below.

One might ask why reconstruction has not been experimentally 5 observed for the (100) $\mathrm{Au}, \mathrm{Ag}$, and Pt surfaces, even if surface dipoles are also present. The reason could be the strong stability of thiols on these lattices (see $\gamma$ values in the Tables) which is even higher than that found for the same thiols on the (111) surfaces.

\section{3.2. The structure and chemistry of the reconstructed surfaces}

The previous analysis allows us to conclude that alkanethiol selfassembly leads to reconstruction of the $\mathrm{Au}(111)$ surfaces with formation of $\mathrm{RS}-\mathrm{Au}_{\mathrm{ad}}-\mathrm{SR}$ complexes, while protection of the 15 metallic core of Au nanoclusters $(<2 \mathrm{~nm}$ in size $)$ is made by both RS- $\mathrm{Au}_{\mathrm{ad}}-\mathrm{SR}$ and $\mathrm{RS}-\mathrm{Au}_{\mathrm{ad}}-\mathrm{SR}-\mathrm{Au}_{\mathrm{ad}}-\mathrm{SR}$ moieties. The formation of RS-Au $\mathrm{ad}^{-} \mathrm{SR}$ complexes originates vacancies at the $\mathrm{Au}$ surface $\left(\theta_{v a c}=1 / 6\right)$. Also thiol adsorption induces surface reconstruction to form low density outer metal layers on $\operatorname{Ag}(111)\left(\theta_{\text {vac }}=2 / 7\right)$ 20 and $\mathrm{Cu}(111)\left(\theta_{\text {vac }} 1 / 3\right)$, i.e. with large number of vacancies at the metal surface. In these cases the S-head is coordinated to threefold and fourfold coordinated hollow sites, respectively,

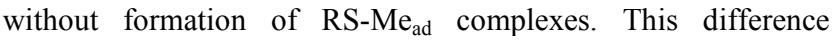
between $\mathrm{Au}\left(\mathrm{RS}-\mathrm{Me}_{\mathrm{ad}}\right.$ ) and $\mathrm{Cu}$ surfaces (RS- adsorbed at highly

25 coordinated sites) could be assigned to the more ionic character of the S-metal bond of $\mathrm{Cu}^{30}$ and $\mathrm{Ag}$ than $\mathrm{Au}$. Note that the vacancy model has been also consistent with experimental data of AgNPs $\approx 2 \mathrm{~nm}$, where the surface structure is compatible with that found for the reconstructed $\operatorname{Ag}(111)$ surface. In contrast, smaller 30 $\mathrm{Ag}$ and $\mathrm{Cu}$ clusters $(<2 \mathrm{~nm})$ are protected by more complex $\mathrm{RS}_{m} \mathrm{Me}_{n}$ species.

One interesting conclusion from the comparative analysis of this group is that the difference in $\gamma$ values between the thiols on the $\mathrm{R}$ and $U$ (111) substrate surfaces smears out as the hydrocarbon

35 chain length increases. It seems that optimization of the vdW interactions between long alkyl chains in the reconstructed surface lattices forces displacement of the metal surface atoms into slightly unfavorable energetic positions, a fact that reflects in slightly higher $E_{r}$ values. This opens an interesting question about 40 the possible coexistence of $\mathrm{U}$ and $\mathrm{R}$ domains on SAMs of intermediate chain length, and perhaps only $U$ domains for the longest thiols.

Concerning adsorbed thiolates on the (100) surfaces of all these metals, the DFT calculations reveal that they exhibit a better

45 stability than the respective (111) faces in terms of $\gamma$, as shown in the corresponding Tables. Therefore, we expect RS• adsorbates rather than a significant surface reconstruction with surface atom ejection or formation of RS-Me $\mathrm{Me}_{\mathrm{ad}}$ complexes. The exception is thiols on the $\mathrm{Cu}(100)$ surface in electrolyte solution where RS-

${ }_{50} \mathrm{Cu}_{\mathrm{ad}}$ species has been observed by STM. However, in this case these species can be favored by the enhanced formation of $\mathrm{Cu}_{\mathrm{ad}}$ in the electrolyte solution and under an applied potential to the electrochemical interface.

On the other hand, one would expect no reconstruction on the ${ }_{55} \mathrm{Pt}(111)$ surface but extensive reconstruction on the $\operatorname{Pd}(111)$, $\mathrm{Ni}(111), \mathrm{Pd}(100)$ and $\mathrm{Ni}(100)$ surfaces where thiol adsorption leads to the formation of the complex metal thiolate and sulfide structures due to $\mathrm{C}-\mathrm{S}$ bond scission.

\subsection{Thiolate decomposition}

${ }_{60}$ The ability for molecular dissociation for the catalytically active $\mathrm{Ni}$ group surfaces decreases from $\mathrm{Ni}$ to $\mathrm{Pt}$. In fact, the less reactive among these metals is $\mathrm{Pt}$, which requires $T \approx 300 \mathrm{~K}$ to induce some $\mathrm{C}-\mathrm{S}$ bond scission, while this reaction proceeds well below room temperature for clean $\mathrm{Pd}$ and $\mathrm{Ni}$ surfaces. The ${ }_{65}$ analysis of the PDOS indicates that, upon thiol adsorption, there is an electron density transfer from the metal $d$-band to the antibonding molecular orbitals of thiol molecules that weakens the $\mathrm{S}-\mathrm{C}$ bond, resulting in its elongation and final breakage. We propose that this process involves the interaction between the $\mathrm{C} 1$ 70 atom of adsorbed thiolates and the catalytically active metal surface. This interaction is favored when thiolate molecules are in LD configuration, compared to thiolates in SU configuration. On the other hand, it is expected that short thiols have a longer residence time in LD configuration on the metal surface than 75 longer thiols that rapidly reorganize in the SU configuration driven by the stronger vdW interactions and also to increase the number of thiolate bonds on the surface. Therefore, the amount of S should depend on the efficiency of the metal surface for the C-S bond cleavage during the residence time of the molecule in the ${ }_{80} \mathrm{LD}$ configuration. It is evident that $\mathrm{Pd}$ and $\mathrm{Ni}$ surfaces are more catalytically active than Pt explaining the significant amount of atomic $\mathrm{S}$ on these surfaces. After $\mathrm{S}$ formation, the center of the $d$ band is lowered in energy with respect to the clean surface, i.e. the surface is "passivated" allowing adsorption of intact thiol 85 molecules and SAM formation. This process is thermodynamically favored as the stability of the thiolate $+\mathrm{S}$ lattices is higher than that of plain adsorbed thiolates, as shown in Tables 5,6, and 7 for all these metals. It is reasonable that the strong $\mathrm{S}$ adsorption on $\mathrm{Pd}$ and Ni promotes surface reconstruction 90 despite the relatively high cohesion energies of these surfaces. The sulfidization process should be restricted to the first surface layers or to the bulk metal depending on the temperature due to energy barriers for S diffusion.

On the other hand, for the $\mathrm{Cu}$ group also some sulfidization of the 95 surfaces had been observed even though the mechanisms of this process can be related to side reactions and chemical degradation of the layer, as discussed in what follows.

\subsection{Chemical degradation and contamination}

Exposure to ambient conditions can result in the formation of 100 certain amount of disulfides and sulfonates. In particular, thiol desorption by oxidation of thiolates is the preferred pathway for $\mathrm{Au}, \mathrm{Ag}, \mathrm{Cu}$ and $\mathrm{Pt}$ surfaces. This process takes place in ambient conditions and also in liquid phases, such as ethanol. Indeed, the presence of light and $\mathrm{O}_{2}$ promotes thiolate oxidation to disulfides 105 and also to sulfonates. Both species are easily desorbed from the surface (the adsorption energy is too weak) so that continuous exposure in ambient conditions results in slow degradation of the SAMs. This process involves $\mathrm{O}_{3}$, formed via $\mathrm{UV}$ visible radiation and $\mathrm{O}_{2}$ molecules, which react with the $\mathrm{S}$-heads forming oxidized ${ }_{110} \mathrm{~S}$ products. The rate of these side reactions also depend on the electrolyte and solvent where these products can be solubilised thus conditioning the liquid-media where SAMs can be formed, used and stored.

SAM degradation produces NPs sintering even at room 115 temperature, as shown in TEM images of MBA-protected AgNPs (Figure 13a) two weeks after their synthesis (Figure 13b). XPS S $2 p$ data for the aged AgNPs (Figure 13d) show that the total amount of S slightly decreases with respect to that of the freshly prepared AgNPs (Figure 13c), although the $162 \mathrm{eV}$ component 120 corresponding to thiolates decreases and the $163 \mathrm{eV}$ component, corresponding to disulfides, increases. A similar behavior has been reported during the aging of SAMs on planar Au surfaces. ${ }^{208}$ The degradation of the protective MBA layer results in sintering by neck formation between adjacent NPs, and therefore, the 125 increase in AgNP size from $6 \mathrm{~nm}$ to $15 \mathrm{~nm}$ (Figure 13a,b). These data show that sintering takes places even with a small 
degradation of the thiolate layer, as recently reported for AuNPs. ${ }^{84}$ Also, DT-capped AuNPs at $323 \mathrm{~K}$ approach and grow into large single or twinned crystals because of the van der Waals attraction and the heat generated by the exothermic formation of disulfides. ${ }^{209}$ Interestingly, recent thermogravimetric analysis and differential scanning calorimetry measurements on AuNPs with the same thiol capping but different size show that larger NPs lose ligands and sinter faster than smaller NPs, suggesting a greater stability of the ligand shell on smaller NPs. ${ }^{84}$ This can be 10 explained by considering the curved surfaces of smaller NPs that have a large number of defective sites, where thiols are more strongly bonded than at the facets of larger NPs. Indeed, highlynanostructured surfaces had shown to preserve SAMs-integrity respect to planar low-defect surfaces. ${ }^{208}$

${ }_{15}$ Sintering processes at low temperature are important for applications of metallic NPs as precursor inks for metallic thin films and patterns. Also, non-bonded thiol molecules (physisorbed) can be present in the SAMs. They can be trapped by chain-chain interactions or hydrophobic forces in aqueous 20 media, both leading to interdigitation, or hydrogen bonding between $\mathrm{COOH}, \mathrm{NH}_{2}$ and $\mathrm{OH}$ terminal groups of the chemisorbed thiolates and those of the free thiol molecules. ${ }^{210}$ Small amounts of other contaminants can also be found in thiol SAMs, like small quantities of oxides/hydroxides for reactive 25 metals such as $\mathrm{Cu}$ or $\mathrm{Ni}$ when prepared from the liquid phase or after partial degradation in ambient conditions.

There are other interesting chemical processes when selfassembly is performed in liquid phase that result in dramatic changes in surface chemistry. In fact, SAMs of some small thiols 30 (like MT, small thiols with terminal $\mathrm{COOH}$ groups or containing $\mathrm{N}$ atoms) prepared in liquid phase exhibit significant amounts of atomic S. In these cases the solvent facilitates either the C-S cleavage reaction or the formation of disulfides (RS-SR) species that can undergo a further decomposition to atomic $\mathrm{S}$ leading to

35 fast sulfidization, as shown for 4-mercatopyridine in aqueous solutions (Figure 13). The presence of atomic $S$ is not only reflected by the increase in the $\mathrm{S} 2 p$ signal at $161 \mathrm{eV}$ but also by changes from island-like structure to vacancy island structure of the $\mathrm{Au}$ surface induced by the strong $\mathrm{S}-\mathrm{Au}$ bond. Some other 40 thiol molecules, such as thioacetic acid, are highly unstable even in nonpolar solvents, resulting in a fast and complete sulfidization of the $\mathrm{Au}$ substrate. ${ }^{211}$ Solvent-mediated decomposition and sulfidization have also been reported for MT. ${ }^{212}$ In the case of TMA SAMs on Au(111) the mechanism involves the charge 45 withdraw by the $\mathrm{S}$ atom from the gold surface, and the stabilization of the negatively charged leaving group by electronic resonance with the carboxylic group at alpha position to $\mathrm{C}-\mathrm{S}$ bond ${ }^{66}$. Also $\mathrm{Au}$ can exhibit some catalytic activity for organic reactions, including $\mathrm{C}-\mathrm{S}$ bond breaking, due to the ${ }_{50}$ presence of a high defect density at nanoparticle surfaces. Therefore, we expect more atomic $\mathrm{S}$ for this kind of short thiols on NPs, irrespective of the method used for their synthesis.

Finally, in order to find proper conditions and materials able to reduce SAM degradation, thiolate-Me and thiolate-environment 55 interactions need to be considered. In nanostructured metalsurfaces a compromise effect between reactivity (catalytic activity in $\mathrm{C}-\mathrm{S}$ bond breaking) and $\mathrm{S}-\mathrm{Me}$ bond strength (that hinders the thiolates avoiding disulfide formation), determines the surface chemistry and stability of the resulting SAM. To further 60 understand this problem more research is needed regarding SAM's degradation on (100) metal surfaces.
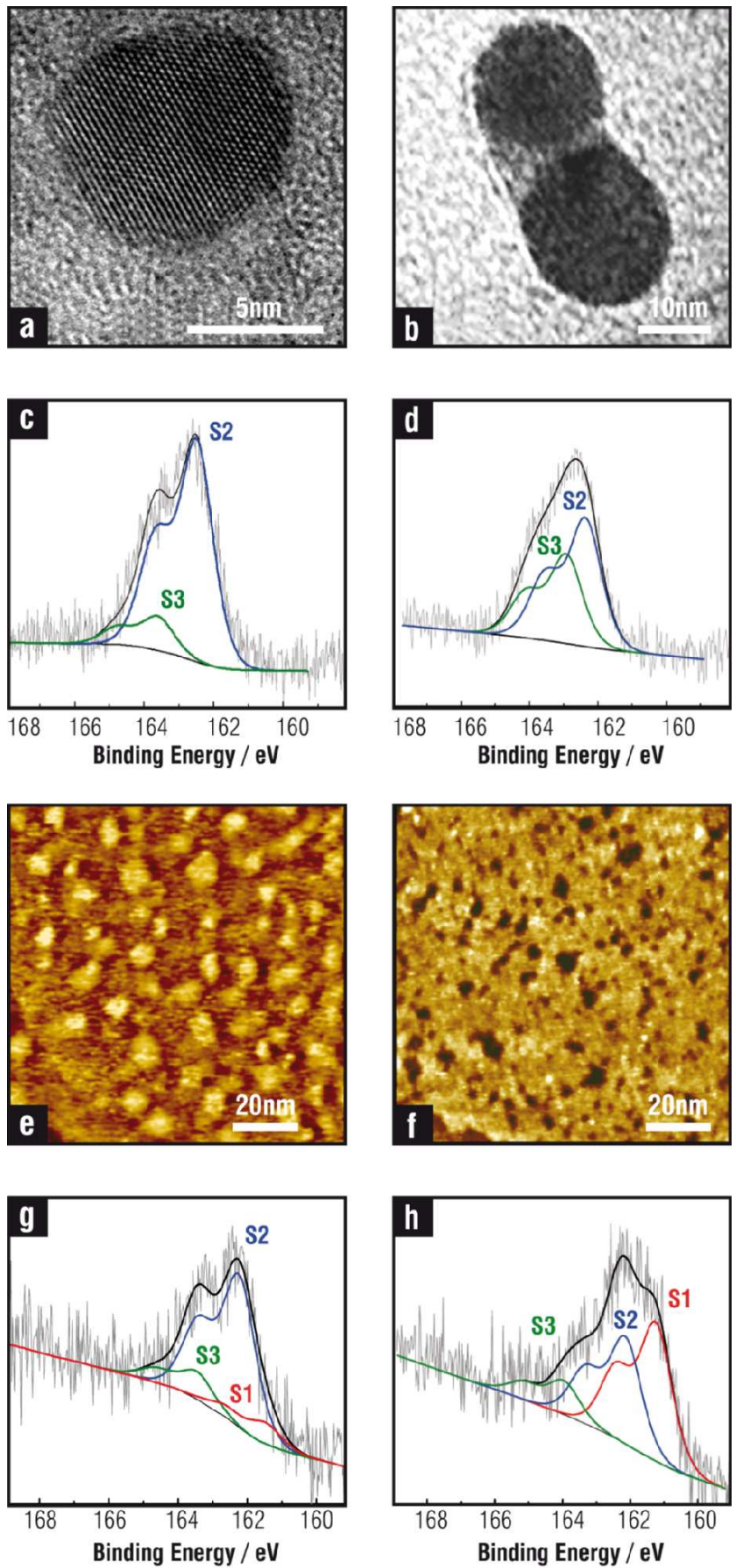

Figure 13. MBA capped Ag NPs a) freshly prepared and b) after ${ }_{65}$ 14-day aging (TEM images taken by Dr. Eugenia Zelaya at CABCNEA). (c) and (d) XPS spectra of NPs shown in (a) and (b) respectively. $a, c$ an d) Adapted with permission from J. Phys. Chem. C 2013, 117, 24967-24974. Copyright (2013) American Chemical Society. (e) Au islands in a 4-MPy SAM on Au(111). (f) 70 Monoatomic height pits in a degraded 4-MPy SAM on Au(111)leading a S-Au SAM. (g) XPS spectra of nondegraded 4MPy SAM on Au(111) (h) Sulfide covered Au(111) after degradation of the 4-MPy SAM. (e-h) Adapted with permission from Langmuir, 2012, 28, 6839-6847. Copyright (2012) 75 American Chemical Society.

\section{Conclusions}


We have made an extensive revision of thiolate SAMs on (111) and (100) surfaces of the $\mathrm{Cu}$ and Ni group metals, which have a wide range of technological applications ranging from medicine to spintronics. In particularly a detailed analysis of S-Me 5 interactions, vdW forces, and the thermodynamic stability that guide the self-assembly of thiols into dense surface structures for $\mathrm{Au}, \mathrm{Ag}, \mathrm{Cu}, \mathrm{Pt}, \mathrm{Pd}$ and $\mathrm{Ni}$ has been made. The comparative study allows us to explain surface reconstructions in terms of vacancy production and complex thiolate-metal formation in the case of 10 coinage metals, and the key role of adsorbed $\mathrm{S}$ on thiol selfassembly on the catalytically active Ni group metals. Differences and similarities between planar, nanoparticle, and nanocluster surfaces related to the surface chemistry have also been highlighted. The presence of $\mathrm{S}$ on the coinage metals is also 15 discussed in relation to the thiol molecules, presence of impurities, solvent used and surface defects. Finally, we have analyzed the consequences of SAM degradation via disulfide, a pathway common for all metal surfaces, and the possible formation of multilayers via $\mathrm{vdW}$ forces between non-bonded 20 thiols.

Future directions and challenges for these systems should involve: 1) the experimental determination of the mixed $\mathrm{S} /$ thiolate surface structure of the $\mathrm{Ni}$ group metals, 2) the identification of the self-assembly or environmental conditions 25 that influences the degradation of the adsorbed thiolates on the $\mathrm{Cu}$ group metals, in particular on the more reactive metal nanoparticle surfaces, 3) the impact of the $\mathrm{S}$ atoms on the poisoning/activation of the catalytic properties and electronic behavior of the functionalized surfaces, 4 ) a detailed experimental

30 study on thiolate structure and surface chemistry on the (100) surfaces, which have been scarcely studied and are important for a complete understanding of thiolate-protected metal nanoparticles.

\section{Acknowledgements}

35 We acknowledge financial support from ANPCyT (PICT 20100423, PICT 2006-621, PICT 2010-2554, PICT-2012-0836, PRH74), CONICET (PIP 11220090100139, 112200801000362 and 112200801000983, 1122012010093), Universidad Nacional de La Plata (UNLP), and CTQ2011-24784 MICINN, Spain. P. C. 40 thankfully acknowledges the computer resources provided by Atlante, Canary Islands Supercomputing Infrastructure- Red Española de Supercomputación. MEV is CIC-PBA-Researcher.

\section{References}

1. A. Ulman, An Introduction to Ultrathin Organic Films: From

45 Langmuir-Blodgett to Self-Assembly, Academic Press, Boston, 1991.

2. A. Ulman, Chem. Rev., 1996, 96, 1533-1554.

3. J. C. Love, L. A. Estroff, J. K. Kriebel, R. G. Nuzzo and G. M. Whitesides, Chem. Rev., 2005, 105, 1103-1170.

${ }_{50} 4$. C. Vericat, M. E. Vela, G. Benitez, P. Carro and R. C. Salvarezza, Chem. Soc. Rev., 2010, 39, 1805-1834.

5. R. G. Pillai, M. D. Braun and M. S. Freund, Langmuir, 2010, 26, 269-276.

6. V. Sashuk, ACS Nano, 2012, 6, 10855-10861.

55 7. Y. Choi, Y. Jeong, H. Chung, E. Ito, M. Hara and J. Noh, Langmuir, 2007, 24, 91-96.

8. C. Vericat, G. A. Benitez, D. E. Grumelli, M. E. Vela and R. C. Salvarezza, J. Phys.: Condens. Matter, 2008, 20, 184004.

9. J.-P. Hong, A.-Y. Park, S. Lee, J. Kang, N. Shin and D. Y. 60 Yoon, Appl. Phys. Lett., 2008, 92, 143311.
10. P. E. Laibinis, G. M. Whitesides, D. L. Allara, Y. T. Tao, A. N. Parikh and R. G. Nuzzo, J. Am. Chem. Soc., 1991, 113, 7152-7167.

11. J. C. Azcarate, G. Corthey, E. Pensa, C. Vericat, M. H. 65 Fonticelli, R. C. Salvarezza and P. Carro, J.Phys.Chem.Lett., 2013, 4, 3127-3138.

12. D. Grumelli, C. Vericat, G. Benitez, M. E. Vela, R. C. Salvarezza, L. J. Giovanetti, J. M. Ramallo-López, F. G. Requejo, A. F. Craievich and Y. S. Shon, J.Phys.Chem C, 2007, 111, 7179-7184.

13. J. A. Rodriguez, M. Kuhn and J. Hrbek, Chem. Phys. Lett., 1996, 251, 13-19.

14. N. B. Luque and E. Santos, Langmuir, 2012, 28, 1147211480 .

75 15. D. Karhánek, T. Bučko and J. Hafner, J. Phys.: Condens. Matter, 2010, 22, 265005.

16. W. T. Geng, J. Nara and T. Ohno, Thin Solid Films, 2004, 464-465, 379-383.

17. K. Sotthewes, V. Geskin, R. Heimbuch, A. Kumar and H. J. 80 W. Zandvliet, APL Materials, 2014, 2, 010701.

18. A. S. Barnard, Crystal Growth \& Design, 2013, 13, 54335441.

19. G. D. Barmparis, K. Honkala and I. N. Remediakis, J.Chem.Phys., 2013, 138, 064702-064709.

85 20. C. Vericat, M. E. Vela, G. A. Benitez, J. A. M. Gago, X. Torrelles and R. C. Salvarezza, J. Phys.: Condens. Matter, 2006, 18, R867.

21. C. M. Crudden, J. H. Horton, I. I. Ebralidze, O. V. Zenkina, A. B. McLean, B. Drevniok, Z. She, H.-B. Kraatz, N. J.

90 Mosey, T. Seki, E. C. Keske, J. D. Leake, A. Rousina-Webb and G. Wu, Nat. Chem, 2014, advance online publication.

22. G. Kresse and J. Hafner, Phys.Rev.B, 1993, 48, 13115-13118.

23. G. Kresse and J. Furthmüller, Comput. Mater. Sci., 1996, 6, 15-50.

95 24. M. Dion, H. Rydberg, E. Schröder, D. C. Langreth and B. I. Lundqvist, Phys. Rev. Lett., 2004, 92, 246401.

25. J. Klimeš, D. R. Bowler and A. Michaelides, J. Phys.: Condens. Matter, 2010, 22, 074203.

26. J. Carrasco, B. Santra, J. Klimeš and A. Michaelides, Phys. Rev. Lett., 2011, 106, 026101.

27. J. Carrasco, J. Klimeš and A. Michaelides, J.Chem.Phys., 2013, 138, 024708.

28. D. Otálvaro, T. Veening and G. Brocks, J.Phys.Chem C, 2012, 116, 7826-7837.

105 29. Y. Wang, Q. Chi, J. Zhang, N. S. Hush, J. R. Reimers and J. Ulstrup, J. Am. Chem. Soc., 2011, 14856-14859.

30. H. Groenbeck, J.Phys.Chem C, 2010, 114, 15973-15978.

31. E. Torres, A. T. Blumenau and P. U. Biedermann, ChemPhysChem, 2011, 12, 999-1009.

110 32. L. Ferrighi, Y.-x. Pan, H. Grönbeck and B. Hammer, J.Phys.Chem C, 2012, 116, 7374-7379.

33. M. P. Andersson, Journal of Theoretical Chemistry, 2013, 2013, 9 .

34. R. Urcuyo, E. Cortés, A. A. Rubert, G. Benitez, M. L. Montero, N. G. Tognalli, A. Fainstein, M. E. Vela and R. C. Salvarezza, J.Phys.Chem C, 2011, 115, 24707-24717. 
35. S. A. DiBenedetto, A. Facchetti, M. A. Ratner and T. J. Marks, Adv. Mater., 2009, 21, 1407-1433.

36. V. Faramarzi, C. Raimondo, F. Reinders, M. Mayor, P. Samorì and B. Doudin, Appl. Phys. Lett., 2011, 99, 233104.

s 37. J. W. Ndieyira, M. Watari, A. D. Barrera, D. Zhou, M. Vogtli, M. Batchelor, M. A. Cooper, T. Strunz, M. A. Horton, C. Abell, T. Rayment, G. Aeppli and R. A. McKendry, Nat Nano, 2008, 3, 691-696.

38. A. M. Masillamani, N. Crivillers, E. Orgiu, J. Rotzler, D.

10 Bossert, R. Thippeswamy, M. Zharnikov, M. Mayor and P. Samorì, Chem. Eur. J., 2012, 18, 10335-10347.

39. C. Raimondo, N. Crivillers, F. Reinders, F. Sander, M. Mayor and P. Samorì, Proc Natl Acad Sci U S A, 2012, 109, 1237512380 .

15 40. D. Xie, C. Li, L. Shangguan, H. Qi, D. Xue, Q. Gao and C. Zhang, Sensor.Actuat.B-Chem, 2014, 192, 558-564.

41. E. Skrzyńska, J. Ftouni, A.-S. Mamede, A. Addad, M. Trentesaux, J.-S. Girardon, M. Capron and F. Dumeignil, $J$. Mol. Catal. A: Chem., 2014, 382, 71-78.

20 42. D. G. Matei, H. Muzik, A. Gölzhäuser and A. Turchanin, Langmuir, 2012, 28, 13905-13911.

43. S. B. Darling, A. W. Rosenbaum, Y. Wang and S. J. Sibener, Langmuir, 2002, 18, 7462-7468.

44. G. E. Poirier, W. P. Fitts and J. M. White, Langmuir, 2001,

$25 \quad \mathbf{1 7}, 1176-1183$.

45. K. Sotthewes, H. Wu, A. Kumar, G. J. Vancso, P. M. Schön and H. J. W. Zandvliet, Langmuir, 2013, 29, 3662-3667.

46. P. Maksymovych, D. C. Sorescu and J. T. Yates, Jr., Phys. Rev. Lett., 2006, 97, 146103.

30 47. A. H. Ayyad, J. Stettner and O. M. Magnussen, Phys. Rev. Lett., 2005, 94, 066106.

48. P. Maksymovych, O. Voznyy, D. B. Dougherty, D. C. Sorescu and J. T. Yates Jr, Prog. Surf. Sci., 2010, 85, 206240.

35 49. G. E. Poirier and E. D. Pylant, Science, 1996, 272, $1145-$ 1148 .

50. S. Seo and H. Lee, J.Phys.Chem C, 2011, 115, 15480-15486.

51. E. Pensa, E. Cortés, G. Corthey, P. Carro, C. Vericat, M. H. Fonticelli, G. Benítez, A. A. Rubert and R. C. Salvarezza,

40 Acc. Chem. Res., 2012, 45, 1183-1192.

52. D. G. Castner, K. Hinds and D. W. Grainger, Langmuir, 1996, 12, 5083-5086.

53. X. Torrelles, E. Barrena, C. Munuera, J. Rius, S. Ferrer and C. Ocal, Langmuir, 2004, 20, 9396-9402.

45 54. R. G. Nuzzo, B. R. Zegarski and L. H. Dubois, J. Am. Chem. Soc., 1987, 109, 733-740.

55. M. G. Roper, M. P. Skegg, C. J. Fisher, J. J. Lee, V. R. Dhanak, D. P. Woodruff and R. G. Jones, Chem. Phys. Lett., 2004, 389, 87-91.

50 56. P. Carro, E. Pensa, C. Vericat and R. C. Salvarezza, J.Phys.Chem C, 2013, 117, 2160-2165.

57. J. Gao, F. Li and Q. Guo, J.Phys.Chem C, 2013, 117, 2498524990.

58. O. Voznyy and J. J. Dubowski, Langmuir, 2009, 25, 7353$55 \quad 7358$.
59. X. Torrelles, C. Vericat, M. E. Vela, M. H. Fonticelli, M. A. D. Millone, R. Felici, T. L. Lee, J. Zegenhagen, G. Muñoz, J. A. Martín-Gago and R. C. Salvarezza, J. Phys. Chem. B, 2006, 110, 5586-5594.

${ }_{60}$ 60. A. Bashir, W. Azzam, M. Rohwerder and A. Terfort, Langmuir, 2013, 29, 13449-13456.

61. N. Nishi, D. Hobara, M. Yamamoto and T. Kakiuchi, J.Chem.Phys., 2003, 118, 1904-1911.

62. B. M. Ocko, X. Z. Wu, E. B. Sirota, S. K. Sinha, O. Gang and

65 M. Deutsch, Phys.Rev.E, 1997, 55, 3164-3182.

63. K. Edinger, A. Goelzhaeuser, K. Demota, C. Woell and M. Grunze, Langmuir, 1993, 9, 4-8.

64. C. A. McDermott, M. T. McDermott, J.-B. Green and M. D. Porter, J.Phys.Chem., 1995, 99, 13257-13267.

70 65. M. Watari, R. A. McKendry, M. Vögtli, G. Aeppli, Y.-A. Soh, X. Shi, G. Xiong, X. Huang, R. Harder and I. K. Robinson, Nat Mater, 2011, 10, 862-866.

66. J. C. Azcárate, M. A. Floridia Addato, A. Rubert, G. Corthey, G. S. Kürten Moreno, G. Benítez, E. Zelaya, R. C. Salvarezza and M. H. Fonticelli, Langmuir, 2014, 30, 1820-1826.

67. E. Pensa, A. A. Rubert, G. Benitez, P. Carro, A. González Orive, A. Hernández Creus, R. C. Salvarezza and C. Vericat, J.Phys.Chem C, 2012, 116, 25765-25771.

68. E. Pensa, P. Carro, A. A. Rubert, G. Benítez, C. Vericat and 80 R. C. Salvarezza, Langmuir, 2010, 26, 17068-17074.

69. H. Schmidbaur and A. Schier, Chem. Soc. Rev., 2008, 37, 1931-1951.

70. B. Hammer and J. K. Norskov, Advances in Catalysis Academic Press, 2000.

85 71. M. Nakaya, M. Shikishima, M. Shibuta, N. Hirata, T. Eguchi and A. Nakajima, ACS Nano, 2012, 6, 8728-8734.

72. G. Heimel, F. Rissner and E. Zojer, Adv. Mater., 2010, 22, 2494-2513.

73. G. Heimel, L. Romaner, E. Zojer and J.-L. Bredas, Acc. Chem. Res., 2008, 41, 721-729.

74. S. Srivastava, A. Verma, B. L. Frankamp and V. M. Rotello, Adv. Mater., 2005, 17, 617-621.

75. L. H. Dubois, B. R. Zegarski and R. G. Nuzzo, J.Chem.Phys., 1993, 98, 678-688.

95 76. M. Schweizer, H. Hagenström and D. M. Kolb, Surf. Sci., 2001, 490, L627-L636.

77. E. Ito, J. Noh and M. Hara, Chem. Phys. Lett., 2008, 462, 209-212.

78. J. Stettner and A. Winkler, Langmuir, 2010, 26, 9659-9665.

100 79. I. I. RzezÌnicka, J. Lee, P. Maksymovych and J. T. Yates Jr, J. Phys. Chem. B, 2005, 109, 15992-15996.

80. Y. W. Yang and L. J. Fan, Langmuir, 2002, 18, 1157-1164.

81. C. Vericat, M. E. Vela, G. Andreasen, R. C. Salvarezza, L. Vázquez and J. A. Martin-Gago, Langmuir, 2001, 17, 49194924.

82. P. A. Waske, N. Meyerbröker, W. Eck and M. Zharnikov, J.Phys.Chem C, 2012, 116, 13559-13568.

83. A. Shaporenko, A. Terfort, M. Grunze and M. Zharnikov, J. Electron. Spectrosc. Relat. Phenom., 2006, 151, 45-51.

110 84. B. L. Smith and J. E. Hutchison, J.Phys.Chem C, 2013, 117, 25127-25137. 
85. D. Jose, J. E. Matthiesen, C. Parsons, C. M. Sorensen and K. J. Klabunde, J.Phys.Chem.Lett., 2012, 3, 885-890.

86. P. D. Jadzinsky, G. Calero, C. J. Ackerson, D. A. Bushnell and R. D. Kornberg, Science, 2007, 318, 430-433.

5 87. Q. K. Ong, J. Reguera, P. J. Silva, M. Moglianetti, K. Harkness, M. Longobardi, K. S. Mali, C. Renner, S. De Feyter and F. Stellacci, ACS Nano, 2013, 7, 8529-8539.

88. S. K. Volkman, Y. Pei, D. Redinger, S. Yin and V. Subramanian, 2004.

10 89. B. de Boer, A. Hadipour, R. Foekema, T. van Woudenbergh, M. M. Mandoc, V. D. Mihailetchi and P. W. M. Blom, Organic Optoelectronics and Photonics, SPIE, Bellingham, WA, 2004.

90. G. Carotenuto and F. Nicolais, Materials, 2009, 2, 13231340.

91. X. Yuan, M. I. Setyawati, A. S. Tan, C. N. Ong, D. T. Leong and J. Xie, NPG Asia Mater, 2013, 5, e39.

92. S. Silver, L. Phung and G. Silver, J. Ind. Microbiol. Biotechnol., 2006, 33, 627-634.

20 93. J. Elechiguerra, J. Burt, J. Morones, A. Camacho-Bragado, X. Gao, H. Lara and M. Yacaman, Journal of Nanobiotechnology, 2005, 3, 6 .

94. P. Singh and D. A. Buttry, J.Phys.Chem C, 2012, 116, 1065610663.

25 95. G. He, Y. Song, B. Phebus, K. Liu, C. P. Deming, P. Hu and S. Chen, Sci. Adv. Mater., 2013, 5, 1727-1736.

96. H.-T. Rong, S. Frey, Y.-J. Yang, M. Zharnikov, M. Buck, M. Wühn, C. Wöll and G. Helmchen, Langmuir, 2001, 17, 15821593.

30 97. V. Brunetti, B. Blum, R. C. Salvarezza, A. J. Arvia, P. L. Schilardi, A. Cuesta, J. E. Gayone and G. Zampieri, J. Phys. Chem. B, 2002, 106, 9831-9838.

98. P. N. Abufager, L. Alvarez Soria, M. L. Martiarena, K. Reuter and H. F. Busnengo, Chem. Phys. Lett., 2011, 503, 713574.

99. M. Yu, D. P. Woodruff, C. J. Satterley, R. G. Jones and V. R. Dhanak, J.Phys.Chem C, 2007, 111, 10040-10048.

100. P. Fenter, P. Eisenberger, J. Li, N. Camillone, S. Bernasek, G. Scoles, T. A. Ramanarayanan and K. S. Liang, Langmuir,

$40 \quad 1991,7,2013-2016$.

101. F. Bensebaa, T. H. Ellis, E. Kruus, R. Voicu and Y. Zhou, Langmuir, 1998, 14, 6579-6587.

102. K. Heister, M. Zharnikov, M. Grunze and L. S. O. Johansson, J.Phys.Chem.C., 2001, 105, 4058-4061.

45 103. L. M. Rodríguez, J. E. Gayone, E. A. Sánchez, O. Grizzi, B. Blum and R. C. Salvarezza, J.Phys.Chem.C., 2006, 110, 7095-7097.

104. M. Yu, S. M. Driver and D. P. Woodruff, Langmuir, 2005, 21, 7285-7291.

50 105. D. Torres, P. Carro, R. C. Salvarezza and F. Illas, Phys. Rev. Lett., 2006, 97, 226103.

106. J. V. Maya Girón, E. Zelaya, A. Rubert, G. Benítez, P. Carro, R. C. Salvarezza and M. E. Vela, J.Phys.Chem C, 2013, 117, 24967-24974.

55 107. H. Kondoh, H. Tsukabayashi, T. Yokoyama and T. Ohta, Surf. Sci., 2001, 489, 20-28.
108. D. M. Alloway, A. L. Graham, X. Yang, A. Mudalige, R. Colorado, V. H. Wysocki, J. E. Pemberton, T. Randall Lee, R. J. Wysocki and N. R. Armstrong, J.Phys.Chem C, 2009, $60 \quad \mathbf{1 1 3}, 20328-20334$.

109. M. Lewis, M. Tarlov and K. Carron, J. Am. Chem. Soc., 1995, 117, 9574-9575.

110. I. Chakraborty, A. Govindarajan, J. Erusappan, A. Ghosh, T. Pradeep, B. Yoon, R. L. Whetten and U. Landman, Nano Lett., 2012, 12, 5861-5866.

111. J. D. Padmos and P. Zhang, J.Phys.Chem.C, 2012, 116, 23094-23101.

112. C. Battocchio, C. Meneghini, I. Fratoddi, I. Venditti, M. V. Russo, G. Aquilanti, C. Maurizio, F. Bondino, R. Matassa, M. Rossi, S. Mobilio and G. Polzonetti, J.Phys.Chem.C, 2012, 116, 19571-19578.

113. G. Corthey, A. A. Rubert, A. L. Picone, G. Casillas, L. J. Giovanetti, J. Ramallo-López, E. Zelaya, G. A. Benitez, F. G. Requejo, M. José-Yacamán, R. C. Salvarezza and M. H.

75 Fonticelli, J.Phys.Chem C, 2012, 116, 9830-9837.

114. M. Farrag, M. Thämer, M. Tschurl, T. Bürgi and U. Heiz, J.Phys.Chem.C, 2012, 116, 8034-8043.

115. H. Xiang, S.-H. Wei and X. Gong, J. Am. Chem. Soc., 2010, 132, 7355-7360.

80 116. A. Desireddy, B. E. Conn, J. Guo, B. Yoon, R. N. Barnett, B. M. Monahan, K. Kirschbaum, W. P. Griffith, R. L. Whetten, U. Landman and T. P. Bigioni, Nature, 2013, 501, 399-402.

117. H. Yang, Y. Wang, H. Huang, L. Gell, L. Lehtovaara, S. 85 Malola, H. Häkkinen and N. Zheng, Nat Commun, 2013, 4, 2422.

118. D. F. Lim, S. K. Goulet, M. Bergkvist, J. Wei, K. C. Leong and C. S. Tan, J. Electrochem. Soc., 2011, 158, H1057H1061.

90 119. O. Azzaroni, M. Cipollone, M. E. Vela and R. C. Salvarezza, Langmuir, 2001, 17, 1483-1487.

120. D. F. Lim, X. F. Ang, J. Wei, C. M. Ng and C. S. Tan, Electrochem. Solid-State Lett., 2010, 13, H412-H415.

121. E. Färm, V. Marko, R. Mikko and L. Markku, Semicond. Sci. Technol., 2012, 27, 074004.

122. C. M. Whelan, M. Kinsella, H. M. Ho and K. Maex, J. Electrochem. Soc., 2004, 151, B33-B38.

123. T. Y. Dong, H. H. Wu, C. Huang, J. M. Song, I. G. Chen and T. H. Kao, Appl. Surf. Sci., 2009, 255, 3891-3896.

100 124. D. Mott, J. Yin, M. Engelhard, R. Loukrakpam, P. Chang, G. Miller, I.-T. Bae, N. Chandra Das, C. Wang, J. Luo and C.-J. Zhong, Chem. Mater., 2009, 22, 261-271.

125. G. Ma, Y. Zhou, X. Li, K. Sun, S. Liu, J. Hu and N. A. Kotov, ACS Nano, 2013, 7, 9010-9018.

105 126. K. Wong, K.-Y. Kwon, B. V. Rao, A. Liu and L. Bartels, J. Am. Chem. Soc., 2004, 126, 7762-7763.

127. H. Kondo, N. Saito, F. Matsui, T. Tsuzuki, T. Ota and H. Yoem, Nippon Kagakkai Koen Yokoshu, 1999, 76, 158.

128. S.-Y. Hong, P.-C. Yeh, J. I. Dadap and R. M. Osgood, ACS $110 \quad$ Nano, 2012, 6, 10622-10631.

129. S. M. Driver and D. P. Woodruff, Surf. Sci., 2000, 457, 1123. 
130. S. M. Driver and D. P. Woodruff, Langmuir, 2000, 16, 6693-6700.

131. H. Walch, J. Dienstmaier, G. Eder, R. Gutzler, S. Schlögl, T. Sirtl, K. Das, M. Schmittel and M. Lackinger, J. Am. Chem.

5 Soc., 2011, 133, 7909-7915.

132. F. Bussolotti, M. G. Betti and C. Mariani, Phys.Rev.B, 2006, 74, 125422.

133. H. Kondoh, N. Saito, F. Matsui, T. Yokoyama, T. Ohta and H. Kuroda, J.Phys.Chem.C., 2001, 105, 12870-12878.

10 134. Y.-C. Yang, A. Taranovskyy and O. M. Magnussen, Langmuir, 2012, 28, 14143-14154.

135. M. M. Sung, W. J. Yun, S. S. Lee and A. Y. Kim, Bull. Korean Chem. Soc., 2003, 24, 610 - 612.

136. M. M. Sung and Y. Kim, Bull. Korean Chem. Soc., 2001, 22, $748-752$.

137. N. Sandhyarani and T. Pradeep, J. Mater. Chem., 2001, 11, 1294-1299.

138. O. Furlong, B. Miller, Z. Li and W. T. Tysoe, Surf. Sci., 2011, 605, 606-611.

20 139. G. J. Jackson, D. P. Woodruff, R. G. Jones, N. K. Singh, A. S. Y. Chan, B. C. C. Cowie and V. Formoso, Phys. Rev. Lett., 2000, 84, 119-122.

140. A. Ganguly, I. Chakraborty, T. Udayabhaskararao and T. Pradeep, J. Nanopart. Res., 2013, 15, 1-7.

25 141. K. Graff, Metal Impurities in Silicon Device Fabrication, Springer- Verlag, Berlin, 1995.

142. J. M. Beebe, V. B. Engelkes, L. L. Miller and C. D. Frisbie, J. Am. Chem. Soc., 2002, 124, 11268-11269.

143. A. Y. Kim, PhD Thesis, 1998.

30 144. C. M. Kim and J. Bechhoefer, J.Chem.Phys., 2013, 138, 014707.

145. G. Liu, M. J. Arellano-Jiménez, C. B. Carter and A. Agrios, J. Nanopart. Res., 2013, 15, 1-13.

146. E. G. Castro, R. V. Salvatierra, W. H. Schreiner, M. M.

35 Oliveira and A. J. G. Zarbin, Chem. Mater., 2010, 22, 360370.

147. J. Chen, B. Lim, E. P. Lee and Y. Xia, Nano Today, 2009, 4, 81-95.

148. S. F. Li, Y. H. Guo, W. W. Sun, D. L. Sun and X. B. Yu, J.Phys.Chem C, 2010, 114, 21885-21890.

149. S. E. Eklund and D. E. Cliffel, Langmuir, 2004, 20, $6012-$ 6018.

150. M. A. Floridia Addato, A. Rubert, G. Benitez, E. Zelaya, G. Cabello, A. Cuesta, J. E. Thomas, A. Visintin, R. C.

45 Salvarezza and M. H. Fonticelli, J.Phys.Chem C, 2013, 117, 7589-7597.

151. K. Bakhmutsky, N. L. Wieder, M. Cargnello, B. Galloway, P. Fornasiero and R. J. Gorte, ChemSusChem, 2012, 5, 140148.

50 152. T. S. Rufael, J. Prasad, D. A. Fischer and J. L. Gland, Surf. Sci., 1992, 278, 41-50.

153. S. S. Kim, Y. Kim, H. I. Kim, S. H. Lee, T. R. Lee, S. S. Perry and J. W. Rabalais, J.Chem.Phys., 1998, 109, 95749582.

55 154. J. J. Lee, C. J. Fisher, C. Bittencourt, D. P. Woodruff, A. S. Y. Chan and R. G. Jones, Surf. Sci., 2002, 516, 1-15.
155. D. Y. Petrovykh, H. Kimura-Suda, A. Opdahl, L. J. Richter, M. J. Tarlov and L. J. Whitman, Langmuir, 2006, 22, 25782587.

60 156. M. A. Floridia Addato, A. A. Rubert, G. A. Benítez, M. H. Fonticelli, J. Carrasco, P. Carro and R. C. Salvarezza, J.Phys.Chem C, 2011, 115, 17788-17798.

157. Y.-C. Yang, Y.-P. Yen, L.-Y. Ou Yang, S.-L. Yau and K. Itaya, Langmuir, 2004, 20, 10030-10037.

65 158. M. Zharnikov, J. Electron. Spectrosc. Relat. Phenom., 2010, 178-179, 380-393.

159. T. Laiho, J. Lukkari, M. Meretoja, K. Laajalehto, J. Kankare and J. A. Leiro, Surf. Sci., 2005, 584, 83-89.

160. T. S. Rufael, R. J. Koestner, E. B. Kollin, M. Salmeron and J. L. Gland, Surf. Sci., 1993, 297, 272-285.

161. T. H. Lin, T. P. Huang, Y. L. Liu, C. C. Yeh, Y. H. Lai and W. H. Hung, J.Phys.Chem.C., 2005, 109, 14079-14084.

162. H. Dalgleish and G. Kirczenow, Nano Lett., 2006, 6, 12741278.

75 163. C. Dablemont, P. Lang, C. Mangeney, J.-Y. Piquemal, V. Petkov, F. Herbst and G. Viau, Langmuir, 2008, 24, 58325841.

164. X. Le Guével, V. Trouillet, C. Spies, G. Jung and M. Schneider, J.Phys.Chem C, 2012, 116, 6047-6051.

${ }_{80}$ 165. S. Kidambi, J. Dai, J. Li and M. L. Bruening, J. Am. Chem. Soc., 2004, 126, 2658-2659.

166. A. Biffis, M. Zecca and M. Basato, J. Mol. Catal. A: Chem., 2001, 173, 249-274.

167. F. D. Manchester, A. San-Martin and J. M. Pitre, J. Phase $85 \quad$ Equilib., 1994, 15 62-83.

168. F. Favier, E. C. Walter, M. P. Zach, T. Benter and R. M. Penner, Science, 2001, 293, 2227-2231.

169. B. P. S. Chauhan, J. S. Rathore and T. Bandoo, J. Am. Chem. Soc., 2004, 126, 8493-8500.

90 170. M. Y. Berezin, K.-T. Wan, R. M. Friedman, R. G. Orth, S. N. Raman, S. V. Ho and J. R. Ebner, J. Mol. Catal. A: Chem., 2000, 158, 567-576.

171. S. T. Marshall, M. O'Brien, B. Oetter, A. Corpuz, R. M. Richards, D. K. Schwartz and J. W. Medlin, Nat Mater, 2010, 9, 853-858.

172. L. Seung-Yup, Y. Mami and M. Mikio, Sci.Technol.Adv.Mat., 2005, 6, 420.

173. F. Lu, J. Ruiz and D. Astruc, Tetrahedron Lett., 2004, 45, 9443-9445.

100 174. R. Litrán, B. Sampedro, T. C. Rojas, M. Multigner, J. C. Sánchez-López, P. Crespo, C. López-Cartes, M. A. García, A. Hernando and A. Fernández, Phys.Rev.B, 2006, 73, 054404.

175. F. J. Ibañez and F. P. Zamborini, Small, 2012, 8, 174-202.

105 176. F. J. Ibañez and F. P. Zamborini, Langmuir, 2006, 22, 9789 9796.

177. J. C. Love, D. B. Wolfe, R. Haasch, M. L. Chabinyc, K. E. Paul, G. M. Whitesides and R. G. Nuzzo, J. Am. Chem. Soc., 2003, 125, 2597-2609.

110 178. G. Corthey, A. A. Rubert, G. A. Benitez, M. H. Fonticelli and R. C. Salvarezza, J.Phys.Chem C, 2009, 113, 67356742 . 
179. S. T. Marshall, D. K. Schwartz and J. W. Medlin, Langmuir, 2011, 27, 6731-6737.

180. C. Majumder, Langmuir, 2008, 24, 10838-10842.

181. P. Carro, G. Corthey, A. A. Rubert, G. A. Benitez, M. H.

$5 \quad$ Fonticelli and R. C. Salvarezza, Langmuir, 2010, 26, 14655 14662.

182. F. G. Mann and D. Purdie, J.Chem.Soc., 1935, 0, 1549-1563.

183. M. Moreno, F. J. Ibañez, J. B. Jasinski and F. P. Zamborini, J. Am. Chem. Soc., 2011, 133, 4389-4397.

10 184. E. Sadeghmoghaddam, C. Lam, D. Choi and Y.-S. Shon, J. Mater. Chem., 2011, 21, 307-312.

185. E. K. Novakova, L. McLaughlin, R. Burch, P. Crawford, K. Griffin, C. Hardacre, P. Hu and D. W. Rooney, J. Catal., 2007, 249, 93-101.

15 186. Y. Sun, A. I. Frenkel, R. Isseroff, C. Shonbrun, M. Forman, K. Shin, T. Koga, H. White, L. Zhang, Y. Zhu, M. H. Rafailovich and J. C. Sokolov, Langmuir, 2006, 22, 807816.

187. J. M. Ramallo-López, L. Giovanetti, A. F. Craievich, F. C. 20 Vicentin, M. Marín-Almazo, M. José-Yacaman and F. G. Requejo, Physica B, 2007, 389, 150-154.

188. H. Murayama, N. Ichikuni, Y. Negishi, T. Nagata and T. Tsukuda, Chem. Phys. Lett., 2003, 376, 26-32.

189. Y. Liu, C. Sun, T. Bolin, T. Wu, Y. Liu, M. Sternberg, S.

$25 \quad$ Sun and X.-M. Lin, Nano Lett., 2013, 13, 4893-4901.

190. R. Jiang, W. Guo, M. Li, X. Lu, J. Yuan and H. Shan, PCCP, 2010, 12, 7794-7803.

191. Y. Jing, C. Qianwang and Z. Yiqun, J. Phys. D: Appl. Phys., 2008, 41, 205011.

30 192. N. Deo, M. F. Bain, J. H. Montgomery and H. S. Gamble, J. Mater. Sci. - Mater. Electron., 2005, 16, 387-392.

193. S. Bengio, M. Fonticelli, G. Benitez, A. H. Creus, P. Carro, H. Ascolani, G. Zampieri, B. Blum and R. C. Salvarezza, J. Phys. Chem. B, 2005, 109, 23450-23460.

35 194. I. S. Lee, N. Lee, J. Park, B. H. Kim, Y.-W. Yi, T. Kim, T. K. Kim, I. H. Lee, S. R. Paik and T. Hyeon, J. Am. Chem. Soc., 2006, 128, 10658-10659.

195. C. J. Fisher, D. P. Woodruff, R. G. Jones, B. C. C. Cowie and V. Formoso, Surf. Sci., 2002, 496, 73-86.

${ }_{40}$ 196. J. E. Sadler, D. S. Szumski, A. Kierzkowska, S. R. Catarelli, K. Stella, R. J. Nichols, M. H. Fonticelli, G. Benitez, B. Blum, R. C. Salvarezza and W. Schwarzacher, PCCP, 2011, 13, 17987-17993.

197. M. E. Castro and J. M. White, Surf. Sci., 1991, 257, 22-32.

45 198. T. S. Rufael, D. R. Huntley, D. R. Mullins and J. L. Gland, J.Phys.Chem.C., 1998, 102, 3431-3440.

199. D. R. Mullins, T. Tang, X. Chen, V. Shneerson, D. K. Saldin and W. T. Tysoe, Surf. Sci., 1997, 372, 193-201.

200. S. M. Kane, T. S. Rufael, J. L. Gland, D. R. Huntley and D.

$50 \quad$ A. Fischer, J.Phys.Chem.C., 1997, 101, 8486-8491.

201. S. M. Kane and J. L. Gland, Surf. Sci., 2000, 468, 101-108.

202. S.-B. Lei, C. Wang, S.-X. Yin, L.-J. Wan and C.-L. Bai, ChemPhysChem, 2003, 4, 1114-1117.

203. L. Chen, J. Chen, H. Zhou, D. Zhang and H. Wan, Mater. 55 Sci. Eng., A, 2007, 452-453, 262-266.
204. M. Brust, J. Fink, D. Bethell, D. J. Schiffrin and C. Kiely, J. Chem. Soc., Chem. Commun., 1995, 1655-1656.

205. M. F. Calderón, E. Zelaya, G. A. Benitez, P. L. Schilardi, A. H. Creus, A. G. Orive, R. C. Salvarezza and F. J. Ibañez, Langmuir, 2013, 29, 4670-4678.

206. G. Corthey, L. J. Giovanetti, J. M. Ramallo-López, E. Zelaya, A. A. Rubert, G. A. Benitez, F. G. Requejo, M. H. Fonticelli and R. C. Salvarezza, ACS Nano, 2010, 4, 34133421.

${ }_{65}$ 207. W. Daum, S. Lehwald and H. Ibach, Surf. Sci., 1986, 178, 528-536.

208. E. Cortés, A. A. Rubert, G. Benitez, P. Carro, M. E. Vela and R. C. Salvarezza, Langmuir, 2009, 25, 5661-5666.

209. S. Moon, S.-i. Tanaka and T. Sekino, Nanoscale Res. Lett., 2010, 5, 813-817.

210. A. Abraham, E. Mihaliuk, B. Kumar, J. Legleiter and T. Gullion, J.Phys.Chem C, 2010, 114, 18109-18114.

211. J. A. Fischer, V. C. Zoldan, G. Benitez, A. A. Rubert, E. A. Ramirez, P. Carro, R. C. Salvarezza, A. A. Pasa and M. E. Vela, Langmuir, 2012, 28, 15278-15285.

212. F. P. Cometto, V. A. Macagno, P. Paredes-Olivera, E. M. Patrito, H. Ascolani and G. Zampieri, J.Phys.Chem.C, 2010, 114, 10183-10194. 